\title{
Improving Deliverability in Gas Storage Fields by Identifying the Timing and Sources of Damage Using Smart Well Technology
}

\section{FINAL TECHNICAL REPORT}

8 September 2003 - 1 March 2006

J. H. Frantz, Jr., Project Director, Schlumberger K. G. Brown, Principle Investigator, Schlumberger W. K. Sawyer, Principle Consultant, Schlumberger P. A. Zyglowicz, Technician, Schlumberger J. P. Spivey, Phoenix Reservoir Engineering

March 2006

DE-FC26-03NT41743

Schlumberger Consulting Services 1310 Commerce Drive Park Ridge 1

Pittsburgh, PA 15275-1011 


\section{DISCLAIMER}

This report was prepared as an account of work sponsored by an agency of the United States Government. Neither the United States Government nor any agency thereof, nor any of their employees, makes any warranty, express or implied, or assumes any legal liability or responsibility for the accuracy, completeness, or usefulness of any information, apparatus, product, or process disclosed, or represents that its use would not infringe privately owned rights. Reference herein to any specific commercial product, process, or service by trade name, trademark, manufacturer, or otherwise does not necessarily constitute or imply its endorsement, recommendation, or favoring by the United States Government or any agency thereof. The views and opinions of authors expressed herein do not necessarily state or reflect those of the Unites States Government or any agency thereof. 


\section{ABSTRACT}

This report summarizes the work performed under contract DE-FC26-03NT41743. The primary objective of this study was to develop tools that would allow Underground Gas Storage (UGS) operators to use wellhead electronic flow measurement (EFM) data to quickly and efficiently identify trends in well damage over time, thus aiding in the identification of potential causes of the damage.

Secondary objectives of this work included: 1) To assist UGS operators in the evaluation of hardware and software requirements for implementing an EFM system similar to the one described in this report, and 2) To provide a cost-benefit analysis framework UGS operators can use to evaluate economic benefits of installing wellhead EFM systems in their particular fields.

Assessment of EFM data available for use, and selection of the specific study field are reviewed. The various EFM data processing tasks, including data collection, organization, extraction, processing, and interpretation are discussed. The process of damage assessment via pressure transient analysis of EFM data is outlined and demonstrated, including such tasks as quality control, semi-log analysis, and log-log analysis of pressure transient test data extracted from routinely collected EFM data. .

Output from pressure transient test analyses for 21 wells is presented, and the interpretation of these analyses to determine the timing of damage development is demonstrated using output from specific study wells. Development of processing and interpretation modules to handle EFM data interpretation in horizontal wells is also a presented and discussed.

A spreadsheet application developed to aid underground gas storage operators in the selection of EFM equipment is presented, discussed, and used to determine the costbenefit of installing EFM equipment in a gas storage field.

Recommendations for future work related to EFM in gas storage fields are presented and discussed. 


\section{TABLE OF CONTENTS}

DISCLAIMER

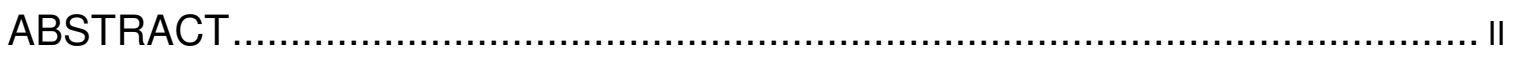

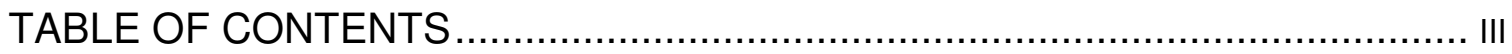

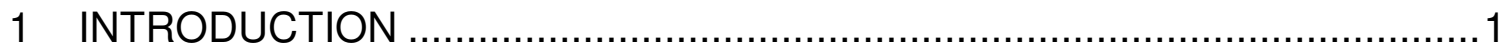

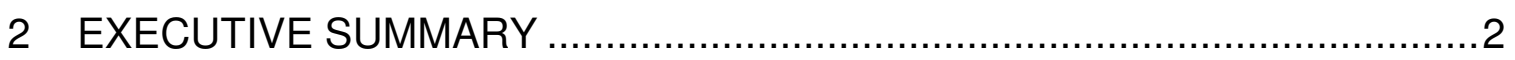

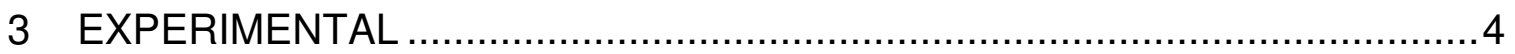

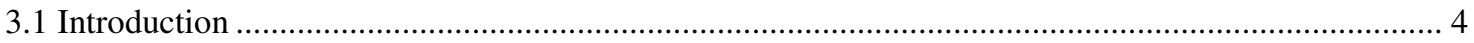

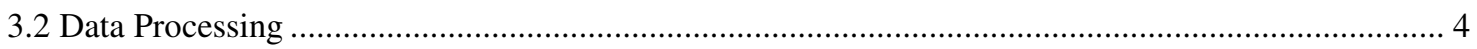

3.2.1 Data Assessment and Selection of Field for Vertical Well Pilot Study .................................... 4

3.2.2 Data Collection and Organization............................................................................................... 5

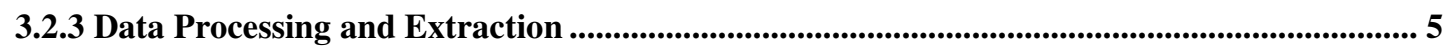

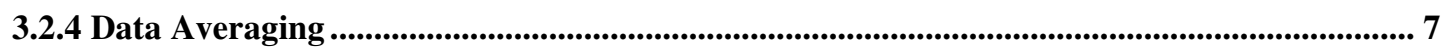

3.2.5 Identification of Candidate Shutin Periods ............................................................................ 7

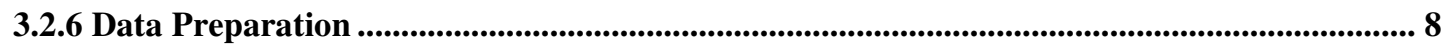

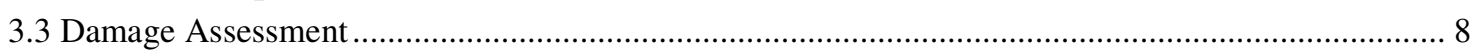

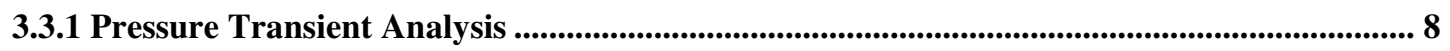

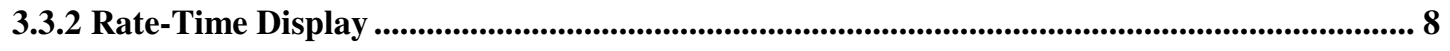

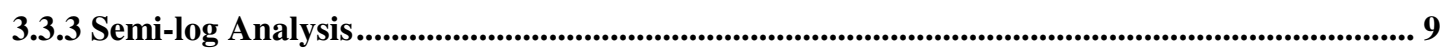

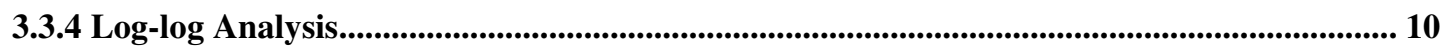

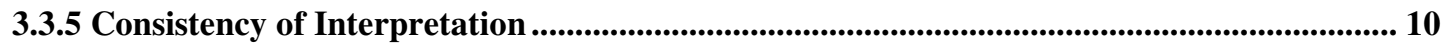

3.3.6 Quality Control............................................................................................................. 11

3.3.7 Plotting and Interpreting Damage Histories ............................................................... 12

3.3.8 Development of a Horizontal Well Model ...................................................................................... 14

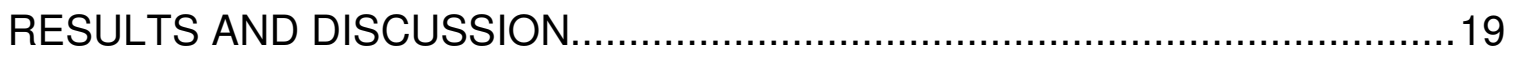

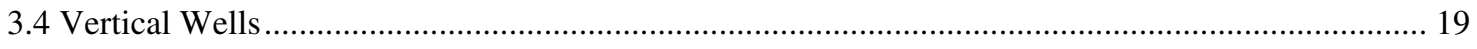

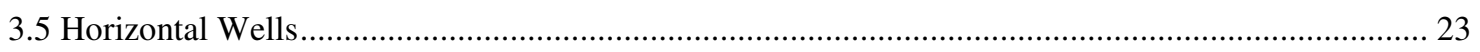

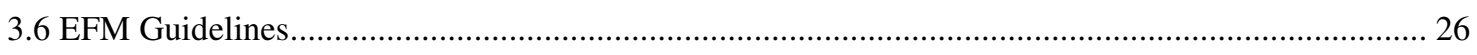

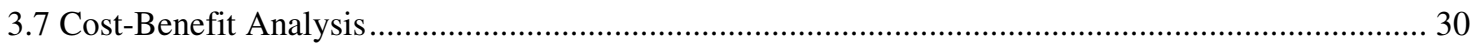

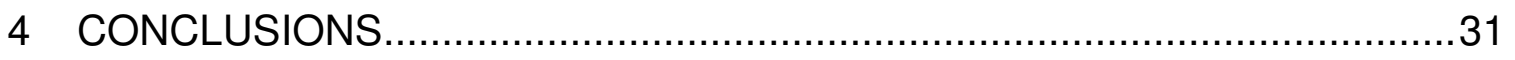

REFERENCES

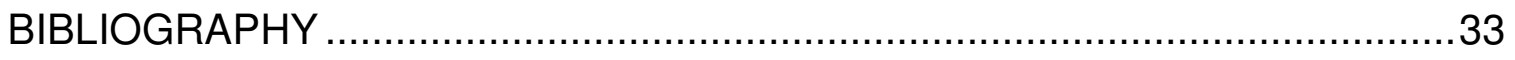

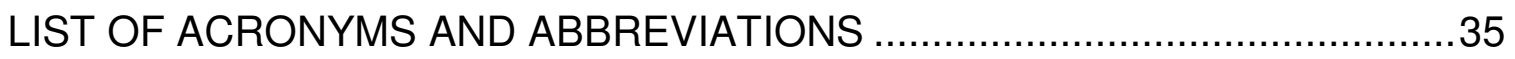

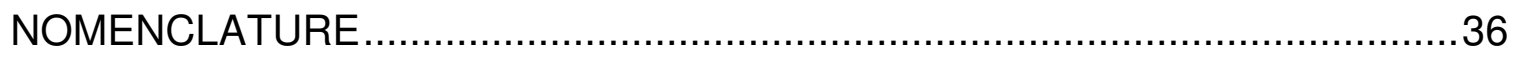

APPENDIX I: EQUATIONS USED FOR WEIGHTED LINEAR REGRESSION .....................37

APPENDIX II: USER INSTRUCTIONS FOR DAMAGE SOFTWARE ............................40

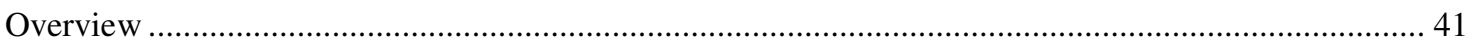

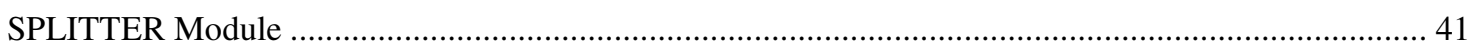

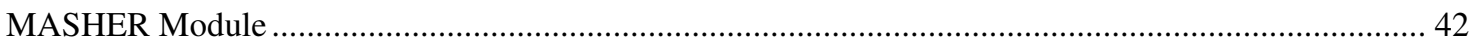

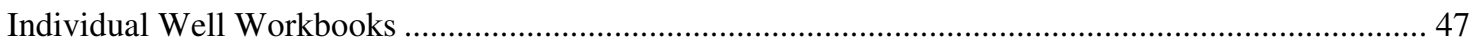

APPENDIX III: ANALYSES RESULTS FOR INDIVIDUAL WELLS ...............................50 


\section{LIST OF GRAPHICAL MATERIALS}

\section{$\underline{\text { Tables }}$}

Table 1-Sheets in well pressure transient test workbook generated by MASHER......... 8

Table 2-Start and end times for horizontal well flow regimes .................................... 15

Table 3-Parameters used in Monte Carlo study to determine which flow regimes are likely to occur for a horizontal well in a gas storage field. .................................... 16

Table 4-Statistics from Monte Carlo study for horizontal well flow regime start and end times

\section{Figures}

Fig. 1: Detailed flowchart of module MASHER ..................................................... 6

Fig. 2 - Cartesian graph of pressure and rate vs. date for the selected test period............. 9

Fig. 3 - Semi-log graph of shutin pressure change vs. time for the selected test period. ... 9

Fig. 4 - Log-log graph of shutin pressure change vs. time for the selected test period. ... 10

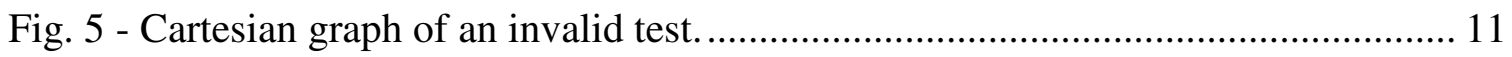

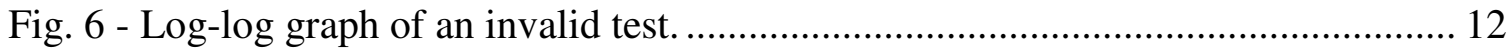

Fig. 7 - Graph of apparent skin factor vs. absolute value of rate ................................. 12

Fig. 8 - Graph of apparent skin factor vs. rate, negative for withdrawal, positive for

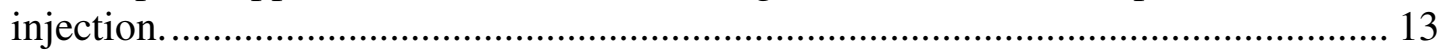

Fig. 9 - Graph of apparent skin factor and damage skin factor vs. date, showing how the components of skin change with time

Fig. 10 - Horizontal well model.

Fig. 11: Overview of rate and pressure, Well A, January 1, 2004 through April 30, 2004.

Fig. 13 - Plot of mechanical skin versus time for Well A............................................. 20

Fig. 14 - Plot of mechanical damage versus rate, Well A............................................. 20

Fig. 15 - Portion of Fig 14 showing 2004 injection operations. .................................. 21

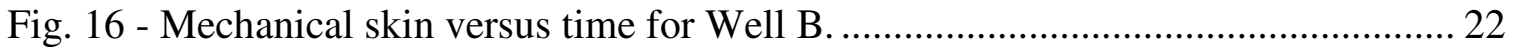

Fig. 17 - Mechanical damage versus rate for Well B. ............................................... 22 


\section{LIST OF GRAPHICAL MATERIALS (CONTINUED)}

Fig. 18 - Mechanical damage versus rate, 2004 injection, Well B................................ 22

Fig. 19: Plot of mechanical damage versus time for Well C...................................... 23

Fig. 21: Overview of rate and pressure data in horizontal study well. .......................... 24

Fig. 23: Plot of mechanical skin versus time for Horizontal Study Well ....................... 24

Fig. 24: Plot of mechanical damage versus rate, Horizontal well ................................. 25

Fig 25: Mechanical damage versus absolute value of rate, horizontal well ................... 25

Fig. 26: Reservoir input parameters requested for EFM guideline module..................... 26

Fig. 27: Wellbore input parameters requested for EFM guideline module ................... 26

Fig. 28: Equipment and data storage input parameters requested for EFM guideline

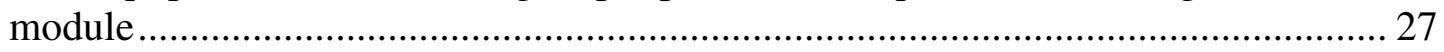

Fig. 29: Computer storage input parameters requested for EFM guideline module......... 27

Fig. 30: Basic fluid properties calculated ............................................................ 28

Fig. 31: Estimated beginning and end times of PTTA flow regimes........................... 28

Fig. 32: Estimated start/end times for flow regimes in vertical wells with hydraulic

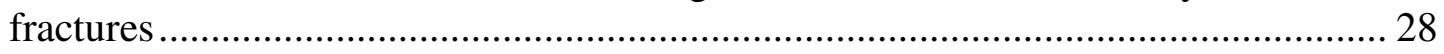

Fig. 33: Estimated start/end times for flow regimes in horizontal wells ....................... 29

Fig. 34: Output showing the minimum data collection frequency required to identify flow

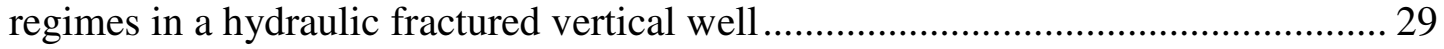




\section{INTRODUCTION}

Most underground gas storage (UGS) wells suffer loss of deliverability over time, often due to unidentified causes. Consequently, deliverability maintenance is one of the primary concerns of UGS operators. We believe that a significant aid to identifying the potential causes of damage in UGS wells would be an increased knowledge of when the damage develops. Specifically, does the damage develop during injection operations, during withdrawal operations, when a change in flow direction occurs, or continuously?

Unfortunately, identifying trends in damage versus time using conventional buildup and falloff tests would be operationally challenging and prohibitively expensive. Commonly employed, cheaper, and less sophisticated method of inferring changes in damage levels from changing flow potential benchmarks, such as $\mathrm{Q}_{100}$ values (e.g., the estimated flow rate at a $\mathrm{dP}^{2}$ of $100,000 \mathrm{psi}^{2}$ ) are, in the authors experience, tenuous at best.

Fortunately, an increasing number of UGS operators are using wellhead electronic flow measurement (EFM) systems capable of collecting high-frequency (e.g., every 5-15 seconds) pressure and flow rate data at the wellhead. Over the course of normal storage operations, wells will often be shut in for short periods of time. Wellhead EFM data collected during these shut-in periods can be analyzed as buildup or falloff tests. Consequently, UGS operators having wellhead EFM systems often have sufficient buildup and falloff test data to identify trends in damage over time.

The primary objective of this study was to develop tools that would allow UGS operators to quickly and efficiently use EFM data to identify trends in well damage over time, thus aiding in the identification of potential causes of the damage.

Secondary objectives of this work included: 1) To assisting UGS operators in evaluating hardware and software requirements to implement EFM systems similar to the one described in this report and 2) To providing a cost-benefit analysis framework that UGS operators can use to evaluate the economic benefits of installing wellhead EFM systems in their particular fields. 


\section{EXECUTIVE SUMMARY}

The primary objective of our study was to improve deliverability in gas storage wells by providing a means to better understanding when damage develops, so that, with this knowledge, operators could identify likely source(s) of damage and make the changes necessary to prevent damage from occurring.

We accomplished this objective by developing a series of software modules to filter, average, and analyze EFM data using Pressure Transient Test Analysis (PTTA) techniques. Using these newly developed tools, we analyzed data from 20 vertical wells and one horizontal well. PTTA results were interpreted and these interpretations were used to determine the timing and type of damage developing in the wells.

In the study field containing the vertical storage wells, we efficiently processed, analyzed and interpreted data from 20 wells over a 1-1/2 yr timeframe (2 million records per well per year). The results yielded estimates of static reservoir parameters such as permeability and the non-Darcy damage coefficient for individual wells. In addition, rate-dependent and time-dependent parameters were estimated and plotted (including the total damage vs rate and mechanical damage vs time).

The following observations are based on overall study results:

- The path of damage development using EFM data from UGS wells can be identified

- Periodic shut-in periods (naturally occurring or induced) in study wells significantly improved the quality of results and had no deleterious effects on field deliverability.

The following general observations are based on results from vertical study wells:

- At transitional times wherein flow direction in the storage field is reversed, some wells evidenced damage levels that increased in a stepwise fashion.

- In some wells, the non-Darcy damage coefficient remained constant during withdrawal operations, but changed at a specific point during injection operations.

- In some wells, neither mechanical nor non-darcy damage varied with time or flow direction.

Modules developed for analysis of EFM data from vertical wells were subsequently adapted to handle EFM data from horizontal wells. Data from one horizontal well was available for study. This data was processed, analyzed, and interpreted, and yielded results that were of similar type and quality as those from vertical wells.

The following general observations are based on results from horizontal study wells:

- Determination of skin values is typically feasible using early linear flow period data.

- Good PTTA results can be obtained in horizontal wells using relatively lowfrequency EFM data (e.g., data collected once every 15-60 minutes).

A second objective of this project was the development of guidelines for the deployment of EFM systems in other storage fields, including:

- Identifying the data collection requirements for typical storage fields

- Identifying the general hardware and software requirements necessary to collect, transmit, store and interpret EFM data. 
We accomplished our second objective by developing additional software modules. These modules require estimates of reservoir properties, well construction details, and technical objectives. Using this input, the software calculates the frequency of data collection necessary to meet the operator's objectives, data storage requirements necessary to store the recommended amount of data collected, transmission mode necessary to transmit the data efficiently, and estimated equipment and installation costs.

Although the cost of any particular EFM system will vary widely, depending on the specific reservoir and facilities properties, and installed cost of $\$ 5,000$ per well was considered reasonable for planning purposes. A third objective of the project was to perform a cost-benefit analysis of installing EFM equipment in UGS fields. A spreadsheet application was developed to accomplish this objective. The application allows the operator to input estimated equipment costs, damage levels, damage reduction expected from stimulation, and stimulation costs for the candidate field. The spreadsheet then calculates results for the field of interest.

Using this application, we performed a cost-benefit analysis for a statistically typical UGS field, assuming existence of minor to moderate damage levels and typical damage reduction levels seen in UGS wells. The results of this analysis suggest the following:

- Estimated revenue generated from the identification and stimulation of only one damaged well is about 1-1/2 times the typical EFM installation cost, suggesting that EFM installation costs are typically recovered in less than one withdrawal season.

- Identification and stimulation of only one damaged well every 4-5 years is necessary to cover ongoing EFM maintenance costs.

Based on the results of this study, we draw the following conclusions:

- Software modules have been developed and demonstrated for vertical and horizontal wells that enable efficient analysis of high frequency EFM data, resulting in an effective tool that can identify the timing of damage development in UGS wells.

- Software modules have been developed for vertical and horizontal wells that provide guidance in the deployment of EFM systems in UGS fields.

- Cost-Benefit analysis suggests that the cost of installation and maintenance of wellhead EFM systems in typical UGS fields is economically justified.

- In horizontal UGS wells relatively low frequency EFM data (e.g., every 15-60 minutes) is probably sufficient for tracking the timing of damage development.

We recommend UGS operators consider the use of wellhead EFM systems to more efficiently manage their operations, maintain deliverability, and track damage development. UGS operators with existing EFM installations should use the tools developed in this project to process wellhead EFM for the purposes of identifying stimulation candidates and determining specific times and operational procedures that result in increased well damage. Also, additional testing of the horizontal well modules should be performed as more data becomes available.

Study results clearly illustrate the potential benefits derived from installing EFM systems, collecting/storing the correct amount of data, and analyzing the resulting data. We believe that widespread adoption of EFM systems will ultimately result in improved storage field performance at reduced cost. 


\section{EXPERIMENTAL}

\subsection{Introduction}

The potential for extremely large data sets exists when collecting high-frequency EFM data in UGS wells for use in PTTA. This is because the duration of the Wellbore Storage (WBS)-dominated flow regime in a typical storage well is extremely short-lived, often lasting only a few minutes.

In such a case, if it is necessary to confidently identify the WBS-dominated flow regime by the unit-slope on a diagnostic plot or type curve, data must be collected about every 10-30 seconds. In the study field having 20 vertical wells, the daily data sets contained about 6,000 data records per well, which corresponds to over 2 million records per year per well.

\subsection{Data Processing}

In an effort to make data management, manipulation, and analysis more manageable for these types of data sets, we developed a series of modules to automatically process, filter, average, store, and analyze high frequency data collected from UGS wells. All of the modules developed in this study are available upon request from the United States Department of Energy (DOE), and require only "off-the-shelf" software (Microsoft $\mathrm{EXCEL}^{\mathrm{TM}}$ ).

To make these modules accessible to as wide an audience as possible, we chose Microsoft Excel Visual Basic for Applications (VBA) as the development platform. Benchmarks against Microsoft Visual $\mathrm{C}++$ showed that the data processing is $\mathrm{I} / \mathrm{O}$ bound, so that the use of VBA instead of a compiled language such as $\mathrm{C}++$ results in only a minor penalty in performance.

\subsubsection{Data Assessment and Selection of Field for Vertical Well Pilot Study}

Columbia had several fields equipped with wellhead EFM data collection systems. Each differed somewhat in the type and frequency of data collection, as well as the number of wells equipped with EFM. Given that the project goals involved analysis of highfrequency EFM data, we felt that daily average rate and pressure data were not sufficient. In addition, we also preferred a field in which all of the wellheads were equipped with EFM, in the event it became necessary to know the total field flow in any calculations. Finally we preferred to use a peaking type field, as this type of field would likely have more frequent shut-in periods and flow rate changes available for analysis.

We finally selected a field in which all 20 storage wells were equipped with wellhead EFM systems. The field was essentially a base load field, so the number of shut-in periods was somewhat limited. Nonetheless, there were a sufficient number of shut-in periods in each well to demonstrate the newly developed tools. The study reservoir consists of a stratigraphic trap in consolidated sandstone. It has an average thickness of about $10 \mathrm{ft}$, an average porosity of about $10 \%$, and an average permeability on the order of $150 \mathrm{md}$. Discovery pressure is approximately 800 psi. 
There are 5 wells in the study field that are designated "keywells." However, these are not keywells in the traditional sense of the word. In most storage fields, keywells are virtually never used for injection or withdrawal. In the study field, keywells were routinely used for storage operations, but were shut-in for 24 hours once every week to obtain an estimate of the reservoir pressure for use in inventory assessment. It should be noted that the operator did not believe the weekly interruption of storage service from these keywells significantly impacted the overall operations of the field.

Considering that the designated keywells in the study yielded considerably more highquality information than the other wells in the field, the practice of periodically shutting in select wells for a brief period should be considered for wells requiring damage diagnosis.

\subsubsection{Data Collection and Organization}

Columbia provided raw EFM data to us on a monthly basis via CD-ROM, which included a separate ASCII data file for each day of the month. Each daily file consisted of a data header followed by as many as 115,000 data records. Data records were recorded every 15 seconds, with a separate record for each well. Each record included date, time, well ID, flowing wellhead pressure, and gas flow rate in fixed-width columns. While formats may differ in detail from operator to operator, this format should be similar to those used by most other operators.

To convert the data to a more convenient format, we wrote a module that we call SPLITTER. SPLITTER reads all of the daily files and then writes the data to a series of separate files, one for each well. To reduce the disk space required and to make processing more efficient, the well files were written in binary format, with each data record comprising fields for date and time, pressure, and rate.

SPLITTER has options to specify the source and destination directories, along with a list of daily files to process. The name for each output well files is the well ID for the corresponding well, concatenated with the file extension .BIN. SPLITTER appends new data to the end of any existing well files, allowing us to easily update the well files to include new monthly data without having to reprocess the data from previous months. SPLITTER is very simple, and may easily be adapted to handle most raw EFM data formats.

\subsubsection{Data Processing and Extraction}

To handle the extremely large number of data points (over 3 million) in each well's data file output by SPLITTER, we wrote a module called MASHER to process the raw highfrequency EFM data. MASHER is much more complex than SPLITTER, but should require little or no modification provided the format of the SPLITTER output files has not been changed. MASHER includes three major components: 1) a gas properties correlation sub-module, 2) a bottomhole pressure calculation sub-module, and 3) a data processing sub-module. A detailed flowchart of MASHER data processing sub-module is shown in Fig. 1 below. 


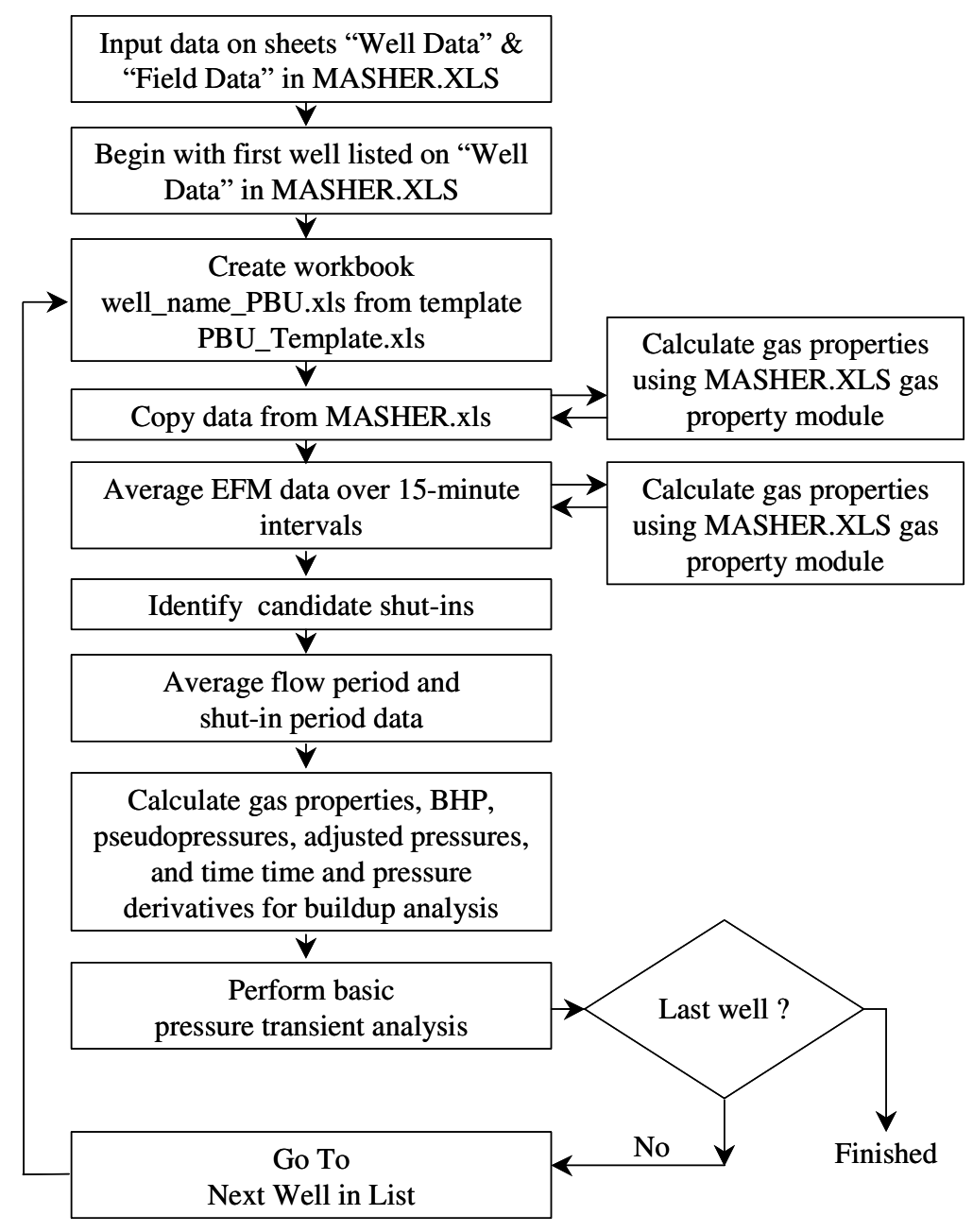

Fig. 1: Detailed flowchart of module MASHER

The gas properties correlation sub-module includes subroutines to calculate pseudocritical temperature and pressure, z-factor, coefficient of isothermal compressibility, gas formation volume factor, gas density, gas viscosity, and gas pseudopressure from industry standard correlations. ${ }^{1-4}$

The bottomhole pressure calculation module uses a fourth-order Runge-Kutta integration scheme with a simple adaptive step-size algorithm to integrate the differential equation for single-phase gas flow in pipe. The Cullendar and Smith ${ }^{4}$ algorithm is not used for two reasons. First, it was designed for quick, hand calculation of bottomhole pressures, rather than as a general-purpose numerical integration scheme. Second, the integral panels in the Cullendar and Smith algorithm may contain a singularity in the integrand when used for calculating bottomhole pressures in injection wells. ${ }^{5,6}$ Thus, the Cullendar and Smith method should never be used for injection cases.

The MASHER data processing submodule processes the high frequency EFM data for each well and builds an Excel workbook of the processed flow and shutin test data. 


\subsubsection{Data Averaging}

Two different averaging strategies were adopted, one for routine flow measurements, the other for candidate shutin test periods.

\subsubsection{Flow Period Data Averaging.}

For flow period measurements, MASHER averages the high-frequency EFM data over 15-minute intervals. MASHER computes the average flow rate and average pressure, and the standard deviation of the rate and pressure during each interval. For each interval, MASHER records the date and time, the number of data points, and the maximum and minimum flow rate and pressure for the interval. MASHER also calculates and records the flowing bottomhole pressure and the adjusted pressure ${ }^{7}$ for each averaged data point.

A data point was flagged as invalid if any of the EFM data points in the interval were flagged as invalid, if there was a flow reversal during the interval, or if the interval contained a mixture of both zero and non-zero EFM rate measurements.

\subsubsection{Shutin Period Data Averaging}

For candidate shutin test periods, MASHER uses a variable-width window to give approximately the same number of data points in each log cycle. For each interval, MASHER fits the calculated bottomhole pressure as a linear function of the logarithm of shutin time. MASHER records the arithmetic average pressure, the geometric average time, and the standard deviation of the pressure from the trend line. A small standard deviation indicates that the semilog straight line provides a good fit of the data. The standard deviations for each interval were used to calculate weight factors for subsequent fitting.

\subsubsection{Identification of Candidate Shutin Periods}

Because of the erratic nature of withdrawal and injection rates in gas storage operations, the MASHER data processing submodule applies a series of filtering rules to the EFM data to identify shutin periods that might be analyzable as buildup or falloff tests.

First, the well has to have been producing or injecting for a specified minimum length of time prior to the beginning of the candidate test period. This minimum flow period should be long enough for wellbore storage phenomena and near-wellbore effects to end and for the radius of investigation to get well beyond the near wellbore region. For the field described in this study, a minimum flow period of twelve hours was chosen.

Second, the shutin period has to be at least as long as a specified minimum duration. As with the flow period, the shutin period should be long enough for wellbore storage phenomena and near-wellbore effects to end, and for the radius of investigation to get well beyond the near wellbore region. For this study, a minimum shutin period of two hours gave a reasonable compromise between allowing too many candidate shutin periods and allowing too few.

Third, for a shutin period to be analyzable, there has to be a specified minimum number of valid data points during the shutin period. For this work, 25 shutin periods were found to be an appropriate minimum number of data points. 


\subsubsection{Data Preparation}

The final step performed by MASHER is to build an Excel workbook with the smoothed EFM data and the pressure transient data for each test period. Each workbook contains a number of worksheets and graphs, as shown in Table 1

Table 1-Sheets in well pressure transient test workbook generated by MASHER.

\begin{tabular}{|l|l|}
\hline \multicolumn{1}{|c|}{ Sheet } & \multicolumn{1}{c|}{ Purpose } \\
\hline Input Data & Reservoir and fluid property data for the well \\
\hline EFM Data & EFM data averaged over 15-minute intervals \\
\hline Work & Temporary work area to hold data for test currently being analyzed \\
\hline Work-PQ & Cartesian graph of rate and pressure vs. time for current test period \\
\hline Work-SL & $\begin{array}{l}\text { Semilog graph of adjusted pressure vs. multirate equivalent adjusted } \\
\text { time for the current test period }\end{array}$ \\
\hline Work-LL & $\begin{array}{l}\text { Log-log graph of adjusted pressure change and adjusted pressure } \\
\text { derivative vs. multirate equivalent adjusted time for current test period }\end{array}$ \\
\hline PBU Summary & Summary table of all test period analyses \\
\hline PBU Database & Database workspace of all test period analyses \\
\hline S' vs q & Graph of effective skin factor s' vs flow rate q \\
\hline S' vs abs(q) & Graph of effective skin factor s' vs the absolute value of flow rate |q| \\
\hline S' vs Date & Graph of effective skin factor s' vs date \\
\hline k vs Date & Graph of in-situ permeability k vs date \\
\hline Well History & Graph of 30-minute averaged rate and pressure vs. date. \\
\hline
\end{tabular}

\subsection{Damage Assessment}

After MASHER has generated the workbooks for each well, the user moves on to the damage assessment phase. During this phase, the user reviews and confirms analysis of the data for each individual test period, then reviews the behavior of the apparent skin factor as a function of time to identify any time-dependent trends in the skin factor.

\subsubsection{Pressure Transient Analysis}

Although MASHER does most of the data preparation for analyzing the transient test data, the user must do the final quality check of the data and the analysis. The MASHERgenerated workbook contains three interactive graph sheets to facilitate this process. Each sheet has a spinner button on the upper left corner to allow the user to navigate through the tests in chronological order, a combo-box to go directly to a specific test, and a check box to indicate whether to include the test in the summary analysis (Fig. 2). In addition, the semi-log and log-log analysis graphs have slider bars to select the middle time region and a toggle button to show or hide straight lines corresponding to the average permeability for all the tests that have been analyzed (Fig. 3).

\subsubsection{Rate-Time Display}

The sheet "Work-PQ", shown in Fig. 2, is a Cartesian graph of the pressure and rate vs. time for the test period being analyzed. The graph shows approximately 48 hours of the flow history prior to shutin, along with the shutin period data. 


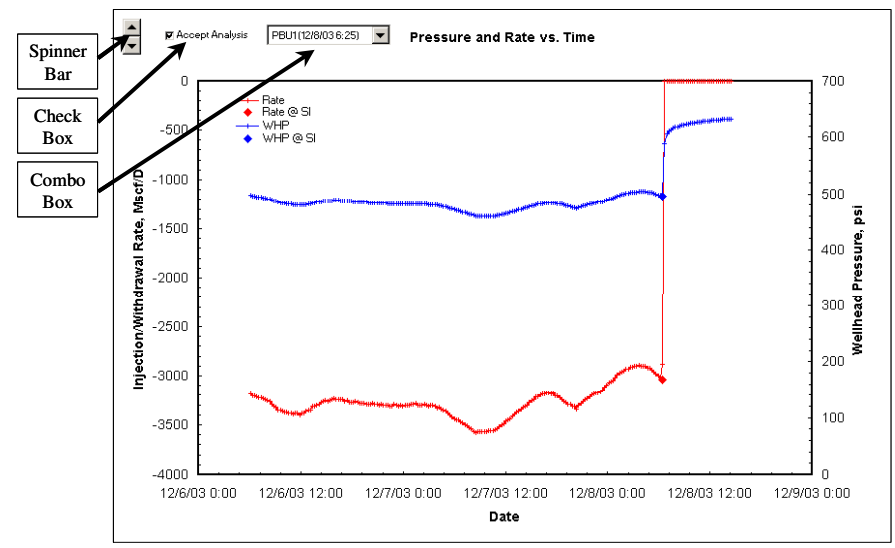

Fig. 2 - Cartesian graph of pressure and rate vs. date for the selected test period.

With this graph, the user can quickly review all the test periods to eliminate any bad tests that might have slipped through the automatic filtering process. Tests that have very erratic rate histories or obvious problems with the data may be rejected simply by unchecking the "Accept Analysis" check box.

\subsubsection{Semi-log Analysis}

The sheet "Work-SL", shown in Fig. 3, shows a semi-log graph of the test period being analyzed. When the user moves the slider bars to select the middle time region, the worksheet automatically fits a semi-log straight line through the selected data and displays the updated fit.

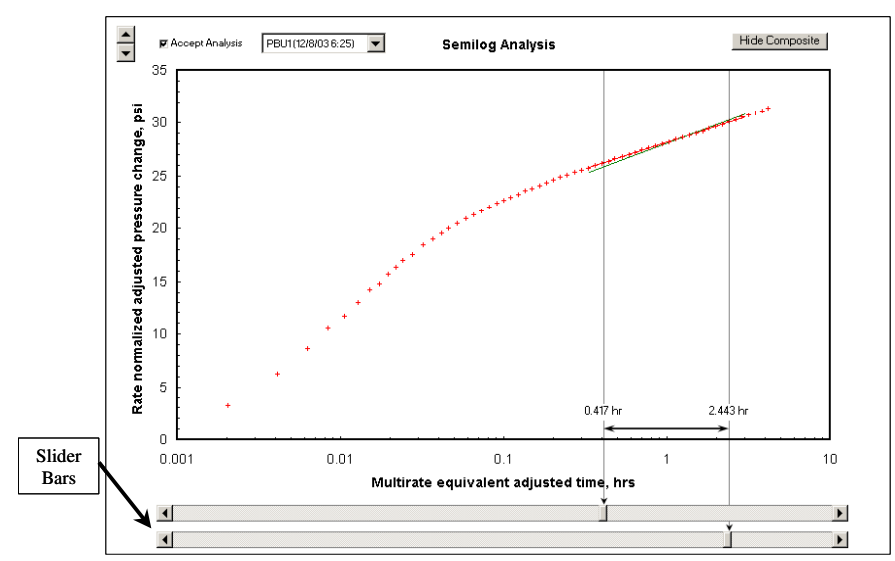

Fig. 3 - Semi-log graph of shutin pressure change vs. time for the selected test period.

Instead of using standard linear regression where the data points are weighted equally, the data points are weighted to reflect the fact that they are themselves the result of an averaging process. A data point early in the test may represent only a single 15 -second measurement, while a point at the end of the test may represent an average of a hundred 
or more 15-second measurements. The Appendix gives the equations used for the weighted linear regression.

\subsubsection{Log-log Analysis}

The sheet "Work-LL" shown in Fig. 4, contains a log-log graph of the test period being analyzed. As with the semi-log graph, when the user moves the slider bars to select the middle time region, the worksheet automatically fits a semi-log straight line through the selected data and displays the updated fit for both the pressure and pressure derivative data. The semi-log and log-log analysis graphs are tied together, so that both graphs use the same middle time region and straight line fit.

When the user selects another test period for analysis, by using the spinner buttons or the drop-down box, the settings for the current test are saved, and the data and settings for the next test are loaded.

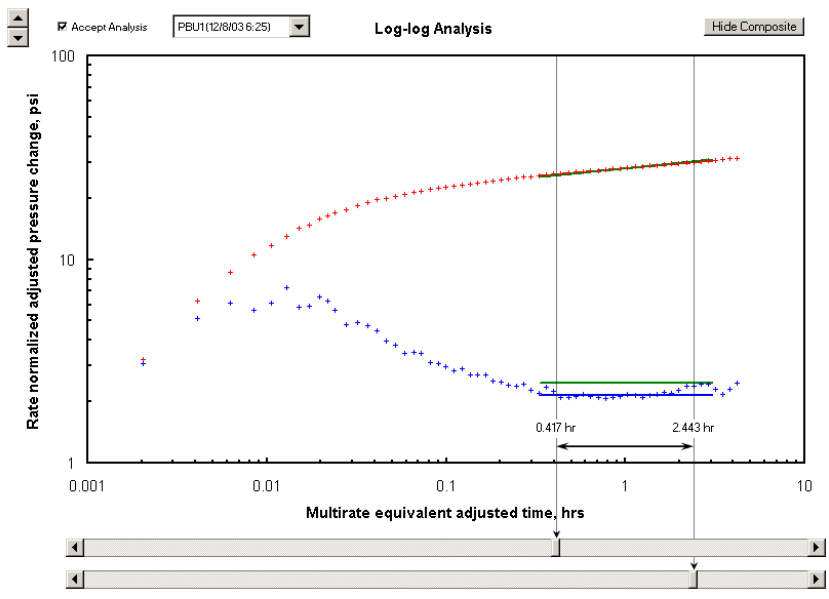

Fig. 4 - Log-log graph of shutin pressure change vs. time for the selected test period.

\subsubsection{Consistency of Interpretation}

One of the key features of MASHER is the ability to ensure consistency of interpretation from test to test. To be able to make meaningful comparisons between skin factors from tests run at different times on the same well, all test analyses should yield similar permeabilities. MASHER promotes consistency in three ways.

First, the pressure transient data are rate-normalized before being plotted on the semilog and log-log graphs. Thus, the pressure response for any valid test should be independent of rate, allowing tests run at different rates to be compared quickly and easily.

Second, default values for the start and end of the middle time region (MTR) are established for each well. As long as there are no problems with the test data before or during the MTR, there is no need to change the start and end times, ensuring that all the test analyses cover the same portion of the reservoir. The user may change the start and end of the MTR for each individual test if needed to eliminate bad data.

Third, the MASHER-generated worksheet calculates an average permeability from all the valid tests, then uses that average permeability to calculate the effective skin factor for each test. In the log-log and semi-log graphs, straight lines corresponding to the average 
permeability are displayed for comparison with the straight lines from the fit of the individual test data. Any test where the permeability differs significantly from the average is likely to be an invalid test.

\subsubsection{Quality Control}

Another of MASHER's key features is the ability to perform quality control quickly and easily. We have found it helpful to use the Cartesian rate and pressure vs. time graph along with the log-log graph.

The Cartesian graph of pressure vs. time for a valid test, such as the one shown in Fig. 2, will have a shutin period that is very smooth. In contrast, the Cartesian graph of pressure vs. time for an invalid test will often exhibit fluctuations in pressure, as shown in Fig. 5. In an ideal test, there will be only small fluctuations in rate prior to shutin. In a bad test, there may be large fluctuations in rate, and the rate immediately prior to the shutin may be very different from the preceding rates.

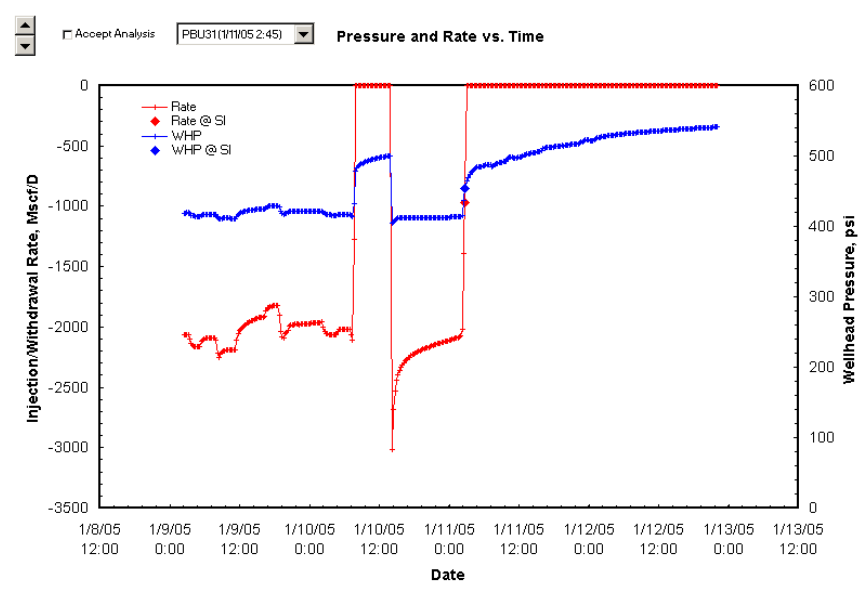

Fig. 5 - Cartesian graph of an invalid test.

The log-log graphs from all valid tests for a single well will look very similar. The derivative will usually be smooth, and will exhibit a horizontal derivative during the correct MTR. In contrast, the log-log graph for an invalid test may exhibit an erratic derivative, as in Fig. 6. The absence of a horizontal derivative or other unexpected behavior may also indicate an invalid test. 


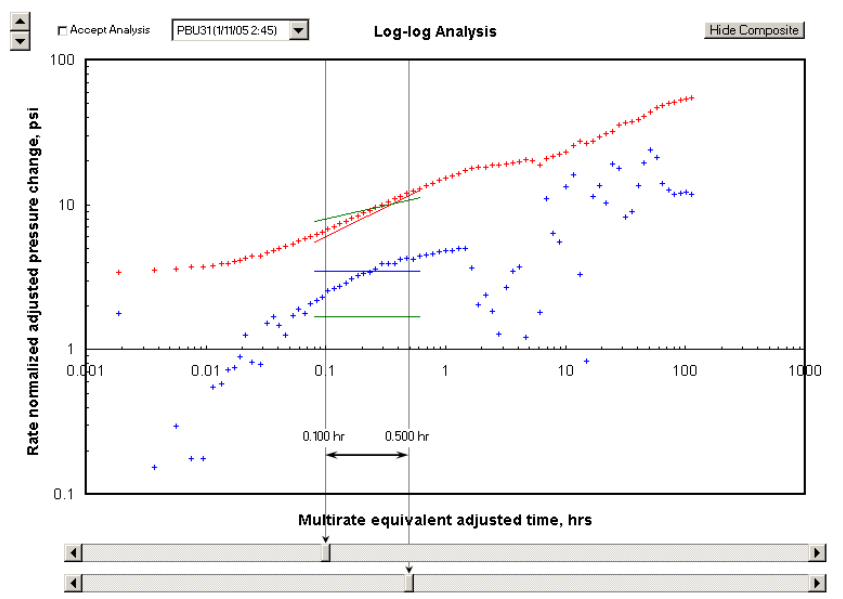

Fig. 6 - Log-log graph of an invalid test.

\subsubsection{Plotting and Interpreting Damage Histories}

After the user has reviewed and analyzed all the test periods, he may review the behavior of the apparent skin factor as a function of rate or time using a summary worksheet and three summary graphs.

The worksheet "PBU Summary" shows a summary of all the test periods and their analyses. The sheet also shows the calculated average permeability for all the test periods with analyzable tests. The graphs "S' vs abs(q)" (Fig. 7) and S' vs q" (Fig. 8) show how the effective skin factor varies with rate, while the "S' vs. Date" graph (Fig. 9) shows how the skin factor changes with time.

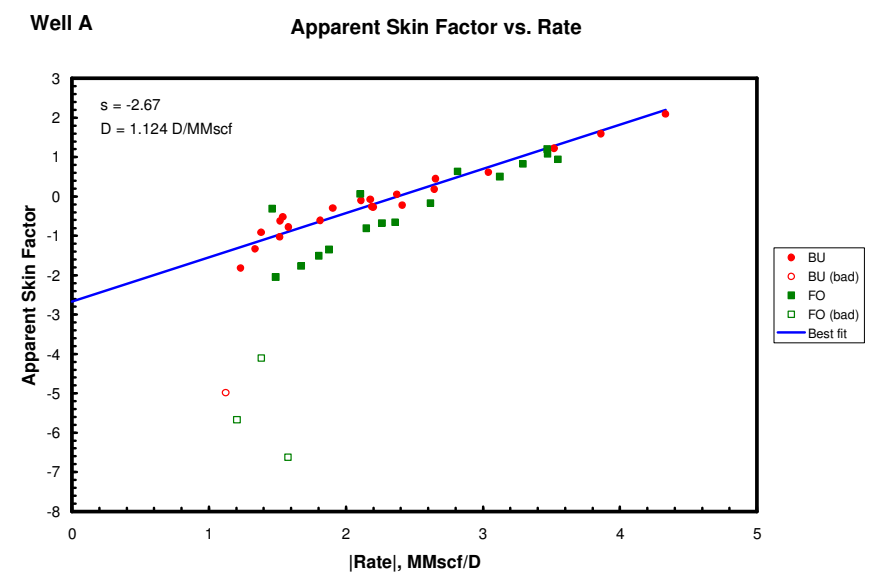

Fig. 7 - Graph of apparent skin factor vs. absolute value of rate. 


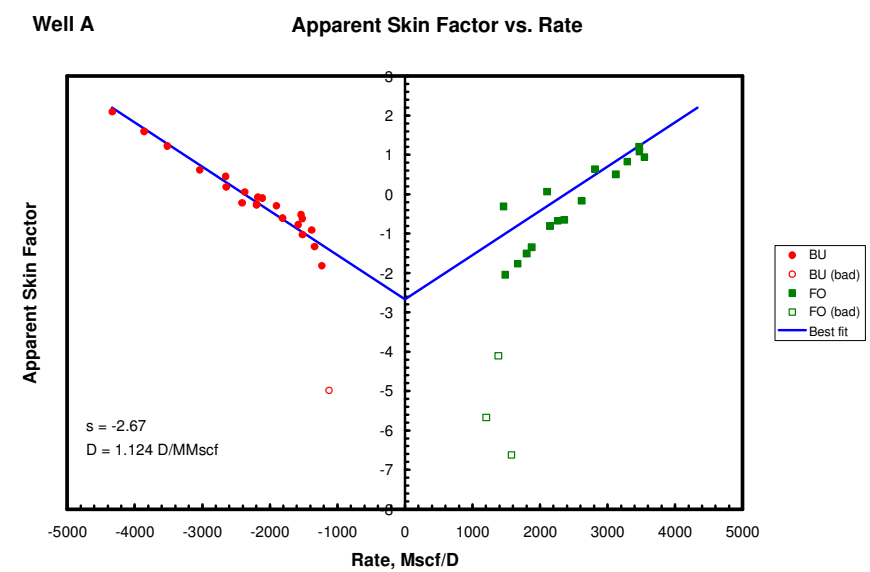

Fig. 8 - Graph of apparent skin factor vs. rate, negative for withdrawal, positive for injection.

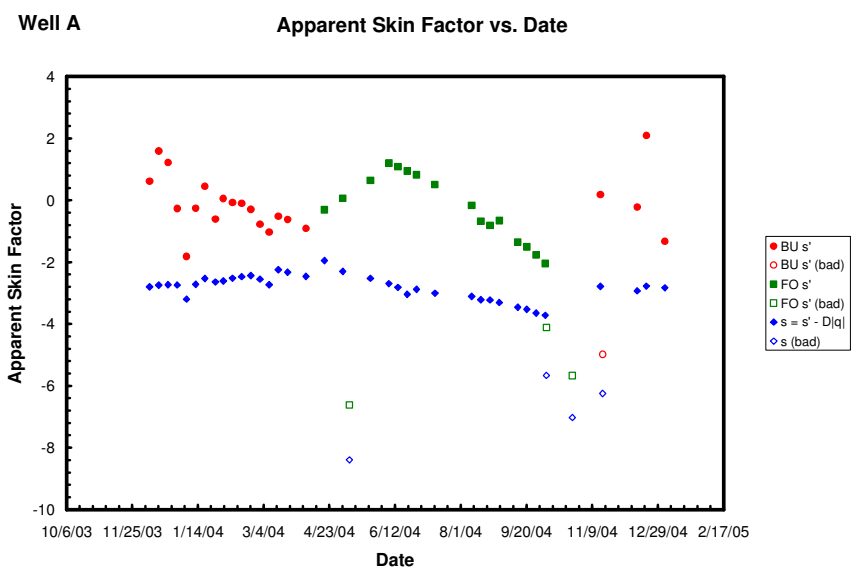

Fig. 9 - Graph of apparent skin factor and damage skin factor vs. date, showing how the components of skin change with time.

The graph "S' vs abs(q)", shown in Fig. 7, looks much like a rate-dependent skin factor analysis for a conventional four-point test. However, in a traditional four-point test, the skin factors plotted on the graph are from tests run at essentially the same time, while the summary graph includes many pressure transient analyses, from tests run over a period of months or years, including both buildup and falloff tests.

If the damage skin factor s and the non-Darcy flow coefficient D are constant with time, the data on "S' vs abs(q)" graph will all fall on a single straight line, and may be used to estimate $\mathrm{s}$ and $\mathrm{D}$ as with a traditional rate-dependent skin analysis.

If either s or D is changing with time, the data will not fall on a single straight line on the "S' vs abs(q)" graph. Instead, the behavior will depend on which skin component is changing, and whether that damage component changes abruptly, or slowly over time.

If either s or D changes abruptly, the data points will fall in groups on two or more different straight lines. If only the damage skin changes, the straight lines will be parallel. The slope will give the constant non-Darcy coefficient, and the y-intercept of each straight line will give the damage skin. If only the non-Darcy coefficient changes, the straight lines will have the same y-intercept and different slopes. 
If either skin component increases continuously with time, the data points will drift upward over time instead of falling in groups on one or more straight lines.

The graph "S' vs q", Fig. 8, shows the apparent skin factor plotted vs. rate with positive rates representing injection and negative rates representing withdrawal. The behavior of this graph is similar to that of the " $S$ ' vs abs(q)" graph, but emphasizes changes in apparent skin factor between the injection and withdrawal seasons.

Fig. 9 shows a graph of apparent skin factor and inferred damage skin factor vs. date. For this case, neither the damage skin nor the non-Darcy flow coefficient show a definite trend with time. As is often the case with base load fields such as this one, the withdrawal rate decreases over time as the reservoir pressure declines, causing the apparent skin factor to decrease as well. In this particular case, the injection rates increase during the injection season, causing the apparent skin factor to rise with time during the course of the injection season.

\subsubsection{Development of a Horizontal Well Model}

The process described above was adapted to enable analysis of wellhead EFM data collected from horizontal wells. The first step in this adaptation process was to development a PTTA module to handle horizontal well data.

A number of different authors have proposed different horizontal well models, often using different nomenclature. Fig. 10 shows the horizontal well model with nomenclature used in this study.

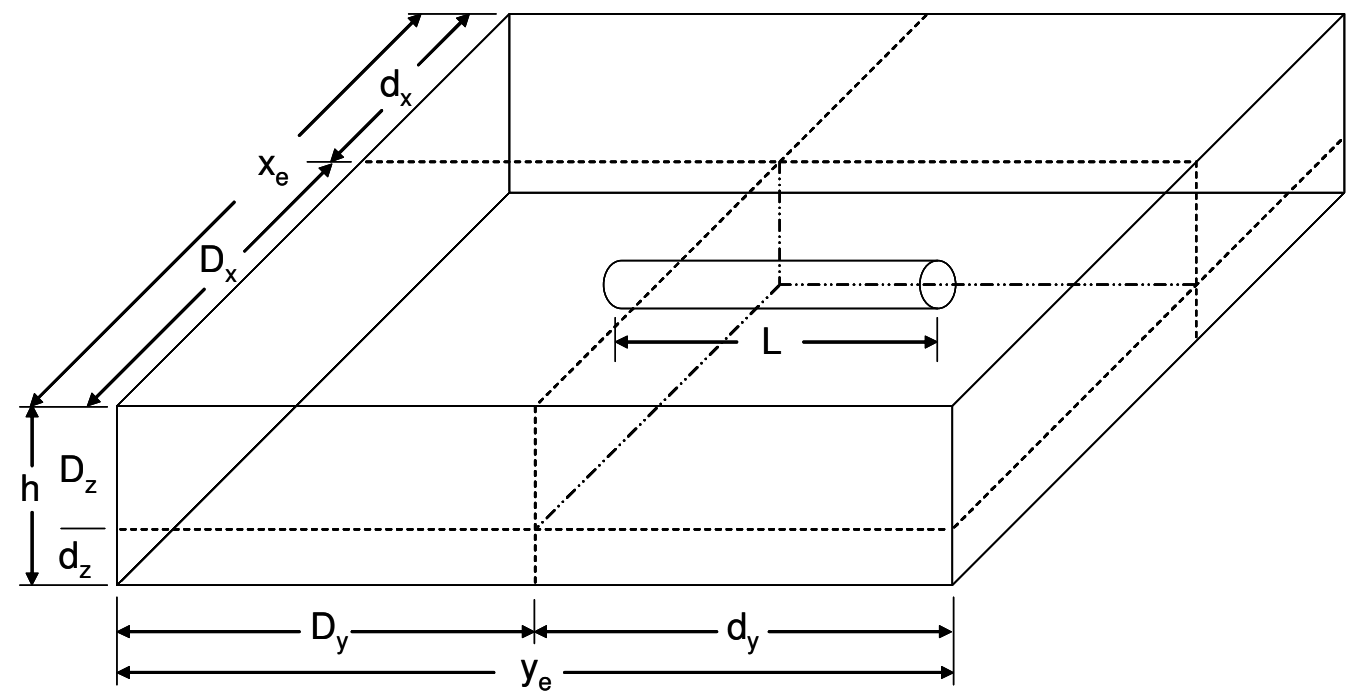

Fig. 10 - Horizontal well model.

The axis of the wellbore lies along the y-axis, and is parallel to one side of a closed rectangular drainage area. The length of the wellbore is h. The width and length of the reservoir are respectively xe and ye, while the reservoir thickness is $h$. The distances from the center of the wellbore to the nearer boundary along each axis are $d_{x}, d_{y}$, and $d_{z}$, while the distances to the further boundary along each axis are $D_{x}, D_{y}$, and $D_{z}$.

\subsubsection{Horizontal Well Flow Regimes}

A number of flow regimes may occur in the pressure response for a horizontal well. ${ }^{8,9}$ The first flow regime to appear is early radial flow (ERF) in the vertical plane 
perpendicular to the wellbore. If the well is off center in the formation, a second radial flow regime, early hemiradial flow (EHRF), will occur after the effects of the nearer boundary in the z-direction are felt, but before the effects of the further boundary are felt. Early linear flow (ELF) may occur after the effects of both top and bottom boundaries are encountered and before any lateral boundaries affect the pressure response. Pseudoradial flow (PRF) may occur if the reservoir is large enough, followed by late linear flow (LLF) and finally by pseudosteady state flow (PSS).

Table 2 gives equations, adapted from Ref. 9, for estimating the beginning and end of each flow regime, in the absence of wellbore storage. In Ref. 9, the limits are based on deviation of the pressure from the ideal response. We modified the equations to give an estimate of the time at which the pressure derivative from an analytical solution deviates by approximately $5 \%$ from the ideal slope of the pressure response for the flow regime in question.

Table 2-Start and end times for horizontal well flow regimes

\begin{tabular}{|c|c|c|c|c|}
\hline $\begin{array}{l}\text { Flow } \\
\text { Regime }\end{array}$ & $\begin{array}{c}\text { Start Time } \\
\text { dimensionless }\end{array}$ & $\begin{array}{l}\text { Start Time } \\
\text { hrs }\end{array}$ & $\begin{array}{c}\text { End Time } \\
\text { dimensionless }\end{array}$ & $\begin{array}{l}\text { End Time } \\
\text { hrs }\end{array}$ \\
\hline WBS & & & $t_{e W B S D}=60 C_{D}$ & $t_{e W B S}=\frac{200,000 \mu c_{w b} V_{w b}}{\sqrt{k_{x} k_{z} L}}$ \\
\hline ERF & $t_{b E R F D}=\frac{4.85}{L_{D}{ }^{2}}$ & $t_{b E R F D}=4,600 \phi \mu c_{t} r_{w}{ }^{2}\left(\frac{1}{\sqrt{k_{x}}}+\frac{1}{\sqrt{k_{z}}}\right)^{2}$ & $t_{\text {eERFD }}=\min \left\{\begin{array}{c}0.00333 \\
0.35\left(\frac{d_{z D}}{L_{D}}\right)^{2} \\
0.271\left(\frac{0.5 * h_{D}}{L_{D}}\right)^{2}\end{array}\right.$ & $t_{e E R F}=\min \left\{\begin{array}{l}12.6 \frac{L^{2} \phi \mu c_{t}}{k_{y}} \\
1,327 \frac{d_{z}^{2} \phi \mu c_{t}}{k_{z}} \\
256 \frac{h^{2} \phi \mu c_{t}}{k_{z}}\end{array}\right.$ \\
\hline EHRF & $t_{b E H R F D}=9.5\left(\frac{d_{z D}}{L_{D}}\right)^{2}$ & $t_{b E H R F}=36,000 \frac{d_{z}^{2} \phi \mu c_{t}}{k_{z}}$ & $t_{\text {eEHRFD }}=\min \left\{\begin{array}{l}0.00318 \\
0.277\left(\frac{D_{z D}}{L_{D}}\right)^{2}\end{array}\right.$ & $t_{e E H R F}=\min \left\{\begin{array}{l}12.1 \frac{L^{2} \phi \mu c_{t}}{k_{y}} \\
1,050 \frac{D_{z}^{2} \phi \mu c_{t}}{k_{z}}\end{array}\right.$ \\
\hline ELF & $t_{b E L F D}=0.478\left(\frac{D_{z D}}{L_{D}}\right)^{2}$ & $t_{b E L F}=1,810 \frac{D_{z}^{2} \phi \mu c_{t}}{k_{z}}$ & $t_{e E L F D}=\min \left\{\begin{array}{c}0.016 \\
0.0533\left(\frac{x_{e D}}{L_{D}}\right)^{2}\end{array}\right.$ & $t_{e E L F}=\min \left\{\begin{array}{l}60.7 \frac{L^{2} \phi \mu c_{t}}{k_{y}} \\
202 \frac{x_{e}^{2} \phi \mu c_{t}}{k_{x}}\end{array}\right.$ \\
\hline PRF & $t_{b P R F D}=1$ & $t_{b P R F}=3,790 \frac{L^{2} \phi \mu c_{t}}{k_{y}}$ & $t_{e P R F D}=\min \left\{\begin{array}{c}0.27\left(1 / 4+\frac{d_{x D}}{L_{D}}\right)^{2} \\
0.29\left(\frac{d_{y D}}{L_{D}}\right)^{2}\end{array}\right.$ & $t_{e P R F}=\min \left\{\begin{array}{c}1,024\left(\frac{L}{4 k_{y}}+\frac{d_{x}}{k_{x}}\right)^{2} \phi \mu c_{t} \\
1,100 \frac{d_{y}^{2} \phi \mu c_{t}}{k_{y}}\end{array}\right.$ \\
\hline
\end{tabular}

For a given flow regime to be interpretable, it is not sufficient that its calculated end time be larger than its start time. To identify a flow regime on a log-log diagnostic plot, it must span at least $1 / 3 \log$ cycle. In other words the end time for the flow regime must be at least $101 / 3$, or 2.15 , times larger than its start time. 
To determine which of these flow regimes are most relevant to gas storage wells, we conducted a simple Monte Carlo experiment where we selected probability distributions for each of the of relevant well and reservoir properties. We then generated 1,000 different cases and calculated the start and end for each of the flow regimes.

For most of the parameters varied in the study, we used a simple triangular distribution defined by the minimum, the mode, and the maximum value for the parameter. For the permeability-related parameters, we used a lognormal distribution.

Table 3 gives a complete list of the parameters considered in the study, along with the distribution and some statistics for each parameter.

Table 3-Parameters used in Monte Carlo study to determine which flow regimes are likely to occur for a horizontal well in a gas storage field.

\begin{tabular}{|c|c|c|c|c|c|c|c|c|c|}
\hline Variable & Definition & Min & Mode & Max & Stdev & P05 & Median & Avg & P95 \\
\hline$r_{w}, f t$ & $\begin{array}{c}\text { Wellbore } \\
\text { Radius }\end{array}$ & 0.25 & 0.5 & 0.75 & & 0.33 & 0.496 & 0.494 & 0.664 \\
\hline $\mathrm{L}, \mathrm{ft}$ & $\begin{array}{l}\text { Effective } \\
\text { Length of } \\
\text { Horizontal }\end{array}$ & 500 & 1500 & 4000 & & 899 & 1959 & 2038 & 3336 \\
\hline $\mathrm{h}, \mathrm{ft}$ & $\begin{array}{c}\text { Net } \\
\text { Thickness }\end{array}$ & 5 & 15 & 50 & & 10.3 & 21.1 & 23.2 & 41.8 \\
\hline$w, f t$ & $\begin{array}{l}\text { Drainage } \\
\text { Distance }\end{array}$ & 100 & 500 & 1000 & & 232 & 531 & 536 & 846 \\
\hline A, acre & $\begin{array}{l}\text { Drainage } \\
\text { Area }\end{array}$ & & & & & 24.3 & 74.6 & 79.7 & 152.6 \\
\hline$\phi$ & Porosity & $5 \%$ & $15 \%$ & $30 \%$ & & $8.8 \%$ & $16.5 \%$ & $16.8 \%$ & $26.0 \%$ \\
\hline$\mu, \mathrm{md}$ & Viscosity & 0.0125 & 0.018 & 0.025 & & 0.0145 & 0.0184 & 0.0185 & 0.023 \\
\hline $\mathbf{p}_{\mathrm{i}}, \mathbf{p s i}$ & $\begin{array}{c}\text { Initial } \\
\text { Pressure }\end{array}$ & 500 & 1500 & 3000 & & 884 & 1646 & 1677 & 2572 \\
\hline$k, \mathrm{md}$ & $\begin{array}{l}\text { Geom Mean } \\
\text { Horiz Perm }\end{array}$ & & 75 & & 1 & 14.6 & 81.0 & 124.2 & 370.6 \\
\hline$k_{y} / k_{x}$ & $\begin{array}{c}\text { Ratio of } \\
\text { Horiz Perms }\end{array}$ & & 0.2 & & 0.5 & 0.0919 & 0.1997 & 0.2261 & 0.4634 \\
\hline$k_{v} / k_{h}$ & $\mathrm{k}_{\mathrm{ver}} / \mathrm{k}_{\text {geo mean horiz }}$ & & 0.1 & & 0.75 & 0.0283 & 0.0966 & 0.1261 & 0.3173 \\
\hline $\mathrm{k}_{\mathrm{x}}, \mathrm{md}$ & $\begin{array}{l}\text { Max Horiz } \\
\text { Perm }\end{array}$ & & & & & 29.7 & 180.4 & 286.6 & 902.1 \\
\hline$k_{y}, m d$ & $\begin{array}{l}\text { Min Horiz } \\
\text { Perm }\end{array}$ & & & & & 6.45 & 36.8 & 57.0 & 178.9 \\
\hline $\mathrm{k}_{\mathrm{z}}, \mathrm{md}$ & Vert Perm & & & & & 0.95 & 7.55 & 15.76 & 53.67 \\
\hline
\end{tabular}

As shown in Table 4, by far the most common flow regimes to occur were ERF and ELF. Out of 1000 cases, ERF occurred in 955 cases, while ELF occurred in 976 cases. However, ERF almost always ended in a few minutes. Wellbore storage will almost certainly obscure the ERF in these cases. In the few cases where ERF lasted more than an hour, the vertical permeability was always very low; it is unlikely that a horizontal well would be used in such an application. Similarly, EHRF occurred in only 43 cases. When EHRF did occur, it usually ended in less than an hour, and would therefore also be 
distorted by WBS effects. Within the range of times feasible for EFM analysis, from a few minutes to a few hours, ELF was by far the most common flow regime to occur. PRF did not occur in any of the cases. PSS will not occur for a buildup or fall off test, so we did not consider PSS for this study. Because ELF was observed in $97.6 \%$ of the Monte Carlo simulation cases, we chose to focus our efforts on this flow regime.

Table 4-Statistics from Monte Carlo study for horizontal well flow regime start and end times

\begin{tabular}{|c|c|c|c|c|c|c|}
\hline $\begin{array}{c}\text { Flow } \\
\text { Regime }\end{array}$ & Count & & P05 & Median & Avg & P95 \\
\hline \multirow{2}{*}{ ERF } & \multirow{2}{*}{596} & Start, hr & 0.000535 & 0.00423 & 0.0101 & 0.0352 \\
\cline { 3 - 7 } & & End, hr & 0.00290 & 0.0306 & 0.0858 & 0.351 \\
\hline \multirow{2}{*}{ EHRF } & \multirow{2}{*}{43} & Start, hr & 0.00249 & 0.0237 & 0.137 & 0.295 \\
\cline { 3 - 7 } & & End, hr & 0.0105 & 0.134 & 0.523 & 1.18 \\
\hline \multirow{2}{*}{ ELF } & \multirow{2}{*}{950} & Start, hr & 0.0063 & 0.0808 & 0.274 & 1.141 \\
\cline { 3 - 7 } & & End, hr & 0.206 & 2.40 & 5.34 & 21.1 \\
\hline
\end{tabular}

\subsubsection{Interpretation of Data From the Early Linear Flow Period}

The pressure response during the early linear flow period for a horizontal well is given by Eq. 1:

$$
p_{i}-p_{w f}=\frac{8.128 q B \mu}{L_{w} h} \sqrt{\frac{t}{k_{x} \phi \mu c_{t}}}+\frac{141.2 q B \mu}{L_{w} \sqrt{k_{x} k_{z}}}\left(s_{c}+s_{d}+D|q|\right)
$$

where sc is the convergence skin, sd is the damage skin, and $D|q|_{\text {is }}$ the rate-dependent skin. The convergence skin is given by

$$
s_{c} \equiv \ln \left(\frac{h}{r_{w}}\right)+\frac{1}{4} \ln \left(\frac{k_{x}}{k_{z}}\right)-\ln \left[\sin \left(\frac{\pi d_{z}}{h}\right)\right]-1.838(2)
$$

Rearranging, we find that we can calculate $\mathrm{k}_{\mathrm{x}}$ as

$$
k_{x}=\left(\frac{8.128 q B}{m_{\text {elf }} L_{w} h}\right)^{2} \frac{\mu}{\phi c_{t}}
$$

and the "total" skin $s^{\prime}=s_{d}+D|q|$, as

$$
s^{\prime}=s_{d}+D|q|=\frac{L_{w} \sqrt{k_{x} k_{z}}}{141.2 q B \mu}\left(p_{i}-p_{t=0}\right)-s_{c}
$$

where $\mathrm{m}_{\mathrm{elf}}$ is the slope, and $\mathrm{pt}=0$ is the intercept, respectively, of a graph of $\mathrm{p}_{\mathrm{wf}} \mathrm{vs}$. the square root of time. 


\section{RESULTS AND DISCUSSION}

\subsection{Vertical Wells}

The analysis techniques described above were employed in 20 vertical wells in the study field, each having EFM data spanning a timeframe of approximately $1 \frac{1 / 2}{2}$ years. The results our analyses yielded estimates of relatively "static" parameters, including permeability and the non-Darcy damage coefficient for individual wells. In addition, rate and time-dependent parameters, including the total damage and mechanical damage were also estimated. Example results are presented below for three wells in the study field.

Permeability values calculated in individual wells ranged from $100 \mathrm{md}$ to $250 \mathrm{md}$. This range agrees reasonably well with the reported average field permeability of $125 \mathrm{md}$. In general, the better the data quality and quantity, the closer the permeabilities determined from our analyses were to the reported average field permeabilities.

An overview plot showing the rate and pressure history for a four-month period is shown for Well A in Fig. 11. As is evident from this plot, there were regularly scheduled shut-in periods in this well, as it was one of the "keywells" in the field. Typically, the well was shut-in for several hours once each weak in order to determine the shut-in reservoir pressure in the field. These regularly scheduled shut-in periods provided a large number of analyzable datasets, which yielded considerable insight into the timing and potential sources of well damage.

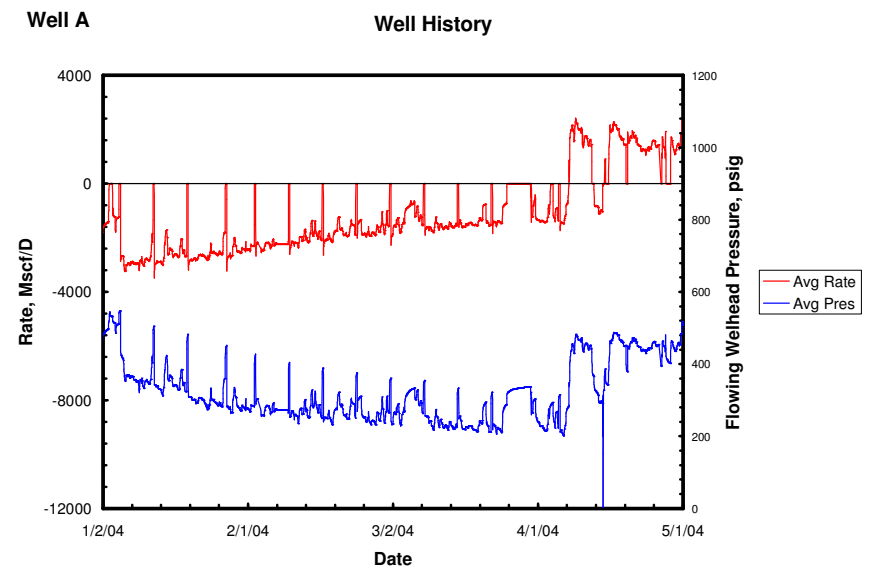

Fig. 11: Overview of rate and pressure, Well A, January 1, 2004 through April 30, 2004.

Fig. 13 shows a plot of mechanical skin versus time for Well A. The timeframe shown in this plot covers much of the 2003-2004 withdrawal season, the entire 2004 injection, and the early portion of the 2004-2005 withdrawal season. As is evident from this plot, the mechanical skin remains relatively constant at about -2.4 during the 2003-2004 withdrawal season. There appears to be a small stepwise increase in the mechanical skin to about -1.9 at the point when the field transitions from withdrawal to injection. During the 2004 injection season, the mechanical skin decreases almost linearly with time to a minimum value of -3.6 . However, at the point when the field transitions from injection 
to withdrawal in the fall of 2004, the mechanical skin damage again exhibits a stepwise increase in the mechanical skin to about -2.5 .

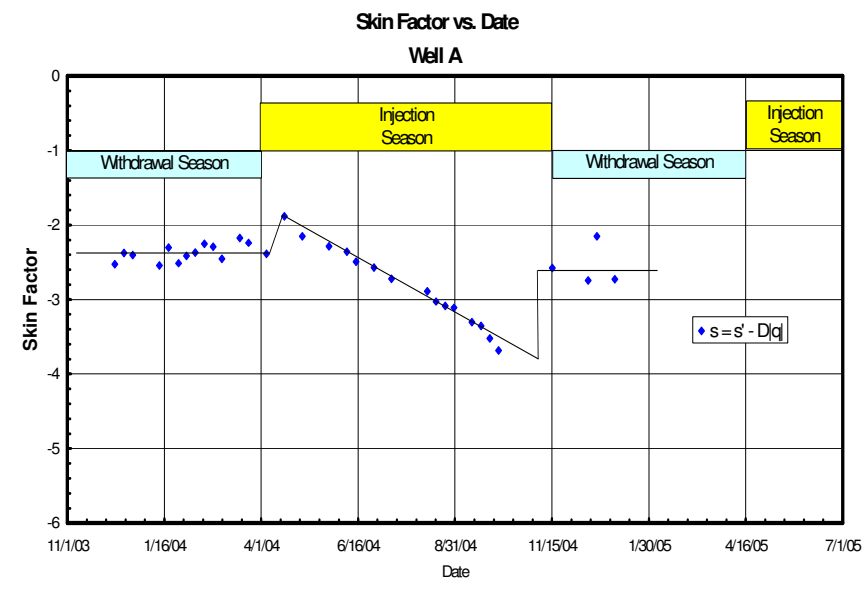

Fig. 13 - Plot of mechanical skin versus time for Well A.

It would appear from the trends observed in Fig. 13 that transitional times wherein flow direction in the storage field is reversed may represent times during which damage levels increase in a stepwise fashion. For the case of switching from withdrawal to injection, some potential causes of the damage increase include pumping water from low-lying sections of the surface gathering system back into the wells and plugging the sandface or changing the relative permeability in the near-wellbore region. For the case of switching from injection to withdrawal, some potential causes of the damage increase might include sanding or possibly a water saturation change in the near-wellbore region.

Additionally, this plot also suggests that damage levels in this study well change continuously (as opposed to step-wise) during injection operations, as evidenced by the nearly linear decline in mechanical damage versus time throughout the 2004 injection season. Insights into changing mechanical damage levels occurring during the 2004 injection season may be obtained from the mechanical damage versus rate plot, Fig. 14.

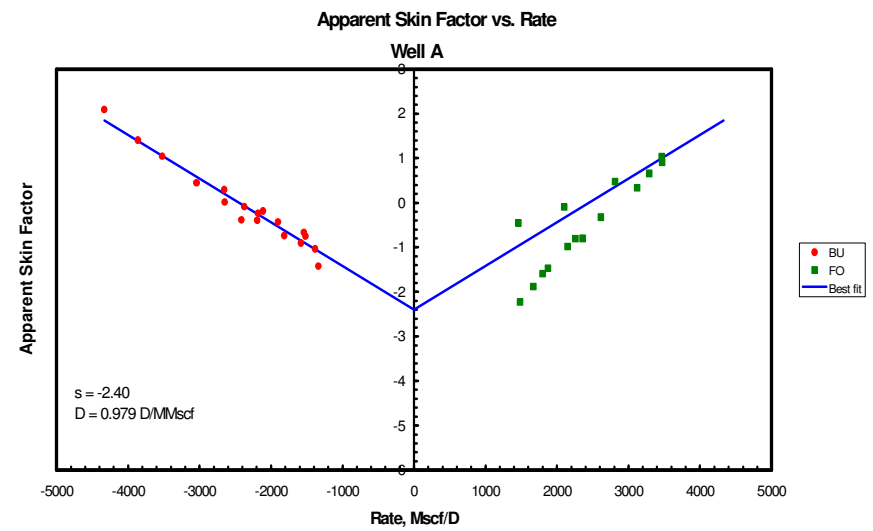

Fig. 14 - Plot of mechanical damage versus rate, Well A. 
Fig. 14 suggests that the non-Darcy damage coefficient remains constant during withdrawal operations, as evidenced by the tightly grouped points along a single line shown on the left portion of the plot (withdrawal operations). However, it appears that the non-Darcy damage may have changed during injection operations, as evidenced by tightly grouped points along two different lines shown on the right portion of the plot (injection operations).

An expanded portion of Fig. 14 that pertains only to 2004 injection operations is shown in Fig. 15, with color-coded points to distinguish between the early and late portions of the 2004 injection season.

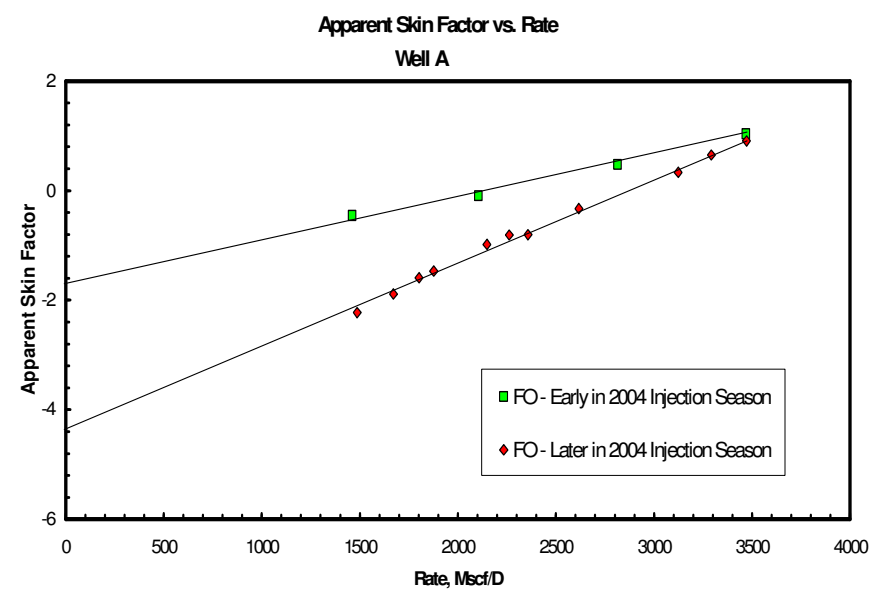

Fig. 15 - Portion of Fig 14 showing 2004 injection operations.

A review of the raw data used to construct Fig. 15 suggests that the non-Darcy damage coefficient (i.e., the slope of the rate versus total skin plot) changes at a specific point in time during the 2004 injection season. Specifically, the change occurred between June 7 and June 14, 2004.

Obviously, this knowledge provides a specific timeframe within which to look for possible causes of the changing damage. In addition, knowing that a significant change occurred specifically in the non-Darcy component of damage suggests a fundamentally different cause of the damage increase. Hence, our analysis results point us to a specific week within which to look for something that causes increased turbulent flow in the well/completion.

These patterns were not unique to this specific well. A second well in the study field exhibited virtually identical patterns in the output plots. Fig. 16 shows the mechanical skin versus time for Well B, which has a shape very similar to that seen in Fig. 13. Fig. 17 shows the mechanical damage versus rate for well $\mathrm{B}$, which has a shape very similar to that seen in Fig. 14. Fig. 18 shows the mechanical damage versus rate for Well B during the 2004 injection season, which has a shape very similar to that seen in Fig. 15. As was the case for Well A, the change occurred between June 7 and June 14, 2004, suggesting the cause of the changing non-Darcy damage is likely related to something regional, as opposed to something site-specific. 


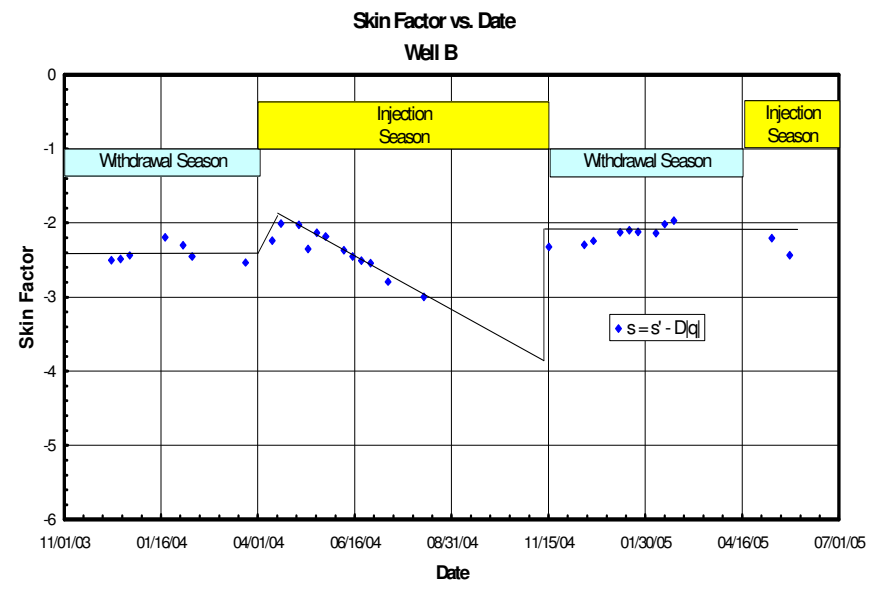

Fig. 16 - Mechanical skin versus time for Well B.

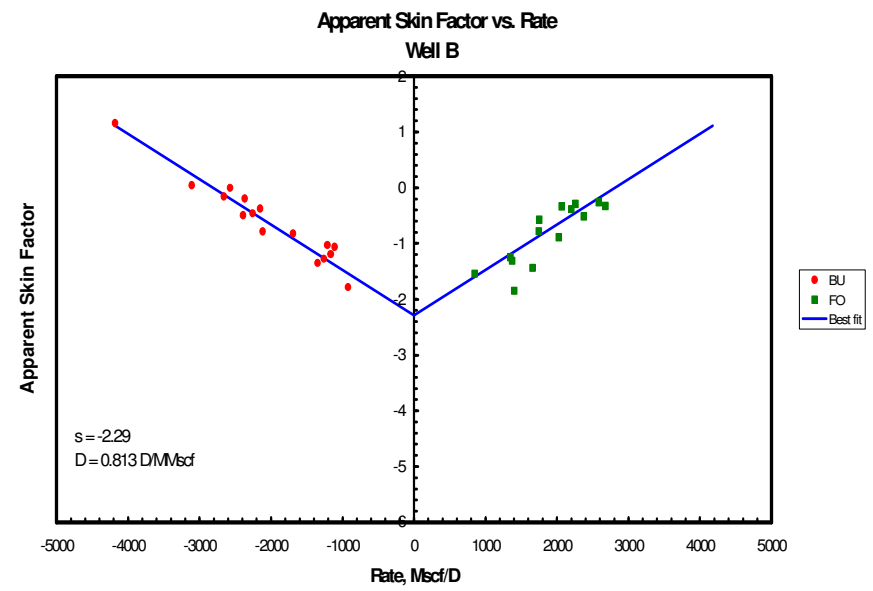

Fig. 17 - Mechanical damage versus rate for Well B.

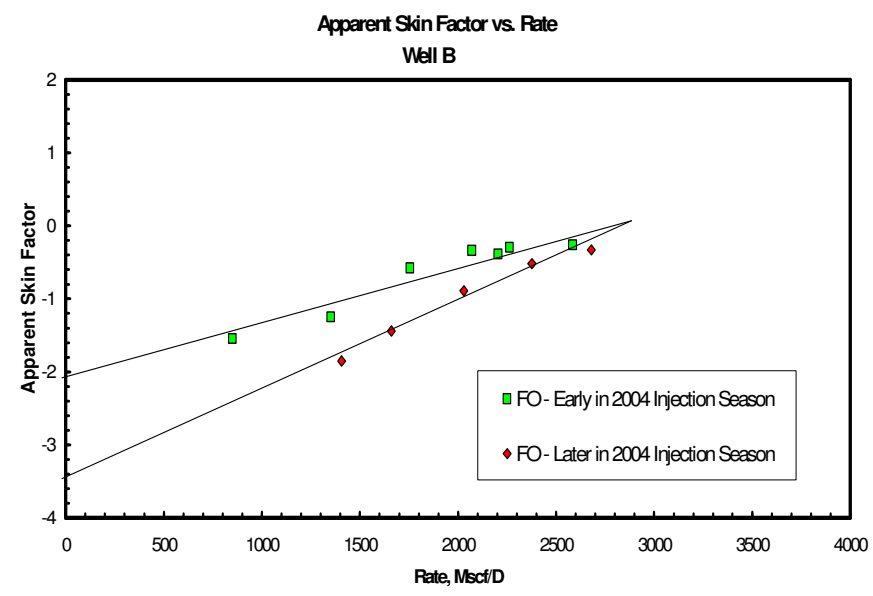

Fig. 18 - Mechanical damage versus rate, 2004 injection, Well B. 
By no means did every well in the field exhibit these trends. In several cases, the available data suggested that there was no significant change in damage levels over time. For example, a plot of mechanical damage versus time for Well C is shown in Fig. 19, which suggests that there was essentially no change in the mechanical damage over time in this well.

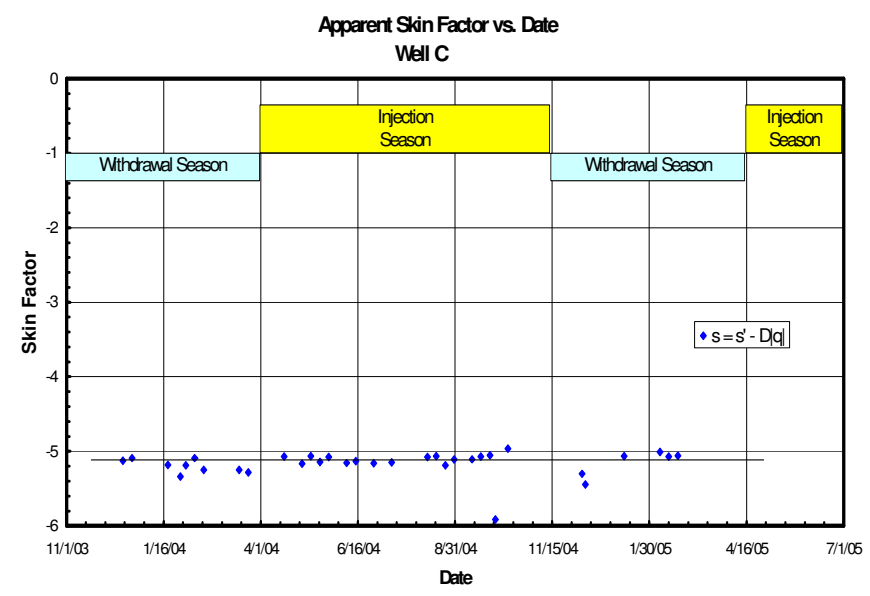

Fig. 19: Plot of mechanical damage versus time for Well C.

In several cases, there was insufficient shut-in data available to estimate damage frequently enough to identify trends such as those shown above. In some cases this was due to lack of shut-in periods. In other cases it was due to malfunctioning EFM equipment resulting in loss of data. We made no attempt modify input parameters (such as the minimum shut-in time) in an effort to get additional results for wells not experiencing equipment problems. We expect this could potentially yield additional useful output.

\subsection{Horizontal Wells}

The analysis techniques described for horizontal wells (section 3.3.8) were employed in one horizontal well having EFM data spanning a timeframe of approximately 4 years. It should be noted that the well had a second horizontal leg added over this time span. Moreover, data prior to the addition of the second leg was sporadic. These issues made making identification of damage trends over time difficult. Nonetheless, analysis of the EFM data successfully demonstrates the effective employment of the PTTA techniques using EFM data developed in this study.

The results our analyses yielded estimates of relatively "static" parameters, including permeability and the non-Darcy damage coefficient for the well. Permeability values calculated in individual wells ranged from $85 \mathrm{md}$ to $115 \mathrm{md}$. This range agrees reasonably well with the reported average field permeability of $125 \mathrm{md}$. As noted above, estimates of rate and time-dependent parameters, including the total damage and mechanical damage are unreliable due to data quality issues and the changing wellbore configuration. 
An overview plot showing the rate and pressure history is shown for Well $\mathrm{H}$ in Fig. 21. As is evident from this plot, data was sporadic prior to the addition of the second horizontal well in 2003.

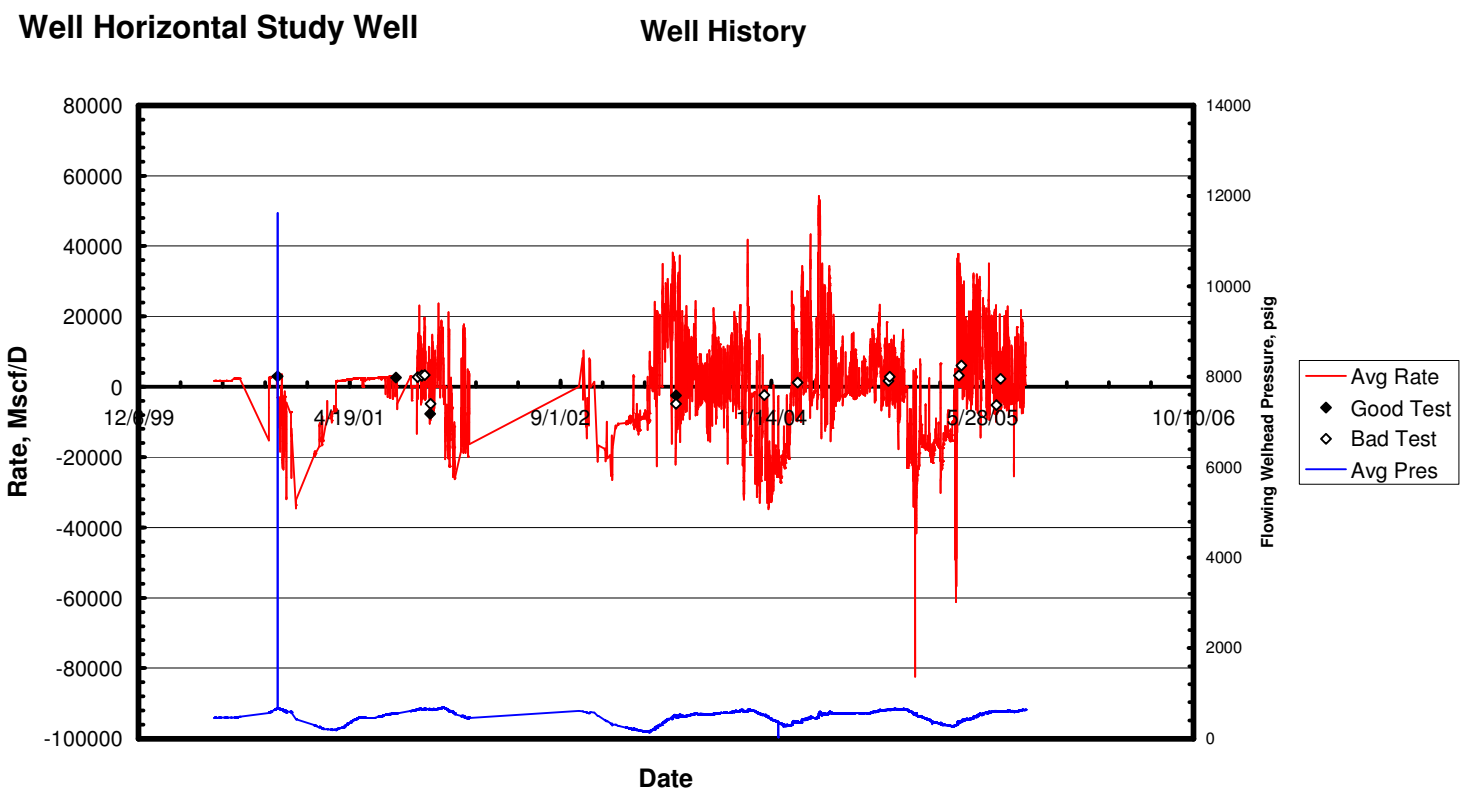

Fig. 21: Overview of rate and pressure data in horizontal study well.

Fig. 23 shows a plot of mechanical skin versus time for Well h. Although this plot suggests that the mechanical skin remains relatively constant during the life of the well, our interpretation must keep in mind the changing well configuration over time.

Apparent Skin Factor vs. Date

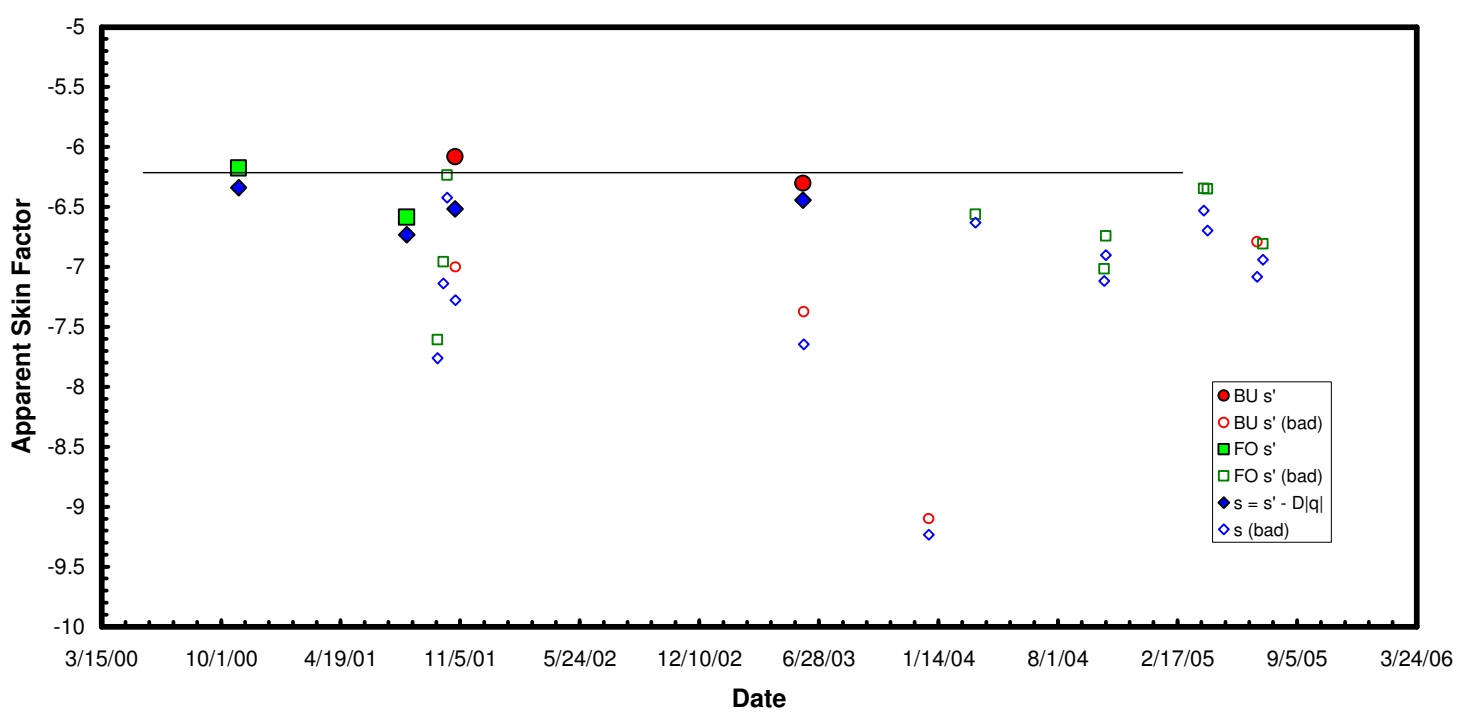

Fig. 23: Plot of mechanical skin versus time for Horizontal Study Well 
The mechanical damage versus rate plot is shown in Fig. 24, and the mechanical damage versus absolute value of rate is shown in Fig 25

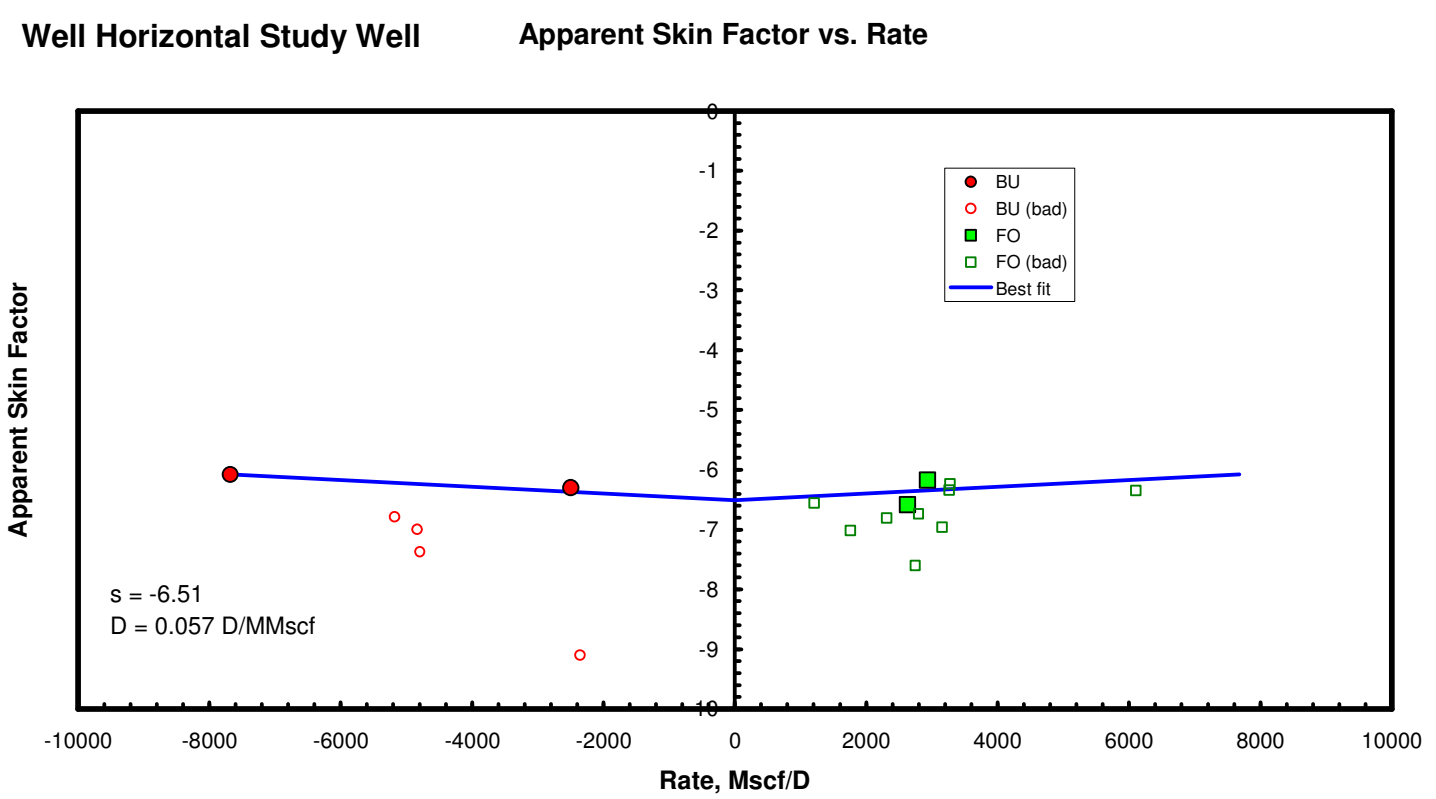

Fig. 24: Plot of mechanical damage versus rate, Horizontal well

Apparent Skin Factor vs. Rate

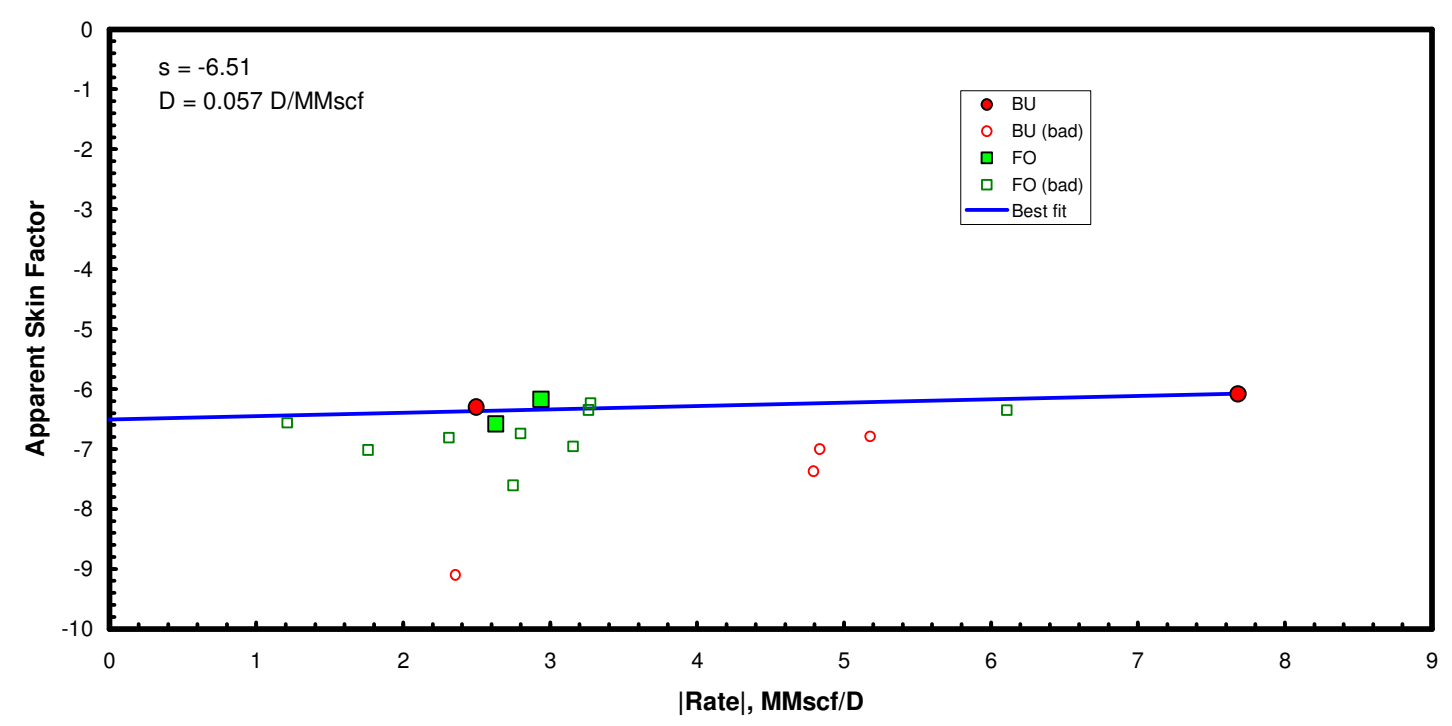

Fig 25: Mechanical damage versus absolute value of rate, horizontal well

Although identification of damage trends over time was not possible in this specific horizontal well, the method of using the horizontal well model to make the calculations necessary to accomplish this have been successful demonstrated. 


\subsection{EFM Guidelines}

The second objective of this project was to develop guidelines for the deployment of EFM systems in storage fields. This task involved identification of the data collection requirements for typical gas storage reservoirs and the general hardware and software needed to collect, transmit, store and interpret EFM data.

We accomplished this objective by developing additional software modules. These modules require the user to input estimates of reservoir properties, well construction details, and technical objectives. Using this input, the software calculates the frequency of data collection necessary to meet the operator's objectives, the data storage requirements necessary to store the recommended amount of data collected, the transmission mode necessary to transmit the data efficiently, and the estimated equipment and installation costs. Software modules were developed for three well configurations vertical unfractured wells, vertical fractured wells, and horizontal unfractured wells. The examples below are for the vertical unfractured well configuration.

Fig. 26 shows the various reservoir input parameters requested. These parameters are used to calculate the beginning and end of various flow regimes typically identified in PTTA. These reservoir parameters are also used to calculate pre-stimulation and post-stimulation rates expected from a typical well in the reservoir.

\begin{tabular}{|r|c|}
\hline \multicolumn{2}{|c|}{ Enter Reservoir Data } \\
\hline 1 - Ave Field Permeability (md) & 124 \\
\hline 2 - Ave Field Porosity (\%) & 11.8 \\
\hline 3 - Gas Specific Gravity & 0.6 \\
\hline 4 - Field Base Pressure (whp, psia) & 380 \\
\hline 5 - Field Top Pressure (whp, psia) & 2575 \\
\hline 6 - Reservoir Temperature (F) & 90 \\
\hline 7 - Reservoir Acreage (ac) & 3000 \\
\hline 8 - Number of I/W Wells in field & 35 \\
\hline 9 - Reservoir Thickness (ft) & 42 \\
\hline
\end{tabular}

Fig. 26: Reservoir input parameters requested for EFM guideline module

Fig. 27 shows the various wellbore input parameters requested. These parameters are used to calculate the wellbore volume, which influences the start and end of the wellbore storage flow regime.

\begin{tabular}{|r|c|}
\hline \multicolumn{3}{|c|}{ Enter Wellbore Volume Related Data } \\
\hline 1 - Min tubing/casing inner diameter (in.) & 2 \\
\hline 2 - Max tubing/casing inner diameter (in.) & 4 \\
\hline 3 - Tubing Depth (ft) & 2300 \\
\hline 4 - Max Depth (ft) & 2691 \\
\hline 5 - Packer on tubing? (y/n) & Yes \\
\hline 6 - Packer Depth (ft) & 2300 \\
\hline 7 - Estimated skin, s' & 0 \\
\hline 8 - Wellbore diameter, in. & 8.25 \\
\hline
\end{tabular}

Fig. 27: Wellbore input parameters requested for EFM guideline module 


\begin{tabular}{|c|c|}
\hline \multirow{2}{*}{\multicolumn{2}{|c|}{ Wellhead EFM Equipment/Storage Requirements }} \\
\hline & \\
\hline Date? & Yes \\
\hline Time? & Yes \\
\hline Pressure? & Yes \\
\hline Flow rate? & $\overline{Y e s}$ \\
\hline Temperature? & Yes \\
\hline Number of other data items (e.g., wellID,voltage, amps): & 3 \\
\hline c - How often do you want to upload data to field office (in hours)? & 1 \\
\hline d - Safety/Backup factor: length of wellhead data storage (in days)? & 7 \\
\hline e - Enter data transmission rate, kbps (if not known, enter 0 , go to f) & $\overline{0}$ \\
\hline$f$ - Choose data transmission medium number from list ( 0 if entered above) & 4 \\
\hline
\end{tabular}

Fig. 28 and Fig. 29 show input required to determine data storage and transmission requirements at various points in the EFM system.

\begin{tabular}{|c|c|}
\hline \multicolumn{2}{|l|}{ Wellhead EFM Equipment/Storage Requirements } \\
\hline a - What data do you want to collect at the wellhead? & \\
\hline Date? & Yes \\
\hline Time? & Yes \\
\hline Pressure? & Yes \\
\hline Flow rate? & Yes \\
\hline Temperature? & Yes \\
\hline Number of other data items (e.g., wellID,voltage, amps): & 3 \\
\hline c - How often do you want to upload data to field office (in hours)? & 1 \\
\hline d - Safety/Backup factor: length of wellhead data storage (in days)? & 7 \\
\hline e - Enter data transmission rate, kbps (if not known, enter 0 , go to f) & $\overline{0}$ \\
\hline$f$ - Choose data transmission medium number from list ( 0 if entered above) & 4 \\
\hline
\end{tabular}

Fig. 28: Equipment and data storage input parameters requested for EFM guideline module

\begin{tabular}{|r|c|}
\hline 5 - Field Office EFM Equipment/Storage Requirements \\
\hline a - How often do you want to upload data to main office (in days)? & 1 \\
\hline b - Safety/Backup factor: length of field office data storage (in days)? & 7 \\
\hline c - Do you want to archive data at the Field Office (if no, enter No \& 0 in d below)? & Yes \\
\hline d - If yes, how often do you wish to archive data (days)? & 365 \\
\hline e - Enter data transmission rate, kbps (if not known, enter 0, go to f) & 0 \\
\hline f - Choose data transmission medium number from list (0 if entered above) & 5 \\
\hline 6 - Main Office EFM Equipment/Storage Requirements \\
\hline a - Safety/Backup factor: length of main office data storage (in days)? & 30 \\
\hline bo you want to archive data at the Main Office (if no, enter No \& 0 in b below)? & No \\
\hline c - If yes, how often do you wish to archive data (days)? & 0 \\
\hline
\end{tabular}

Fig. 29: Computer storage input parameters requested for EFM guideline module

Using the input data discussed above, basic fluid properties necessary for subsequent calculations are determined using industry standard correlations (Fig. 30). The beginning and end of the various flow regimes identified during PTT analysis are then estimated

(Fig. 31) 


\begin{tabular}{|c|c|c|}
\hline \multicolumn{3}{|c|}{ Wellbore Storage Coefficient } \\
\hline $\mathrm{Cg}$ & Vwb & C \\
\hline 0.000345791 & 15.013 & 0.00519141 \\
\hline \multicolumn{3}{|l|}{ Critical Values } \\
\hline Ppc & Tpc & \\
\hline 674.3732 & 354.8974 & \\
\hline \multicolumn{3}{|l|}{ Base Gas Values } \\
\hline $\mathbf{Z}$ & BHP & \\
\hline 0.949706939 & 400.0 & \\
\hline \multicolumn{3}{|c|}{ Top Gas Values } \\
\hline $\mathbf{Z}$ & BHP & \\
\hline 0.79663119 & 2740.7 & \\
\hline VISCave & Ctave & $\begin{array}{c}\text { Feet } \\
\text { re }\end{array}$ \\
\hline 0.020006436 & 0.000273 & 1090 \\
\hline
\end{tabular}

Fig. 30: Basic fluid properties calculated

\begin{tabular}{|cc|}
\hline \multicolumn{2}{|c|}{ Flow Regimes } \\
\hline \multicolumn{2}{|c|}{ Wellbore Storage, WBS } \\
WBS & WBS \\
Start, hrs & End, hrs \\
0.000 & 0.004 \\
\hline 1. Radial & Flow, RF \\
RF & RF \\
Start, hrs & End, hrs \\
0.004 & 1.463 \\
\hline
\end{tabular}

Fig. 31: Estimated beginning and end times of PTTA flow regimes

Fig. 31 shows the estimated beginning and end of the various flow regimes anticipated in a vertical well with no hydraulic fracture. Modules were also developed to calculate the estimated start and end various flow regimes observed in vertical wells having hydraulic fractures (Fig. 32) and horizontal wells (Fig. 33). Similar input data is required in these modules.

\begin{tabular}{|cc|}
\hline \multicolumn{2}{|c|}{ Flow Regimes } \\
\hline Wellbore Storage, WBS \\
WBS & WBS \\
Start, hrs & End, hrs \\
0.000 & 0.002 \\
\hline 2. Bilinear & Flow, BLF \\
BLF & BLF \\
Start, hrs & End, hrs \\
0.000 & 0.00002 \\
\hline 1. Linear & Flow, LF \\
LF & LF \\
Start, hrs & End, hrs \\
0.000 & 0.001 \\
\hline 3. Pseudo-rad Flow, PRF \\
PRF & PRF \\
Start, hrs & End, hrs \\
0.204 & 15.0 \\
\hline
\end{tabular}

Fig. 32: Estimated start/end times for flow regimes in vertical wells with hydraulic fractures 


\begin{tabular}{|c|c|}
\hline \multicolumn{2}{|c|}{ Flow Regimes } \\
\hline \multicolumn{2}{|c|}{ Wellbore Storage, WBS } \\
\hline WBS & WBS \\
\hline Start, hrs & End, hrs \\
\hline 0.000 & 0.00029 \\
\hline \multicolumn{2}{|c|}{ 1. Early Radial Flow, ERF } \\
\hline ERF & ERF \\
\hline Start, hrs & End, hrs \\
\hline 0.000 & 0.008 \\
\hline \multicolumn{2}{|c|}{ 2. Hemiradial Flow, HRF } \\
\hline HRF & HRF \\
\hline Start, hrs & End, hrs \\
\hline 0.265 & 0.008 \\
\hline \multicolumn{2}{|c|}{ 3. Early Linear Flow, ELF } \\
\hline ELF & ELF \\
\hline Start, hrs & End, hrs \\
\hline 0.013 & 5.69 \\
\hline \multicolumn{2}{|c|}{ 4. Late-Pseudoradial Flow, PRF } \\
\hline PRF & PRF \\
\hline Start, hrs & End, hrs \\
\hline 355.2 & 0.03 \\
\hline \multicolumn{2}{|c|}{ 5. Late-Linear Flow, LLF } \\
\hline LLF & LLF \\
\hline Start, hrs & End, hrs \\
\hline 4838.4 & 385.3 \\
\hline
\end{tabular}

Fig. 33: Estimated start/end times for flow regimes in horizontal wells

The above estimates are used to determine the frequency of data collection necessary to identify the flow regimes that should manifest themselves in the type of well being considered. Fig. 34 shows output identifying the data collection frequency required to accomplish the specified objectives in a vertical well with a hydraulic fracture. Similar output is generated for the other types of wells studied.

\begin{tabular}{|c|c|c|}
$\begin{array}{c}\text { Flow } \\
\text { Regime }\end{array}$ & $\begin{array}{c}\text { Freq } \\
\text { sec }\end{array}$ & $\begin{array}{c}\text { Freq } \\
\text { min }\end{array}$ \\
\cline { 1 - 2 } Wellbore Storage & 1.72 & 0.03 \\
\cline { 1 - 1 } Linear & 0.0651 & 0.00108 \\
\cline { 1 - 1 } Bilinear & 0.0010 & 0.00002 \\
\cline { 1 - 1 } Pseudo-radial & 890 & 14.84 \\
\hline
\end{tabular}

Fig. 34: Output showing the minimum data collection frequency required to identify flow regimes in a hydraulic fractured vertical well

The specific flow regimes the storage engineer needs to identify to confidently perform PTTA using EFM data often dictates the minimum data collection frequency necessary at the wellhead. The frequency that field operators and storage engineers want data in the EFM system updated will drive the frequency of required downloads from wellhead to field office and field office to main office.

These requirements, plus the level of redundancy desired to ensure a sufficient safety factor to accommodate unanticipated equipment and power failures will drive the data storage requirements at all locations and the minimum transmission speeds required. 


\subsection{Cost-Benefit Analysis}

A third objective of the project was to perform a cost-benefit analysis of installing EFM equipment in UGS fields. A spreadsheet application was developed to accomplish this objective. The application allows the operator to input estimated equipment costs, typical damage levels, anticipated levels of damage reduction from stimulation, and simulation costs for the candidate field. The spreadsheet then calculates results for the field of interest.

Using this application, we performed a cost-benefit analysis for an UGS field, assuming a statistically "typical" UGS facility, existence of minor to moderate damage levels and typical damage reduction levels seen in UGS wells. Typical average permeability, thickness, wellbore radius, drainage radius, well counts and PVT properties were estimated using information in the AGA database and used as input.

The $\mathrm{dP}^{2}$ value used to estimate pre-stimulation and post-stimulation flow rates was calculated at an average $\operatorname{Pr}$ (i.e., the average of $\mathrm{P}_{\max }$ and $\mathrm{P}_{\text {base }}$ for a typical storage field in the AGA database) and an assumed line pressure of 1000 psi. A small to moderate skin factor was assumed to exist prior to stimulation (pre-stimulation $S_{\text {total }}=10$ ), and the stimulation was assumed to remove $80 \%$ of the pre-stimulation damage present in the well (post-stimulation $S_{\text {total }}=2$ ). A value of $\$ 0.50 / \mathrm{Mscf}$ additional deliverability was assumed, but only $50 \%$ of the calculated increase in deliverability was attributed to the well to account for interference effects with other wells. Stimulation cost was assumed to be $\$ 75,000$.

Our analysis showed that the estimated net revenue generated from the identification and stimulation of only one damaged well is about 1-1/2 times the EFM installation cost, suggesting that EFM installation costs can be recovered in less than one withdrawal season if even one well with moderate damage is identified.. In addition, identification and stimulation of only one damaged well every $4-5$ years is necessary to cover ongoing EFM maintenance costs.

Clearly, the economic benefits associated with the installation and maintenance of wellhead EFM systems in a typical UGS fields more than offsets the investment required, even if the system is only minimally successful at identifying re-stimulation candidates.

It is important to note that this conclusion assumes no other positive impacts on field deliverability result from having wellhead EFM systems in the field. It is the author's experience that these "extraneous" benefits often far outweigh the benefits associated with well stimulations. Actual examples of "extraneous benefits include the identification of malfunctioning safety valves, stuck valves in the header system, and failure to re-open pipeline valves closed for maintenance after the work is done - all of which require essentially no investment to remedy. 


\section{CONCLUSIONS}

The examples presented above clearly demonstrate the potential for using high-frequency wellhead EFM data to monitor damage levels in individual gas storage wells. Specifically, we demonstrated the potential value of monitoring mechanical damage levels and the non-Darcy damage coefficient (D) over time using wellhead EFM data.

The analysis techniques presented allow assessment of damage levels frequently enough to characterize the timing of changing damage levels, as well as the nature of the change in damage (i.e., mechanical or non-Darcy).

The analysis techniques presented in this paper also demonstrate that significant conclusions can be drawn concerning the timing and nature of changing damage levels in storage wells. In the examples presented, the practical consequence of our efforts was a significantly focused search (i.e., narrowed to a one week period) for the cause of an increase in a specific damage type (non-Darcy damage).

The analysis techniques presented are dependent on having periodic shut-in periods available for analysis. Moreover, our best analysis results were obtained in wells briefly shut-in on a weekly basis (i.e., the keywells). Additional theoretical work should be performed to allow analysis of "flow" tests (i.e., drawdown and injectivity tests) in addition to shut-in tests (i.e., buildup and falloff tests). This would eliminate the requirement of reasonably frequent shut-in periods to ensure successful implementation of the techniques presented.

Improved metering would also increase the successful implementation of the techniques developed, since this would allow more accurate identification of true shut-in periods.. Currently, a rate threshold is established, below which we assume the well is shut-in. This is necessary due to the nature of measurement using orifice meters (the type of measurement used in this study), and the fact that storage fields are typically shut-in at the station - not the wellhead (which can cause considerable wellbore storage effects and crossflow within the surface header).

An independent method of identifying shutin periods would reduce the number of invalid tests caused by a low, but non-zero, flow rate triggering the rate threshold. For example, a flow/no-flow indicator at the station could be used to identify field shut-in periods.

A minimal impact on field deliverability was noted by the operator due to shutting in the keywells periodically in the study field. Hence, simply targeting problem wells or wells with suspected deliverability problems for periodic shut-in may be sufficient, and should be tried before other, more costly methods of assessing damage levels over time.

Work tangential to this project suggests that wellhead EFM data collected during flowing periods can be used to estimate the average reservoir pressures over time with sufficient accuracy to perform real-time inventory analyses. The practical consequence of this preliminary work suggests that about 5,000 virtual keywells could be added to the US storage industry using this technology. We recommend additional work be performed in this area. 


\section{REFERENCES}

1. Piper, L.D., McCain, W.D. Jr., Corredor, J.H.: "Compressibility Factors for Naturally Occurring Petroleum Gases," paper SPE 26668 presented at the 1993 SPE Annual Technical Conference and Exhibition, Houston, Texas, 3-6 October.

2. McCain, W.D. Jr.: The Properties of Petroleum Fluids, 2nd ed., Pennwell, 1990.

3. Al-Hussainy, R., Ramey, H.J., Jr., and Crawford, P.B.: "The Flow of Real Gases Through Porous Media,” JPT (May 1966) 624; Trans. AIME 237.

4. Cullendar, N.H. and Smith, R.V.: "Practical Solution of Gas Flow Equations for Wells and Pipelines With Large Temperature Gradients," Trans. AIME 207 (1956) 281-287.

5. Young, K.L.: "Effect of Assumptions Used to Calculate Bottom-Hole Pressures in Gas Wells," JPT (April 1967) 547-550.

6. Dranchuk, P.M., and McFarland, J.D.: "The Effect of the Time Rate of Change of Momentum on Bottom-Hole Pressure in Flowing Gas Wells," J. Cdn. Pet. Tech. (April-June 1974) 34-38.

7. Lee, W.J., Rollins, J.B., and Spivey, J.P.: Pressure Transient Testing, p. ???

8. Goode, P.A., and Thambanayagam, R.K.M.: "Pressure Drawdown and Buildup Analysis of Horizontal Wells in Anisotropic Media," SPEFE (December 1987) 683-697.

9. Odeh, A.S, and Babu, D.K.: "Transient Flow Behavior of Horizontal Wells: Pressure Drawdown and Buildup Analysis," SPEFE (March 1990) 7-15. 


\section{BIBLIOGRAPHY}

Piper, L. D., McCain, W. D., Jr., Corredor, J. H.: "Compressibility Factors for Naturally Occurring Petroleum Gases," paper SPE 26668 presented at the 1993 SPE Annual Technical Conference and Exhibition, Houston, Texas, 3-6 October.

McCain, W. D. Jr.: The Properties of Petroleum Fluids, $2^{\text {nd }}$ ed., Pennwell, 1990.

Al-Hussainy, R., Ramey, H. J., Jr., and Crawford, P. B.: "The Flow of Real Gases Through Porous Media," JPT (May 1966) 624; Trans. AIME 237.

Cullendar, N. H. and Smith, R. V.: "Practical Solution of Gas Flow Equations for Wells and Pipelines With Large Temperature Gradients," Trans. AIME 207 (1956) 281-287.

Young, K. L.: "Effect of Assumptions Used to Calculate Bottomhole Pressures in Gas Wells," JPT (April 1967) 547-550.

Dranchuk, P. M., and McFarland, J. D.: "The Effect of the Time Rate of Change in Momentum on Bottom-Hole Pressure in Flowing Gas Wells," J. Cdn. Pet. Tech. (AprilJune 1974) 34-38.

Lee, W. J., Rollins, J. B., and Spivey, J. P.: Pressure Transient Testing, p.???

Goode, P. A., and Thambanayagam, R. K. M.: "Pressure Drawdown and Buildup Analysis of Horizontal Wells in Anisotropic Media," SPEFE (December 1987) 683-697.

Odeh, A. S., and Babu, D. K.: "Transient Flow Behavior of Horizontal Wells: Pressure Drawdown and Buildup Analysis," SPEFE (March 1990) 7-15.

Brown, K. G., Frantz, Jr., J. H., Sawyer, W. K., and Heckman, Glenn C.: “Assessment of Remediation Treatments in Underground Gas Storage Wells," paper SPE 84393 presented at the 2003 Eastern Regional/AAPG Eastern Section Joint Meeting, Pittsburgh, September 6-10.

Spivey, J. P., Brown, K. G., Sawyer, W. K., and Frantz, Jr., J. H.: "Estimating NonDarcy Flow Coefficient from Buildup Test Data with Wellbore Storage," paper SPE 77484 presented at the 2002 Annual Technical Conference and Exhibition, San Antonio, September 29 - October 2.

Spivey, J. P., Brown, K. G., and Sawyer, W. K.: "Identifying the Timing and Sources of Damage in Gas Storage Wells using Smart Storage Technology," paper SPE 97070 presented at the 2005 Annual Technical Conference and Exhibition, Dallas, October 912.

Tek, M. R.: Natural Gas Underground Storage: Inventory and Deliverability, Penn Well Publishing Co., (1996). 
Bradley, H. B.: Petroleum Engineering Handbook, Society of Petroleum Engineers, (1992).

Pressure Transient Testing - I, Reprint Series, SPE Richardson, TX (2004) 57. 


\section{LIST OF ACRONYMS AND ABBREVIATIONS}

\begin{tabular}{ll} 
AGA & American Gas Association \\
BHP & Bottom Hole Pressure \\
BU & Buildup \\
DOE & Department of Energy \\
EFM & Electronic Flow Measurement \\
EHRF & Early Hemi-Radial Flow \\
ERF & Early Radial Flow \\
FO & Falloff \\
HW & Hardware \\
I/O & Input/Output \\
LL & Log-Log \\
LLF & Late Linear Flow \\
MTR & Middle Time Region \\
PBU & Pressure Buildup \\
PRF & Pseudoradial Flow \\
PSS & Pseudosteady State \\
PTT & Pressure Transient Test \\
PTTA & Pressure Transient Test Analysis \\
SL & Semi-Log \\
SW & Software \\
UGS & Underground Gas Storage \\
VBA & Visual Basic Application \\
WBS & WellBore Storage \\
\hline
\end{tabular}




\section{NOMENCLATURE}

Latin Symbols

$\mathrm{B}$ = formation volume factor, bbl/Mscf

c $=$ compressibility, $\mathrm{psi}^{-1}$

$c_{t}=$ total compressibility, $\mathrm{psi}^{-1}$

$\mathrm{c}_{\mathrm{wb}}=$ compressibility of fluid in wellbore, $\mathrm{psi}^{-1}$

$\mathrm{d}_{\mathrm{x}, \mathrm{y}, \mathrm{z}}=$ distance to nearer of two parallel boundaries in the $(\mathrm{x}, \mathrm{y}, \mathrm{z})$ direction

$\mathrm{D}_{\mathrm{x}, \mathrm{y}, \mathrm{z}}=$ distance to further of two parallel boundaries in the $(\mathrm{x}, \mathrm{y}, \mathrm{z})$ direction

$\mathrm{D}=$ non-Darcy flow rate-dependent skin coefficient

$\mathrm{h}=$ net pay thickness, $\mathrm{ft}$

$\mathrm{k}=$ permeability

$\mathrm{k}_{\mathrm{x}}=$ permeability along $\mathrm{x}$-direction (horizontal plane, perpendicular to wellbore)

$\mathrm{k}_{\mathrm{y}}=$ permeability along $\mathrm{y}$-direction (horizontal plane, parallel to wellbore

$\mathrm{k}_{\mathrm{z}}=$ permeability along $\mathrm{z}$-direction (vertical)

$\mathrm{L}=$ wellbore lateral length, $\mathrm{ft}$

$\mathrm{L}_{\mathrm{w}}=$ wellbore lateral length, $\mathrm{ft}$

$\mathrm{m}_{\text {elf }}=$ slope of early linear flow straight line, $\mathrm{psi} / \mathrm{hr}^{1 / 2}$

$\mathrm{q}=$ flow rate, $\mathrm{Mscf} / \mathrm{D}$

$\mathrm{r}_{\mathrm{w}}=$ wellbore radius, $\mathrm{ft}$

$\mathrm{s}=$ skin factor, dimensionless

$\mathrm{s}_{\mathrm{c}}=$ convergence (geometric) skin factor, dimensionless

$\mathrm{s}_{\mathrm{d}}=$ damage skin factor, dimensionless

$\mathrm{s}^{\prime}=$ total skin factor, dimensionless

$\mathrm{t}=$ time, $\mathrm{hr}$

$\mathrm{V}=$ volume, $\mathrm{bbl}$

$\mathrm{V}_{\mathrm{wb}}=$ wellbore volume, $\mathrm{bbl}$

Greek Symbols

$\phi=$ porosity, fraction

$\mu=$ viscosity, $\mathrm{cp}$

$\underline{\text { Subscripts }}$

$\mathrm{b}=$ begin

$\mathrm{D}=$ dimensionless quantity

e $=$ end

EHRF = early hemiradial flow

ELF = early linear flow

$\mathrm{ERF}=$ early radial flow

PRF = pseudoradial flow

$\mathrm{wb}=$ wellbore

$\mathrm{x}, \mathrm{y}, \mathrm{z}=$ Cartesian coordinate directions 
APPENDIX I: EQUATIONS USED FOR WEIGHTED LINEAR REGRESSION 
The objective function to be minimized is

$$
F=\sum_{j=1}^{N}\left(\frac{p\left(m, p_{1 h r} ; \Delta \bar{t}_{j}\right)-\bar{p}_{j}}{s_{j} / \sqrt{n_{j}}}\right)^{2}
$$

where $p\left(m, p_{1 h r} ; \Delta \bar{t}_{j}\right)$ is the model function given by

$$
p\left(m, p_{1 h r} ; \Delta \bar{t}_{j}\right)=m \log \left(\Delta \bar{t}_{j}\right)+p_{1 h r}
$$

and $m$ and $p_{l h r}$ are the coefficients for the straight line fit. The quantities $n_{j}, \bar{p}_{j}, \Delta \bar{t}_{j}$, and $s_{j}$ are the number of points, the arithmetic average pressure, the geometric average delta time, and the sample standard deviation, respectively, for the high frequency (HF) EFM data points within sampling window $j$.

The equations to be solved are obtained by setting the derivatives of the objective function $\mathrm{F}$ with respect to $m$ and $p_{I h r}$ equal to zero:

$$
\frac{\partial F}{\partial m}=2 \sum_{j=1}^{N}\left[\log \left(\Delta \bar{t}_{j}\right)\left(\frac{p\left(m, p_{1 h r} ; \Delta \bar{t}_{j}\right)-\bar{p}_{j}}{s_{j} / \sqrt{n_{j}}}\right)\right]=0
$$

and

$$
\frac{\partial F}{\partial p_{1 h r}}=2 \sum_{j=1}^{N}\left(\frac{p\left(m, p_{1 h r} ; \Delta \bar{t}_{j}\right)-\bar{p}_{j}}{s_{j} / \sqrt{n_{j}}}\right)=0
$$

Eqs. 7 and 8 form a system of two linear equations in two unknowns, $m$ and $p_{l h r}$. For convenience, these equations may be rearranged as follows: 


$$
\begin{aligned}
\frac{\partial F}{\partial m} & =2 \sum_{j=1}^{N}\left[\log \left(\Delta \bar{t}_{j}\right)\left(\frac{p\left(m, p_{1 h r} ; \Delta \bar{t}_{j}\right)-\bar{p}_{j}}{s_{j} / \sqrt{n_{j}}}\right)\right] \\
& =2 \sum_{j=1}^{N}\left[\log \left(\Delta \bar{t}_{j}\right)\left(\frac{\left(m \log \left(\Delta \bar{t}_{j}\right)+p_{1 h r}\right)-\bar{p}_{j}}{s_{j} / \sqrt{n_{j}}}\right)\right] \\
& =2 \sum_{j=1}^{N}\left[\frac{\left(\log \left(\Delta \bar{t}_{j}\right)\right)^{2}}{s_{j} / \sqrt{n_{j}}}\right] m-2 \sum_{j=1}^{N}\left[\left(\frac{\log \left(\Delta \bar{t}_{j}\right) \bar{p}_{j}}{s_{j} / \sqrt{n_{j}}}\right)\right] p_{1 h r}=0
\end{aligned}
$$

Similarly,

$$
\begin{aligned}
\frac{\partial F}{\partial p_{1 h r}} & =2 \sum_{j=1}^{N}\left(\frac{p\left(m, p_{1 h r} ; \Delta \bar{t}_{j}\right)-\bar{p}_{j}}{s_{j} / \sqrt{n_{j}}}\right) \\
& =2 \sum_{j=1}^{N}\left(\frac{m \log \left(\Delta \bar{t}_{j}\right)+p_{1 h r}-\bar{p}_{j}}{s_{j} / \sqrt{n_{j}}}\right) \\
& =2 \sum_{j=1}^{N}\left(\frac{\log \left(\Delta \bar{t}_{j}\right)}{s_{j} / \sqrt{n_{j}}}\right) m-2 \sum_{j=1}^{N}\left(\frac{\bar{p}_{j}}{s_{j} / \sqrt{n_{j}}}\right) p_{1 h r}=0
\end{aligned}
$$

Eqs. 9 and 10 are solved for the coefficients $\mathrm{m}$ and $p_{l h r}$. Finally, the permeability, $k$, is estimated from the slope $\mathrm{m}$, and the apparent skin factor, s', from the intercept, $\mathrm{p} 1 \mathrm{hr}$, as in conventional semi-log analysis. 
APPENDIX II: USER INSTRUCTIONS FOR DAMAGE SOFTWARE 


\section{Overview}

The Smart Well Pressure Transient Analysis system comprises two modules, SPLITTER and MASHER. SPLITTER reads one or more ASCII data files containing raw EFM data, and writes a separate binary file for each well with the EFM data formatted for MASHER. MASHER reads the EFM data from the binary files, processes the data to identify periods of data that can be analyzed as buildup or falloff tests, and builds a workbook for each well.

\section{SPLITTER Module}

SPLITTER (workbook SPLITTER.xls) is used to reformat ASCII data into a consistent binary file format for MASHER to read. SPLITTER can handle both delimited and fixed width data file formats.

\section{FileFormat Sheet}

To use SPLITTER, first fill in the required and optional data fields in the FileFormat worksheet. Required data are highlighted in yellow; optional data are highlighted in green.

\section{General Section}

Injection algebraic sign. Enter 1 if injection rates in the ASCII file are positive, -1 if injection rates in the ASCII file are negative.

Header rows. Enter the number of header rows in each ASCII data file. SPLITTER will skip these lines when reading the data files.

Format. Enter the type of formatting for the ASCII data files, 1 for delimited data and 2 for data in fixed width columns.

\section{Delimit Characters}

This section is used only for delimited data. For the Tab and Space fields, enter 1 if tabs and spaces, respectively, are used to delimit the data, otherwise enter 0. For the Other delimiters field, enter a list of the other delimiters as a text string. The most common delimiter is the comma, but other delimiters may be used as well.

\section{Preview text}

Enter a line of data from the ASCII file to be processed. The two lines above this field are guides to help you identify the beginning and ending positions for each column of data in a fixed-width file.

\section{Field Setup}

Enter information to tell SPLITTER how to find the desired data fields in the ASCII text file. Date, Rate, and Pressure are always required. Time may be included as part of the Date field. If no Well ID is provided, all data are assumed to belong to the same well.

For delimited data, enter the Column number for each data field as it appears in the ASCII file. Enter 0 if the data field does not appear in the file.

For fixed-width data, enter the Start character position and Length for each field. Enter 0 for Start and Length if the data field is not present. 
The Preview column to the right of the Field setup section shows how the Preview text will be parsed. The Preview values column shows the corresponding numeric values that would be written to the binary file.

\section{SPLITTER Sheet}

The SPLITTER sheet is used to specify the location of the input and output files, the names of the wells to process, and the names of the individual data files to process.

\section{Source directory}

Enter the full pathname of the subdirectory where the input ASCII data files are located.

\section{Destination directory}

Enter the full pathname of the subdirectory where the output binary files are to be placed.

Wells

Enter the Well IDs for the wells to be processed, one well per row.

\section{Files}

Enter the names of the ASCII files to be processed. These files must be in ascending chronological order. SPLITTER may be run multiple times to append new data to the binary output files. To append data, enter only the files containing the new data.

\section{Split button}

Once the FileFormat and SPLITTER worksheets have been filled out, click the Split button to process the data. The status bar at the bottom of the Excel window will show the well and file currently being processed. The Status bar will display "Done." to indicate that SPLITTER is finished. Caution-Note that the processing may take a long time. One benchmark run indicated that processing 2 years of 15 -second data for 20 wells would take approximately 4 hours.

\section{MASHER Module}

MASHER (workbook MASHER.xls) processes high frequency EFM data in binary files to identify potential buildup and falloff data. MASHER also averages the high frequency EFM data over user-selected time intervals.

\section{Field Data sheet}

The Field Data sheet has places to enter data that apply for the entire field. 
General Information section

\begin{tabular}{|l|l|l|}
\hline Input Field & Data Requirement & Comments \\
\hline Operator & Optional & Enter the name of the operator. \\
\hline Field & Optional & Enter the name of the gas storage field. \\
\hline Number of Wells & Required & Enter the number of wells in the field. \\
\hline
\end{tabular}

\section{Engineering Data section}

\begin{tabular}{|c|c|c|}
\hline Input Field & Data Requirement & Comments \\
\hline Initial pressure & Required & $\begin{array}{l}\text { Enter the initial pressure of the storage } \\
\text { reservoir in psia. This value is used as a } \\
\text { reference pressure for fluid property } \\
\text { correlations. }\end{array}$ \\
\hline Gas specific gravity & Required & $\begin{array}{l}\text { Enter the specific gravity of the storage gas, } \\
\text { air }=1.0 \text {. This value is used in calculating } \\
\text { gas PVT properties. }\end{array}$ \\
\hline $\mathrm{H}_{2} \mathrm{~S}$ content & Optional & $\begin{array}{l}\text { Enter the } \mathrm{H}_{2} \mathrm{~S} \text { content of the gas in mole } \\
\text { percent. This value is used in calculating } \\
\text { gas PVT properties. }\end{array}$ \\
\hline $\mathrm{CO}_{2}$ content & Optional & $\begin{array}{l}\text { Enter the } \mathrm{CO}_{2} \text { content of the gas in mole } \\
\text { percent. This value is used in calculating } \\
\text { gas PVT properties. }\end{array}$ \\
\hline $\mathrm{N}_{2}$ content & Optional & $\begin{array}{l}\text { Enter the } \mathrm{N}_{2} \text { content of the gas in mole } \\
\text { percent. This value is used in calculating } \\
\text { gas PVT properties. }\end{array}$ \\
\hline $\begin{array}{l}\text { Water } \\
\text { compressibility }\end{array}$ & Required & $\begin{array}{l}\text { Enter the compressibility of the reservoir } \\
\text { brine at reservoir temperature and pressure. } \\
\text { The default value of } 2.5 \times 10^{-6} \mathrm{psi}^{-1} \text { is } \\
\text { probably good enough for most gas storage } \\
\text { applications. }\end{array}$ \\
\hline $\begin{array}{l}\text { Wellhead } \\
\text { temperature }\end{array}$ & Required & $\begin{array}{l}\text { Enter the average flowing wellhead } \\
\text { temperature for the field. This value is used } \\
\text { in calculating bottomhole pressures from } \\
\text { surface pressure. }\end{array}$ \\
\hline
\end{tabular}


Control Data section

\begin{tabular}{|l|l|l|}
\hline Input Field & Data Requirement & Comments \\
\hline $\begin{array}{l}\text { Minimum flow } \\
\text { time }\end{array}$ & Required & $\begin{array}{l}\text { Enter the minimum duration of continuous } \\
\text { flow (injection or withdrawal) prior to a } \\
\text { candidate test period for the test to be } \\
\text { considered valid. }\end{array}$ \\
\hline Minimum shutin & Required & $\begin{array}{l}\text { Enter the minimum duration of shutin } \\
\text { required for a candidate test period to be } \\
\text { considered valid. }\end{array}$ \\
\hline Points per cycle & Required & $\begin{array}{l}\text { Enter the minimum number of data points } \\
\text { required for a candidate test period to be } \\
\text { considered valid. }\end{array}$ \\
\hline $\begin{array}{l}\text { Time window for } \\
\text { averaging }\end{array}$ & Required & $\begin{array}{l}\text { Enter the desired number of data points per } \\
\text { log cycle after averaging the test data. } \\
\text { Reducing this number will make the } \\
\text { derivative curve smoother; Increasing it will } \\
\text { give more data points. The default value of } \\
\text { 25 seems to be a reasonable place to start. }\end{array}$ \\
\hline $\begin{array}{l}\text { Enter the desired time window for } \\
\text { averaging high frequency EFM data for the } \\
\text { well history } \\
\text { enough that the total number of averaged } \\
\text { data points will be less than 32,000. To } \\
\text { estimate the number of averaged data } \\
\text { points, divide the duration of the period for } \\
\text { which EFM data are being processed by the } \\
\text { time window. }\end{array}$ \\
\hline
\end{tabular}




\section{Well Data Sheet}

The Well Data sheet has a table of wells to be processed. The table also includes wellspecific information.

\begin{tabular}{|l|l|l|}
\hline Input Field & Data Requirement & Comments \\
\hline Rec. No. & Required & Index number. \\
\hline Active & Required & $\begin{array}{l}\text { Enter 1 if the well is to be processed, 0 if the well is to be } \\
\text { skipped. }\end{array}$ \\
\hline Well ID & Required & Enter the Well ID. \\
\hline Well Name & Optional & Enter the Well Name. \\
\hline Well Type & Required & $\begin{array}{l}\text { Enter "vertical", "v", or "vw" for a vertical well; enter } \\
\text { "horizontal", "h", or "hw" for a horizontal well. The text } \\
\text { may be in either upper or lower case. }\end{array}$ \\
\hline$t_{\text {BMTR }}$ & Required & $\begin{array}{l}\text { Enter a cutoff rate below which the flow rate (injection } \\
\text { or withdrawal) will be considered 0, at a wellhead } \\
\text { pressure of 500 psia. This rate is adjusted up or down for } \\
\text { pressures higher or lower than 500 psia. The specific } \\
\text { value required here is dependent on the metering } \\
\text { configuration for the well. }\end{array}$ \\
\hline$t_{\text {EMTR }}$ & Required & $\begin{array}{l}\text { Enter the time for the beginning of the middle time } \\
\text { region for a vertical well, or the early linear flow period } \\
\text { for a horizontal well. }\end{array}$ \\
\hline MD, Top Perf. & Optional & $\begin{array}{l}\text { Enter the time for the end of the middle time region for a } \\
\text { vertical well, or the early linear flow period for a } \\
\text { horizontal well. }\end{array}$ \\
\hline MD, Btm Perf & Optional & Enter the measured depth to the topmost perforation. \\
\hline $\mathrm{r}_{\mathrm{w}}$ & Required & Enter measured depth to the lowest perforation. \\
\hline Net Pay & Optional & $\begin{array}{l}\text { Enter the wellbore radius in feet. Recommended value is } \\
\text { one-half the bit diameter of the bit used to drill through } \\
\text { the storage reservoir section. }\end{array}$ \\
\hline Perm. & Required & $\begin{array}{l}\text { Enter the estimated drainage area of the well. } \\
\text { Enter bottomhole or formation temperature for the well. }\end{array}$ \\
\hline & $\begin{array}{l}\text { Enter thickness of reservoir quality rock in the storage } \\
\text { interval. }\end{array}$ \\
\hline Pater Sat. & Enter the porosity of the reservoir rock. \\
\hline & Enter connate water saturation of the reservoir. \\
\hline & Enter an estimate of the reservoir permeability. \\
\hline
\end{tabular}


Horizontal Well Data section

The data in this section are used only for horizontal wells.

\begin{tabular}{|l|l|l|}
\hline Input Field & Data Requirement & Comments \\
\hline Length & Required & $\begin{array}{l}\text { Enter the length of the wellbore open to } \\
\text { flow in the storage zone. }\end{array}$ \\
\hline $\mathrm{Z}_{\mathrm{wD}}$ & Required & $\begin{array}{l}\text { Enter a number between 0.001 and 0.5 to } \\
\text { specify the vertical position of the wellbore } \\
\text { within the storage interval. This value is } \\
\text { obtained by dividing the distance from the } \\
\text { axis of the wellbore to the nearer of the } \\
\text { upper and lower reservoir boundaries by the } \\
\text { net pay. A value of 0.5 indicates that the } \\
\text { well is centered vertically in the interval. }\end{array}$ \\
\hline $\mathrm{k}_{\mathrm{v}} / \mathrm{k}_{\mathrm{h}}$ & Required & $\begin{array}{l}\text { Enter the ratio of permeability in the vertical } \\
\text { direction to the geometric mean } \\
\text { permeability in the horizontal plane. }\end{array}$ \\
\hline $\mathrm{k}_{\mathrm{x}} / \mathrm{k}_{\mathrm{y}}$ & Required & $\begin{array}{l}\text { Enter the ratio of the permeability in the } x \text { - } \\
\text { direction (in the horizontal plane, } \\
\text { perpendicular to the axis of the wellbore to } \\
\text { that in the } y \text {-direction (parallel to the axis of } \\
\text { the wellbore) }\end{array}$ \\
\hline
\end{tabular}

\section{Tubing Segment Section}

Enter data for at least 1, and up to 5, flow string segments. This data is used to convert wellhead pressure to bottomhole pressure.

\begin{tabular}{|l|l|l|}
\hline Input Field & Data Requirement & Comments \\
\hline Tbg Len. & Required & $\begin{array}{l}\text { Enter the length of the tubing (or casing) } \\
\text { segment. }\end{array}$ \\
\hline Tbg ID & Required & Enter the internal diameter of the segment. \\
\hline Angle & Required & $\begin{array}{l}\text { Enter the angle the segment makes with the } \\
\text { vertical. }\end{array}$ \\
\hline Roughness & Required & $\begin{array}{l}\text { Enter the absolute roughness of the } \\
\text { segment. Clean new tubing will typically } \\
\text { have an absolute roughness of 0.00060 to } \\
0.00065 \text { inches. }\end{array}$ \\
\hline
\end{tabular}

After you have entered all the data, press the "Mash All" button to process the individual well data. 


\section{Individual Well Workbooks}

These workbooks (wellid_PBU.xls) are generated by MASHER, one workbook for each well processed. The format for each workbook is slightly different depending on whether the well is vertical or horizontal. The discussion below will apply to both types of wells except as noted.

Two workbooks, PBUTemplate.xls and HWTemplate.xls, are used as templates for the individual well workbooks. Do not modify either of these!

Do not rename any of the sheets or charts in the individual well workbooks!

\section{Input Data sheet}

The Input Data sheet is filled out by MASHER, and contains all of the well-specific data necessary to analyze the tests for the well.

\section{Work sheet}

The Work sheet is used as a workspace for the analysis. Do not modify this sheet!

\section{Work-PQ chart}

The Work-PQ chart shows a graph of rate and wellhead pressure vs. date for the test currently being analyzed. This chart is primarily used for quality control to determine whether or not a test is valid.

A good test will have a relatively stable flow rate prior to the test and a distinct transition from flowing to shutin on both rate and pressure curves. The large diamonds "Rate @ SI" and "WHP @ SI" indicate the reference rate and last flowing wellhead pressure prior to shutin used for the analysis. These points should fall on the rate and pressure curves, respectively, at the end of the flow period.

Three controls in the upper left corner of the chart are used to navigate through the list of wells and accept or reject each test.

Spinner button. Click the "up" arrow button to switch to the next test; click the "down" arrow to switch to the previous test.

Accept Analysis checkbox. Click this checkbox to accept this as a valid test; click again to ignore this test in calculating the average permeability. These changes become effective when you switch to another test.

Test ID droplist. Click the "down" arrow on the right side of this box to see a list of tests. Click on a test to switch directly to that test.

\section{Work-SL chart}

The Work-SL chart shows a straight line graph for the selected test. The graph is either a semilog graph, for a vertical well, or a square root of time graph, for a horizontal well. The time plotting function is the multirate equivalent adjusted time. For vertical wells, the radial equivalent time is used, while the linear flow equivalent time is used for horizontal wells. The pressure plotting function is the rate-normalized adjusted pressure change.

In addition to the three controls in common with the Work-PQ chart, the Work-SL chart has two slider bars on the bottom of the chart to adjust the beginning and end of the range of data to be analyzed. For a vertical well, data in the middle time region (MTR) are used 
for the analysis. For a horizontal well, data in the early linear flow regime (ELF) are used for the analysis.

As you move, then release, the slider on one of the slider bars, the corresponding flow regime marker will move and the analysis will be updated to reflect the new position. The time corresponding to the position of each slider bar is shown in the text boxes on the flow regime limit lines.

Two straight lines will be drawn through the data within the selected region. The red line ("Best Fit" series) shows a line fit through the data for this test. The green line ("Composite" series) shows a line with a slope corresponding to the average permeability for all the valid tests, forced through the data for this test.

Once all the tests have been reviewed, the bad ones eliminated, and the appropriate flow regime identified for each test, the Composite line should lie virtually on top of the Best Fit line, indicating that all the tests are giving essentially the same permeability. To hide or show the Composite line, toggle the Hide/Show Composite button in the upper right corner of the chart.

\section{Work-LL chart}

The Work-LL chart is a log-log graph of the selected test, showing the rate normalized adjusted pressure change and the logarithmic derivative of the pressure change vs. the multirate equivalent adjusted time.

The MTR for a vertical well will have a horizontal pressure derivative, while the ELF for a horizontal well will have a derivative with a slope of $1 / 2$. For this chart, there are two straight lines fit through the pressure data and two through the derivative data. The red line ("Best Fit") and the blue line ("Best Fit Deriv") show the straight line fit through the selected pressure and pressure derivative data, respectively, for this test. The two green lines ("Composite" and "Composite Deriv") show the position and slope corresponding to the average permeability from all the valid tests.

The two derivative lines provide a sensitive indicator of the deviation of the permeability for this test from the average. For example, if the test gives a permeability that is $10 \%$ higher than the average permeability, the blue derivative line will lie a vertical distance above the green composite derivative line by the distance between 9 and 10 (or 90 and 100 , etc) on the pressure axis.

\section{PBU Summary sheet}

The PBU Summary sheet is both a summary table of all the tests for this well and a work area sheet. Do not edit any cells in this sheet, except for the entries under the "Accept" column heading! To directly accept or reject a specific test, you may put a 1 or 0 , respectively, in the Accept column for the test.

\section{PBU Database sheet}

The PBU Database sheet is a work area sheet. Do not edit any cells in this sheet!

\section{S'vs q chart}

The S' vs q chart shows a graph of the total skin factor $s^{\prime}=s+D|q|$ vs. the flow rate $q$ for all the tests for this well. Buildup tests are shown as red diamonds, and falloff tests as green squares. A solid symbol indicates a valid test data point, while an open symbol indicates a data point corresponding to a bad test. 
The blue lines show the best fit through a graph of $s^{\prime}$ vs. $|q|$. The intercept gives the Darcy component of the skin factor, while the slope gives the non-Darcy component. These two components are shown in the text box on the lower left corner of the graph.

\section{$S^{\prime}$ vs abs(q)}

The S' vs abs(q) chart shows the same data as the $S^{\prime}$ 'vs q chart, plotted against the absolute value of the rate.

\section{S'vs Date}

The $S^{\prime}$ vs Date chart shows a graph of total skin vs. date. The blue diamonds show the estimated Darcy skin component.

\section{k vs Date}

The k vs Date chart shows a graph of permeability vs date. Data points for all correctly analyzed, valid, tests should lie along a single horizontal line. A trend in this graph suggests that the reservoir permeability is changing with time.

\section{Well History}

The Well History chart shows the averaged rate and pressure data for the well. The dates at which the tests occurred are marked with black diamonds; solid diamonds for valid tests, open diamonds for invalid ones.

\section{EFM Data}

The EFM Data sheet is a table of the averaged rate and pressure data for the well, along with some summary statistics. Do not edit the data in this table! 


\section{APPENDIX III: ANALYSES RESULTS FOR INDIVIDUAL WELLS}




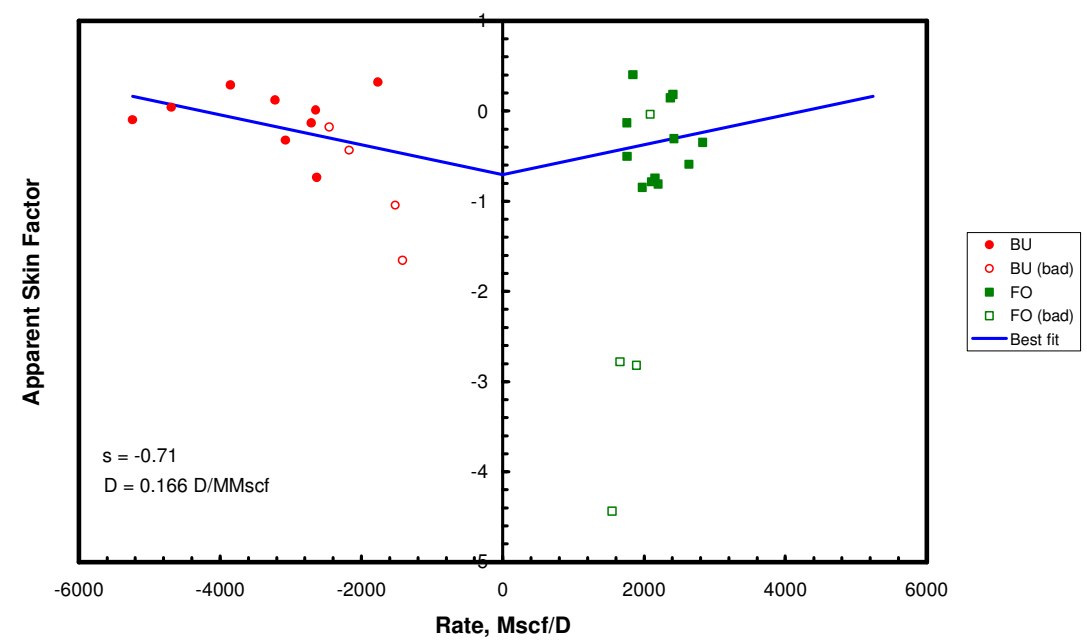

Well 10502

Apparent Skin Factor vs. Rate

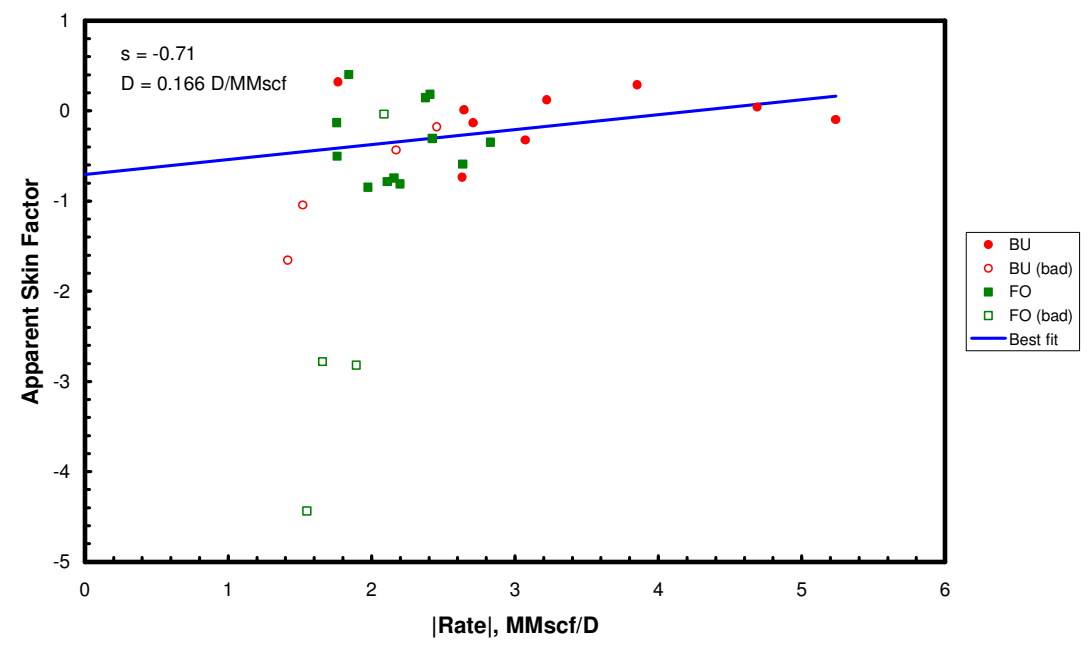

Well 10502

Apparent Skin Factor vs. Date

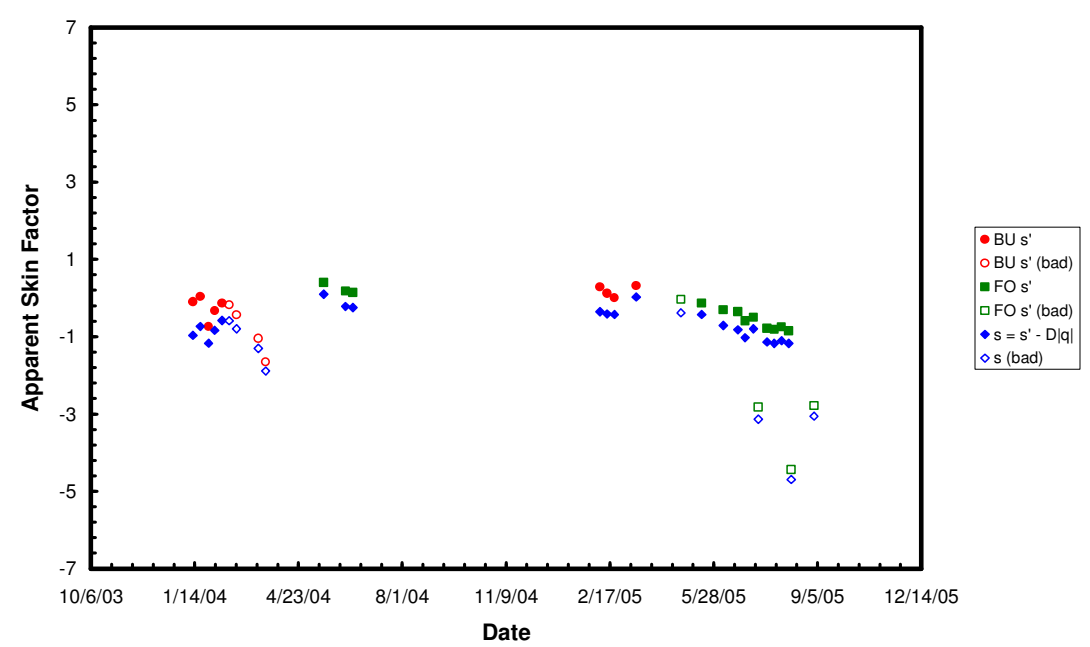




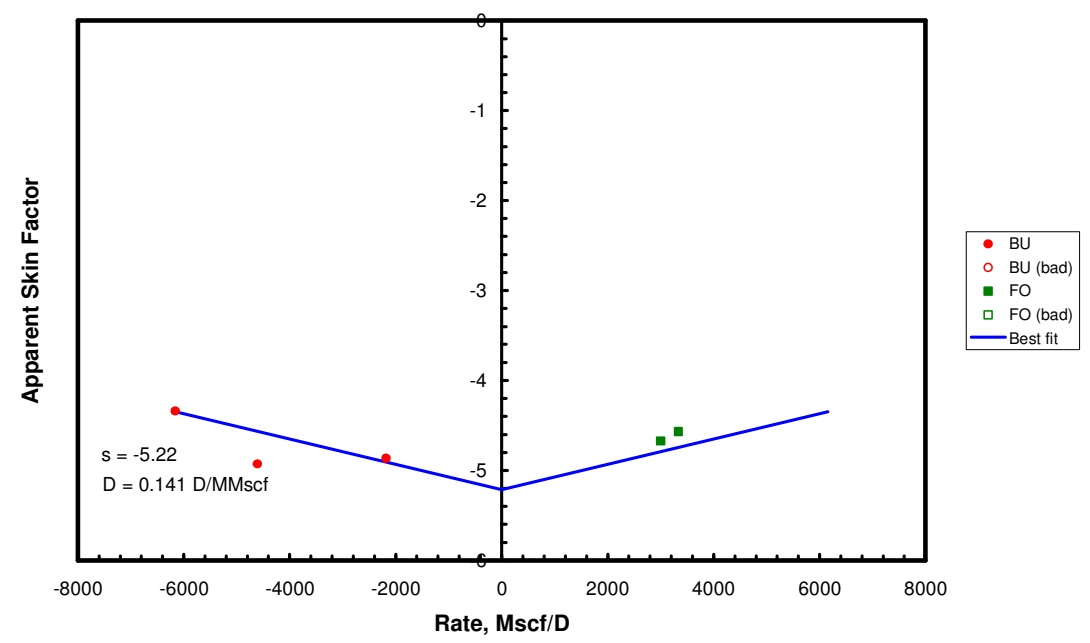

Well 12420

Apparent Skin Factor vs. Rate

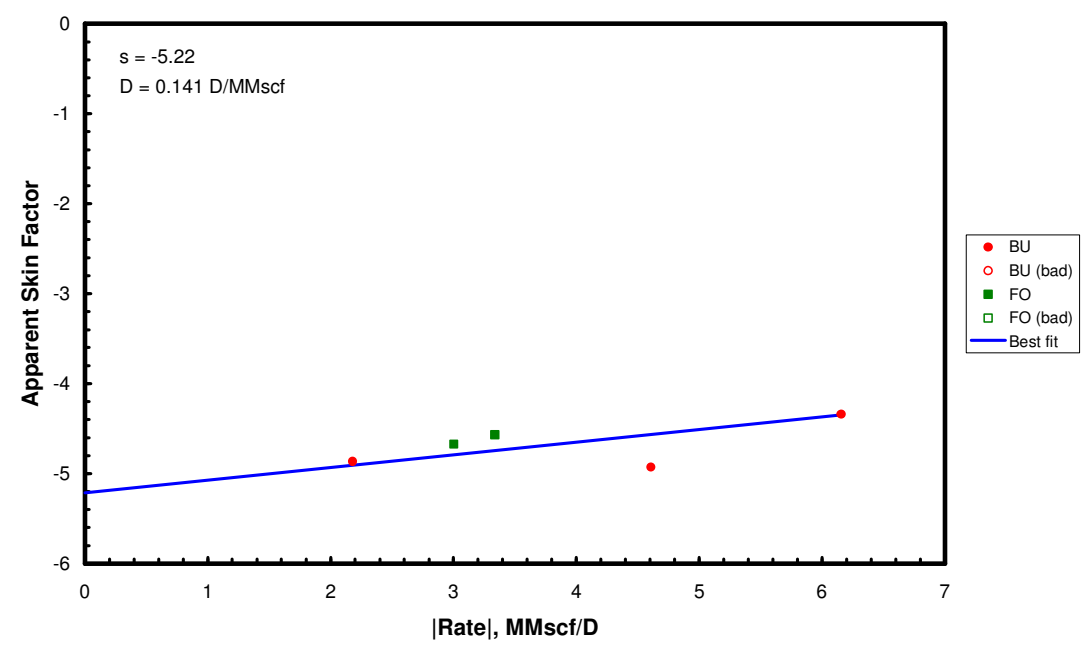

Well 12420

Apparent Skin Factor vs. Date

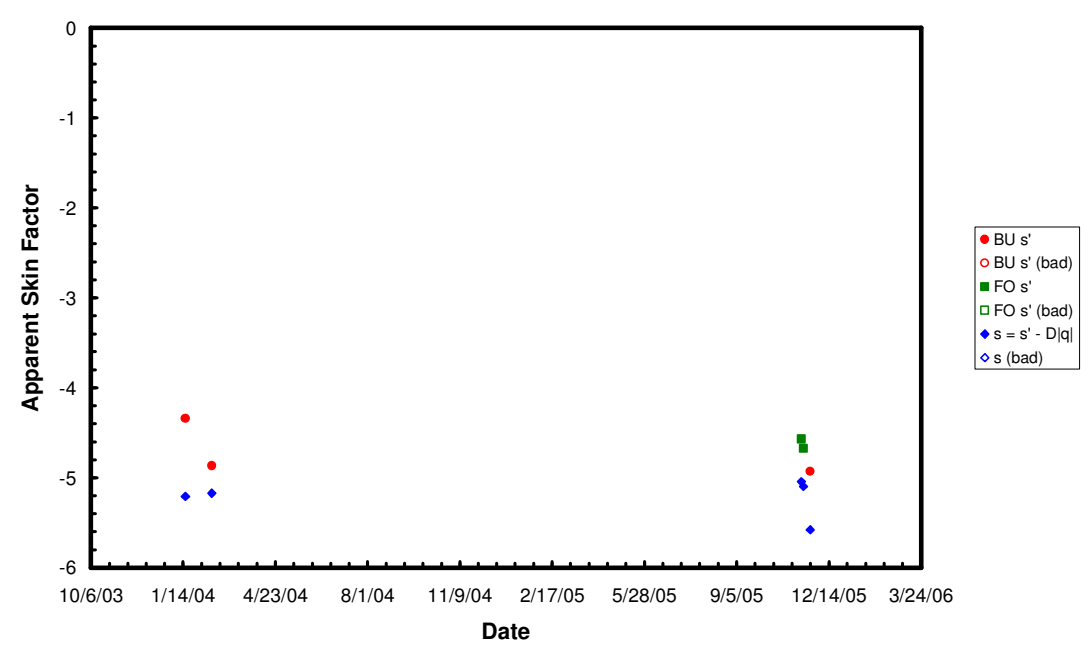



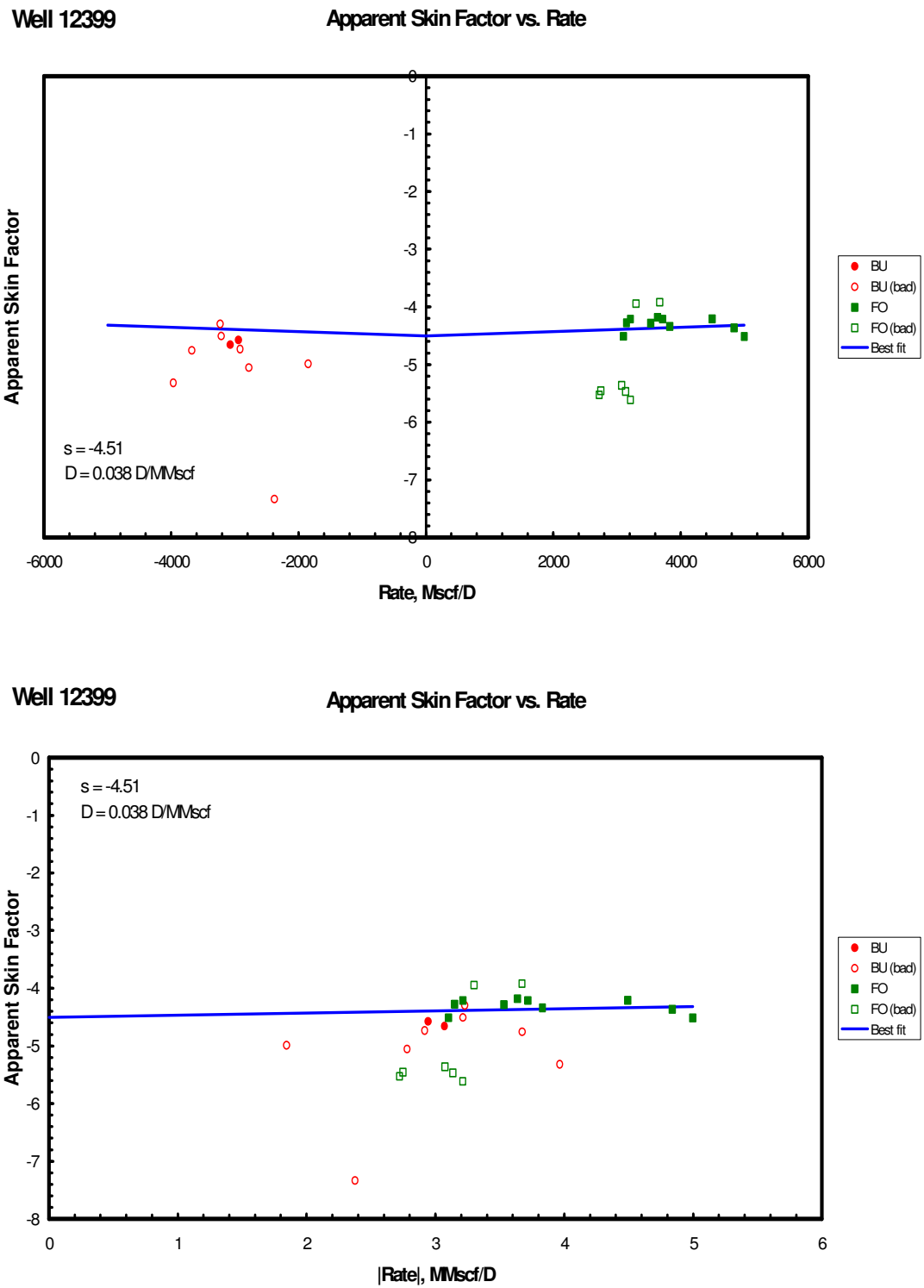

Well $12399 \quad$ Apparent Skin Factor vs. Date

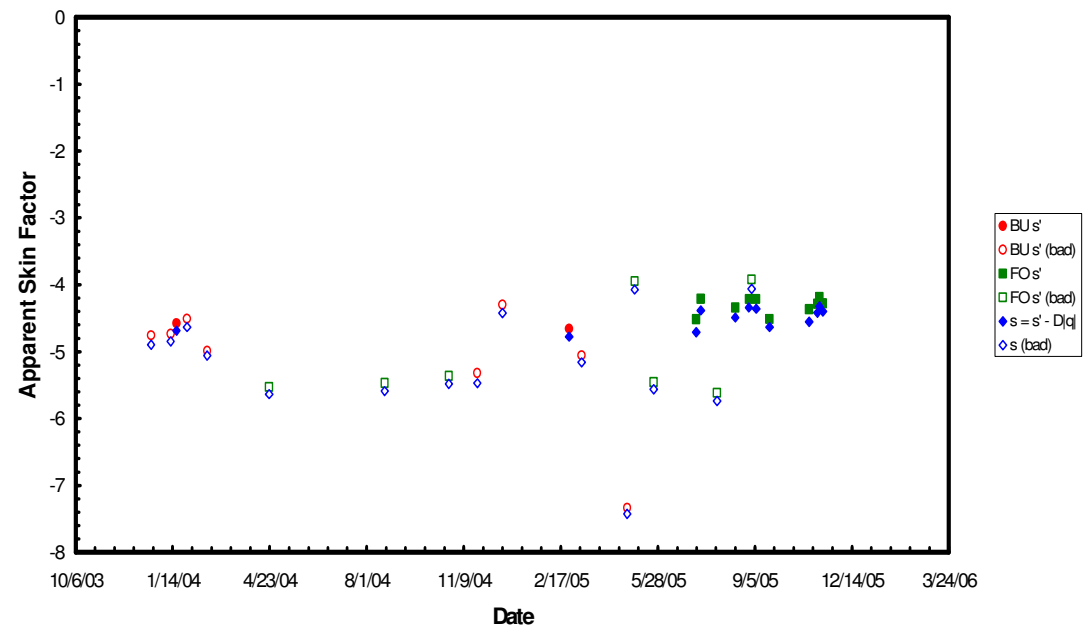




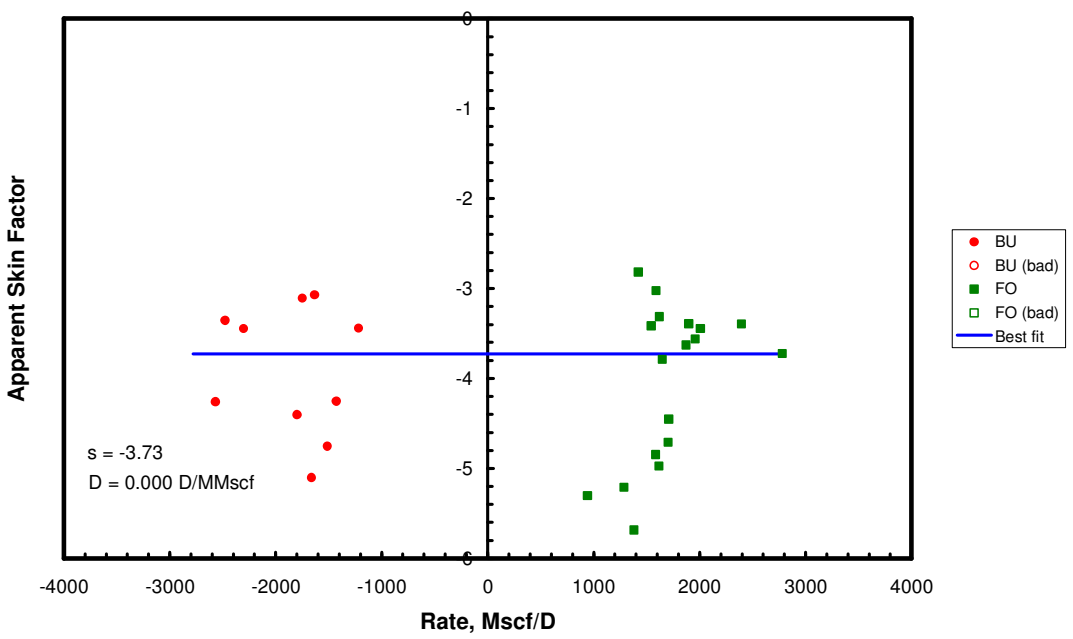

Well 12398

Apparent Skin Factor vs. Rate

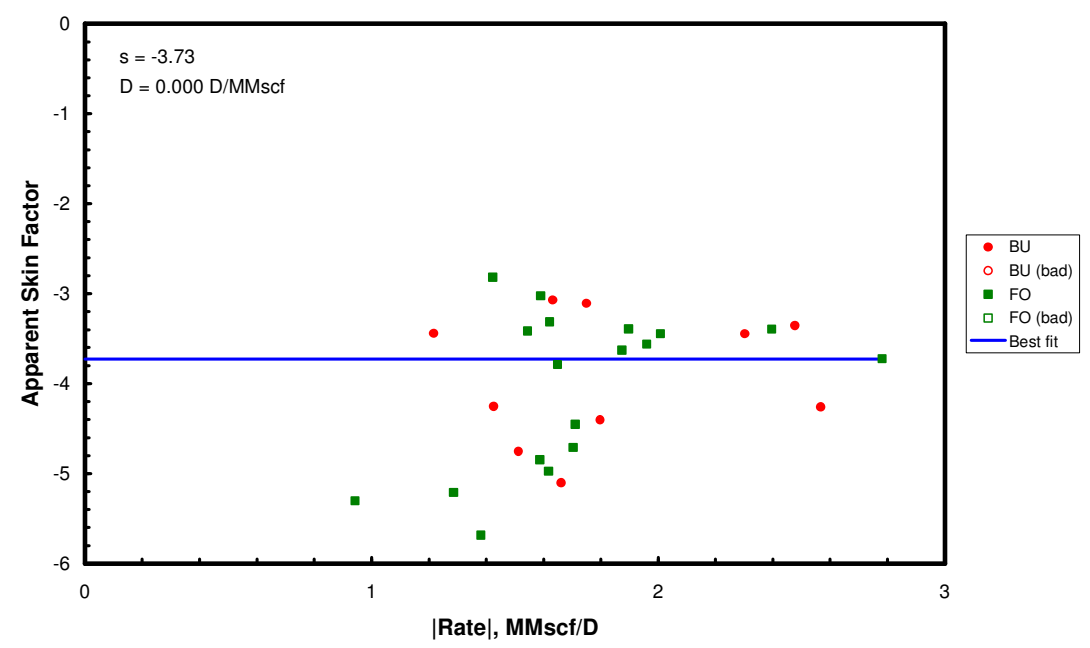

Well 12398

Apparent Skin Factor vs. Date

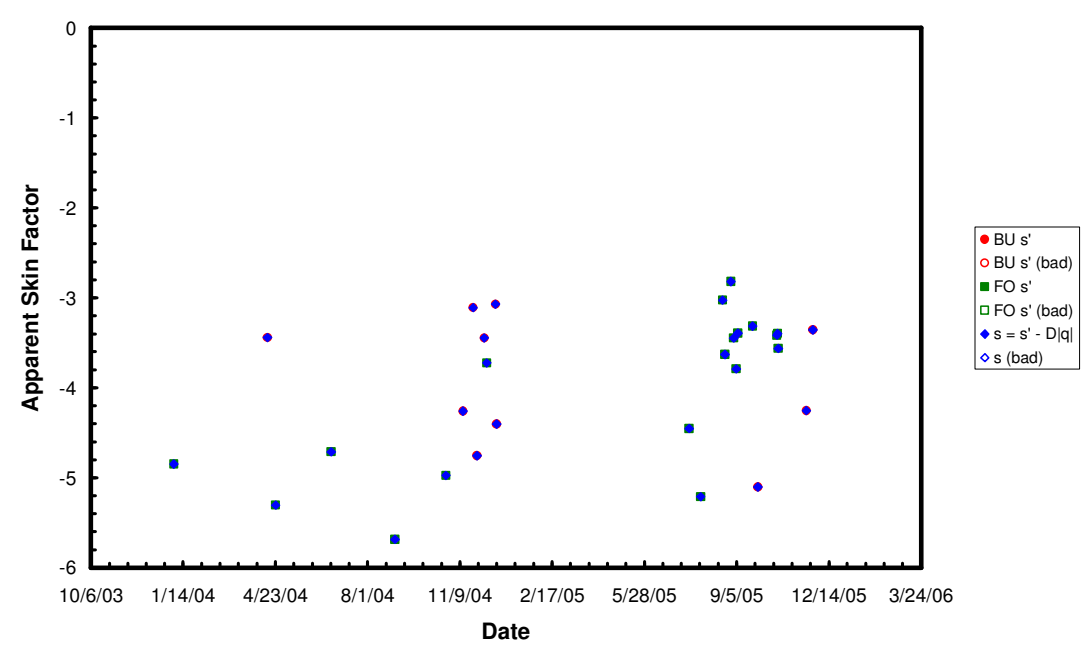




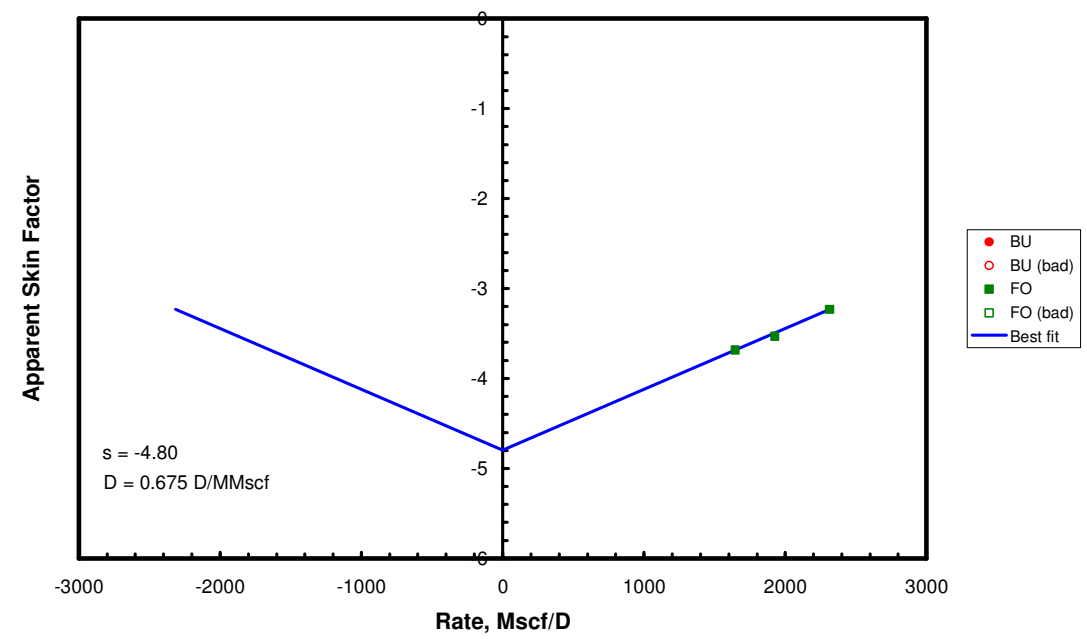

Well 12396

Apparent Skin Factor vs. Rate

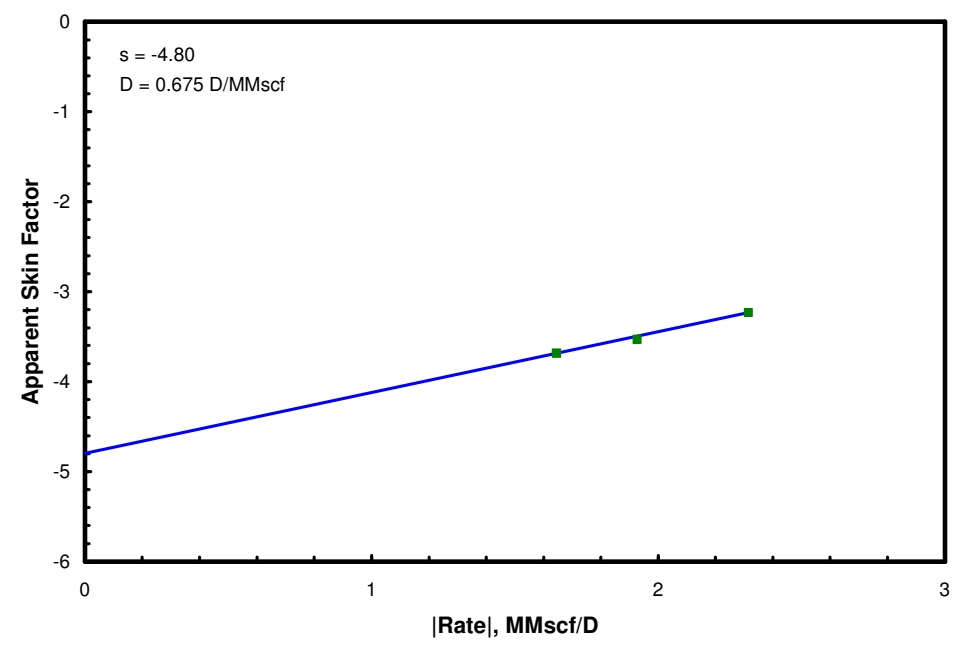

Apparent Skin Factor vs. Date

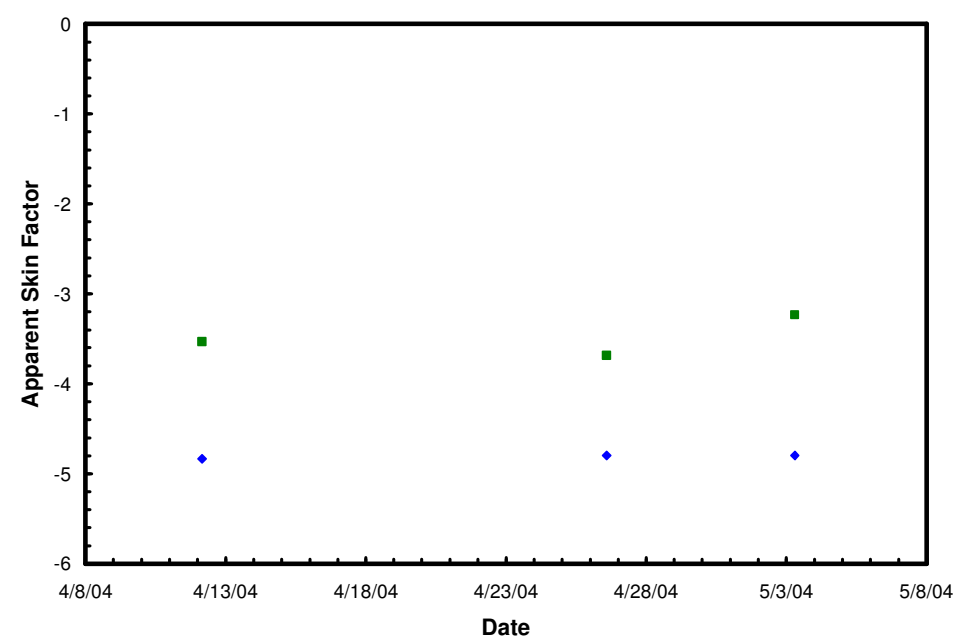

$-\mathrm{BU} \mathrm{s}^{\prime}$
$\mathrm{OBU} \mathrm{s}^{\prime}(\mathrm{bag})$

- BU s' (bad)

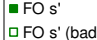

$\bullet s=s^{\prime}-D|q|$

os (bad) 


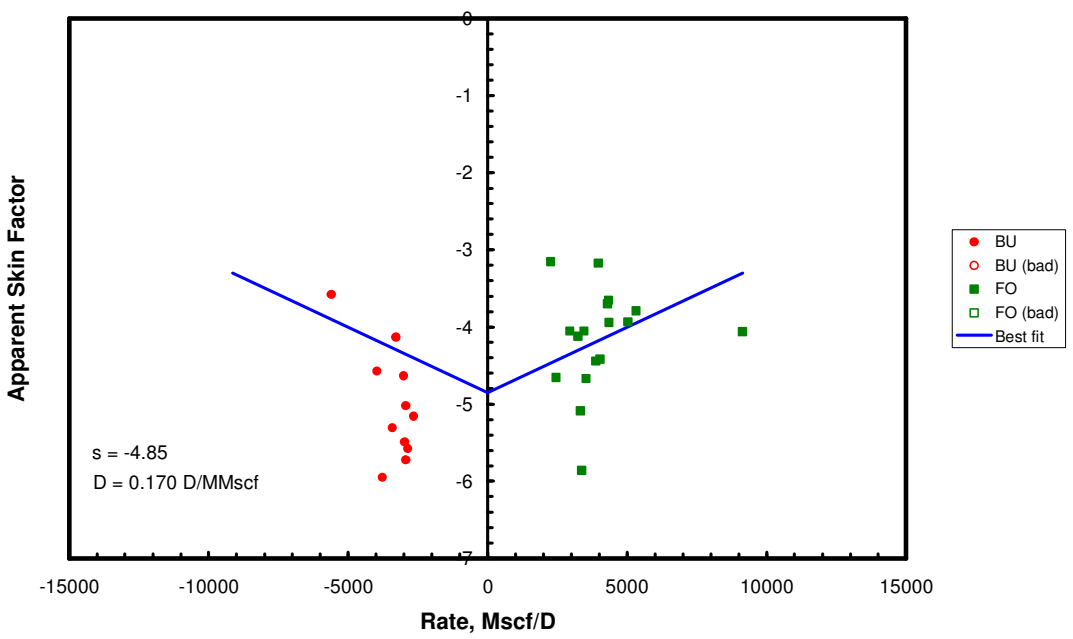

Well 12395

Apparent Skin Factor vs. Rate

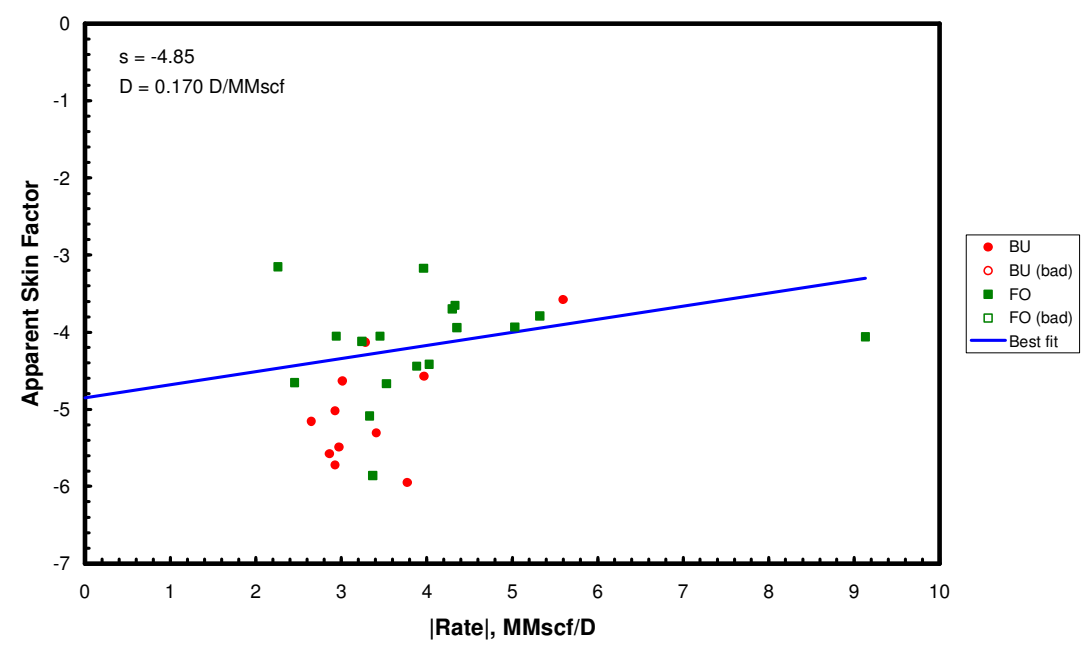

Well 12395

Apparent Skin Factor vs. Date

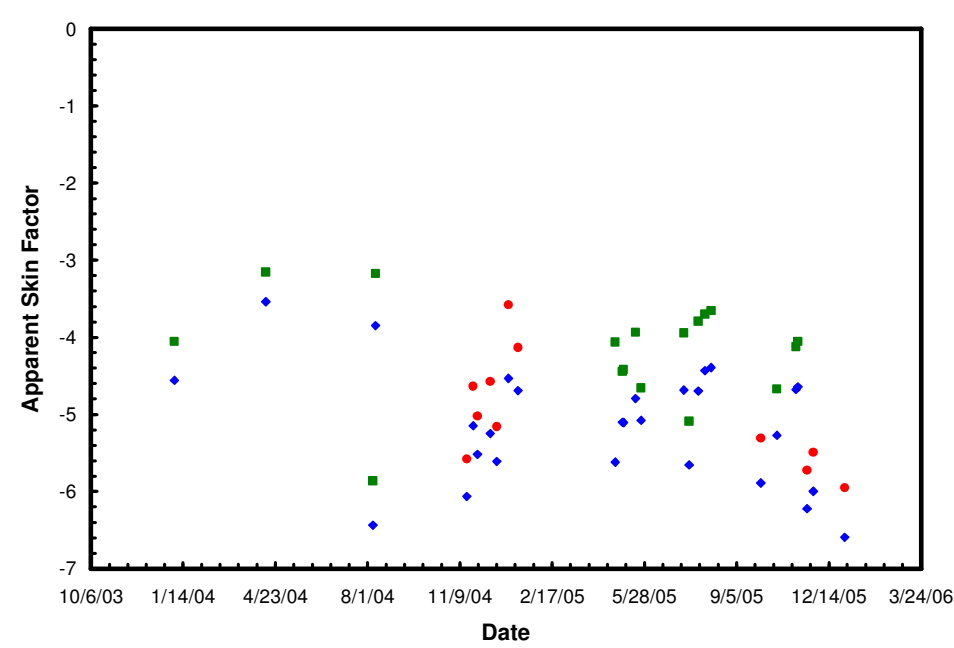

$\bullet$ BU s'

FO $\mathrm{s}^{\prime}$

$\square$ FO s' (bad)

- $s=s^{\prime}-D|q|$

$\diamond s$ (bad) 


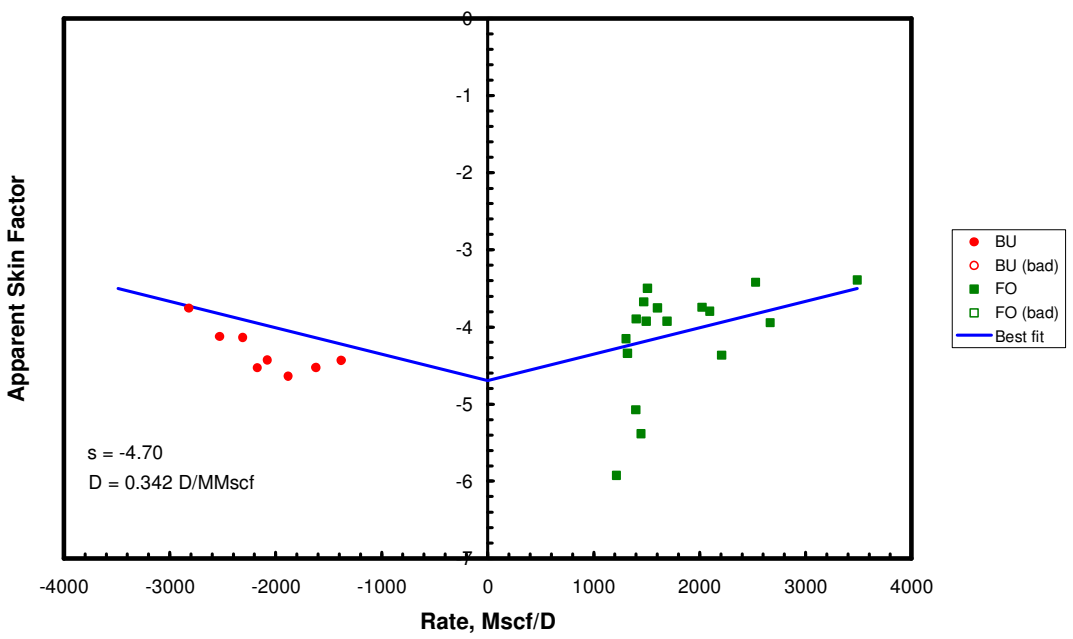

Well 12394

Apparent Skin Factor vs. Rate

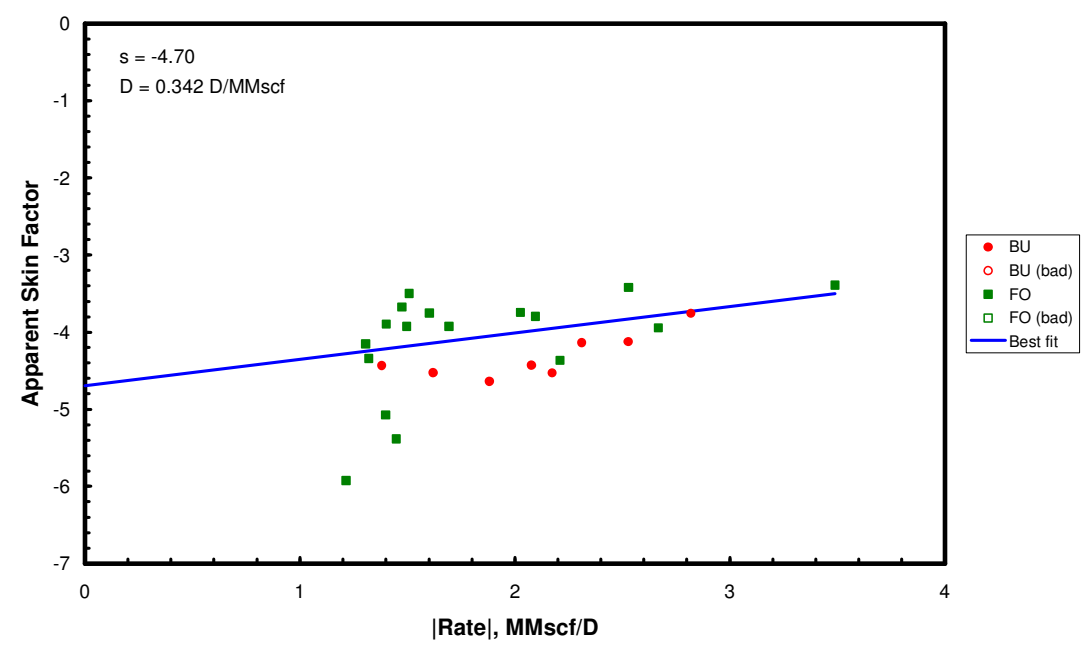

Well 12394

Apparent Skin Factor vs. Date

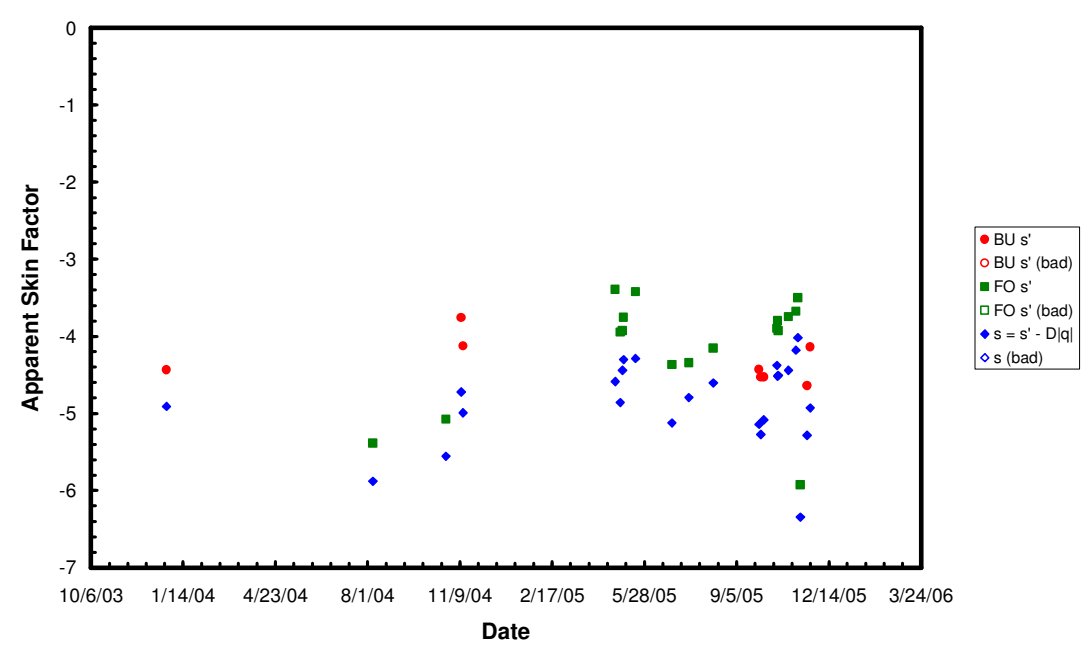




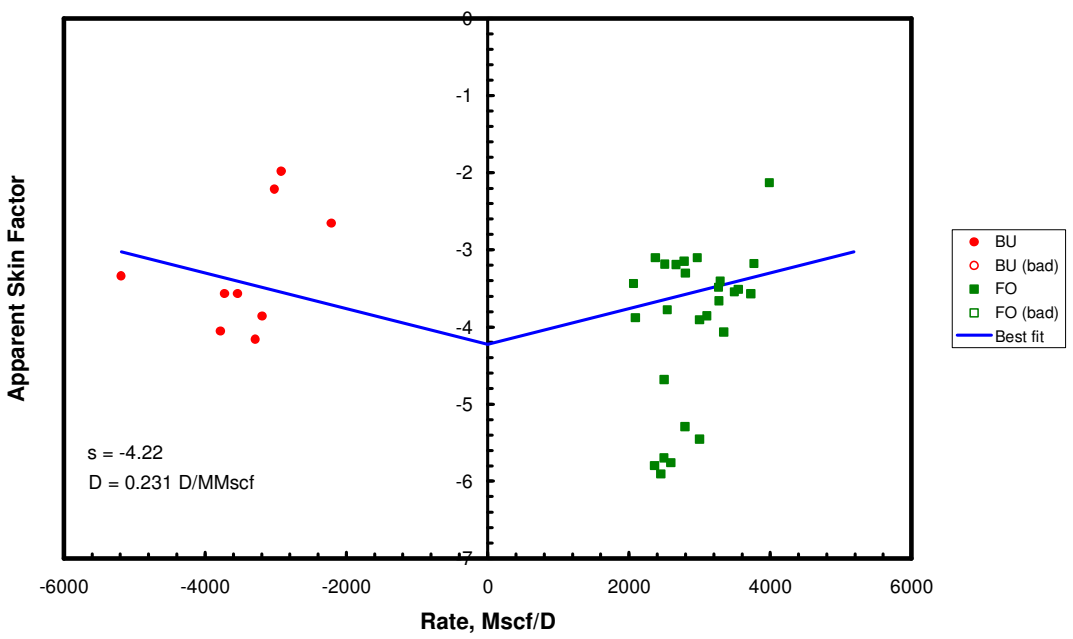

Well 12392

Apparent Skin Factor vs. Rate

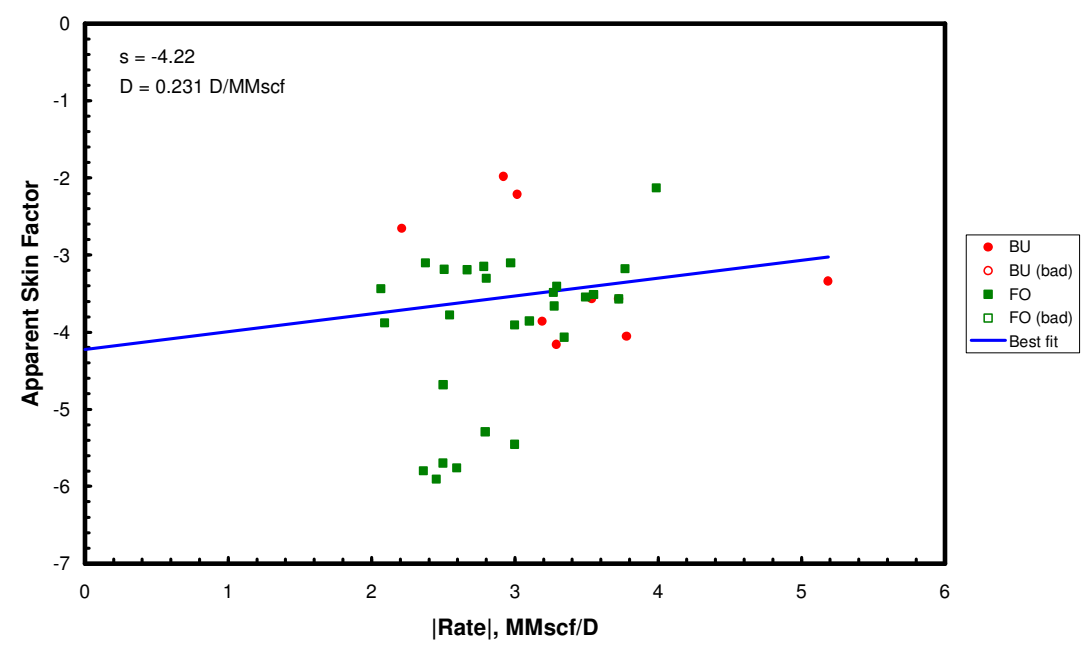

Well 12392

Apparent Skin Factor vs. Date

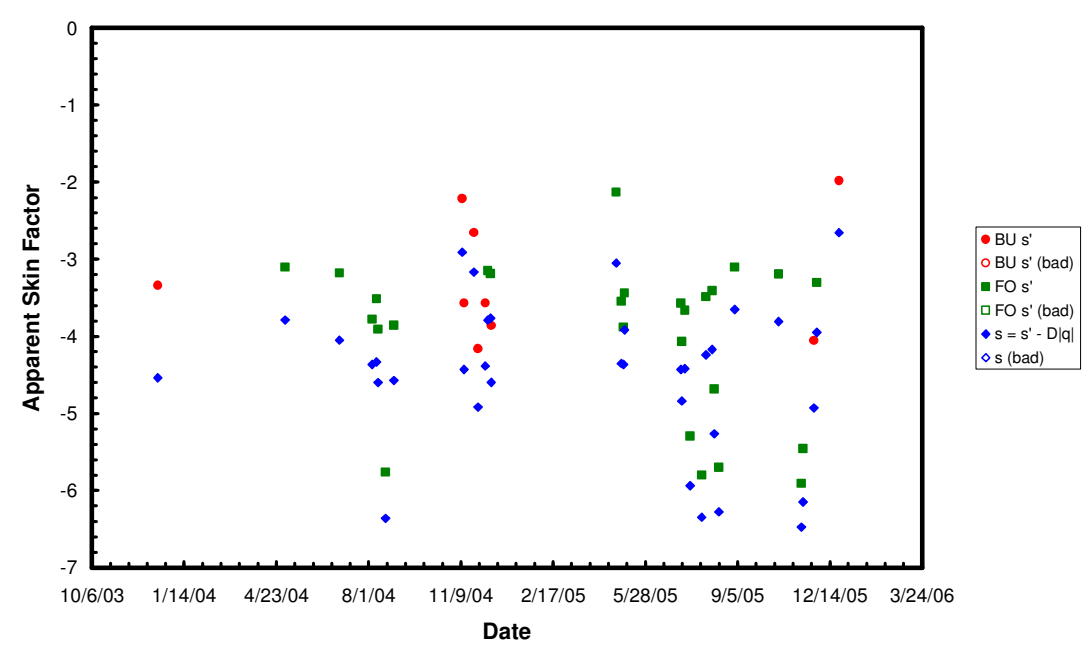




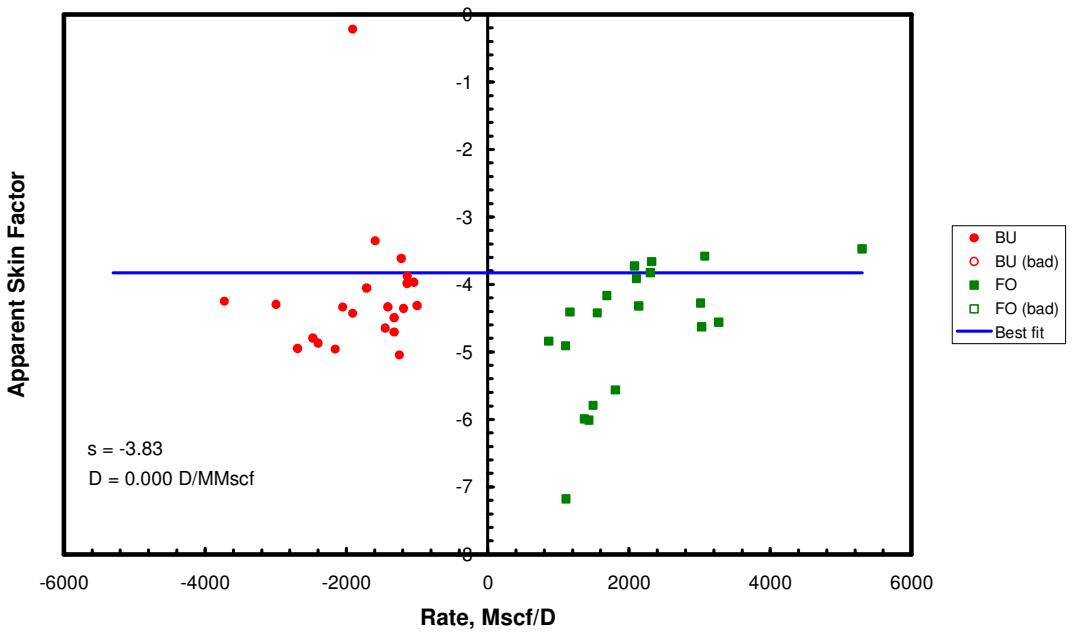

Well 12390

Apparent Skin Factor vs. Rate

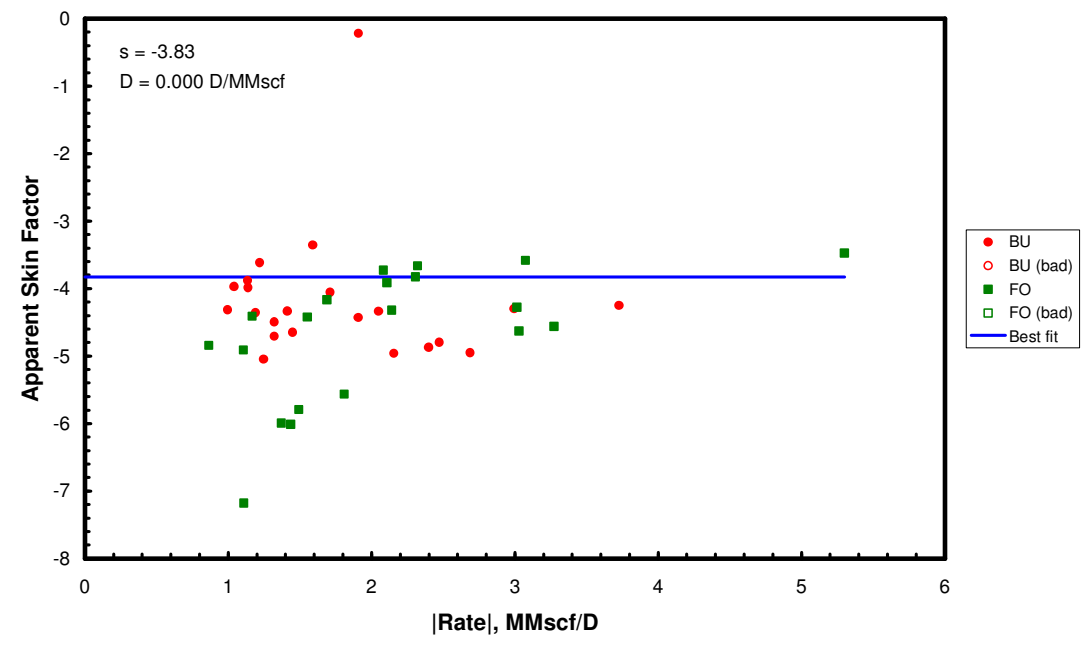

Well 12390

Apparent Skin Factor vs. Date

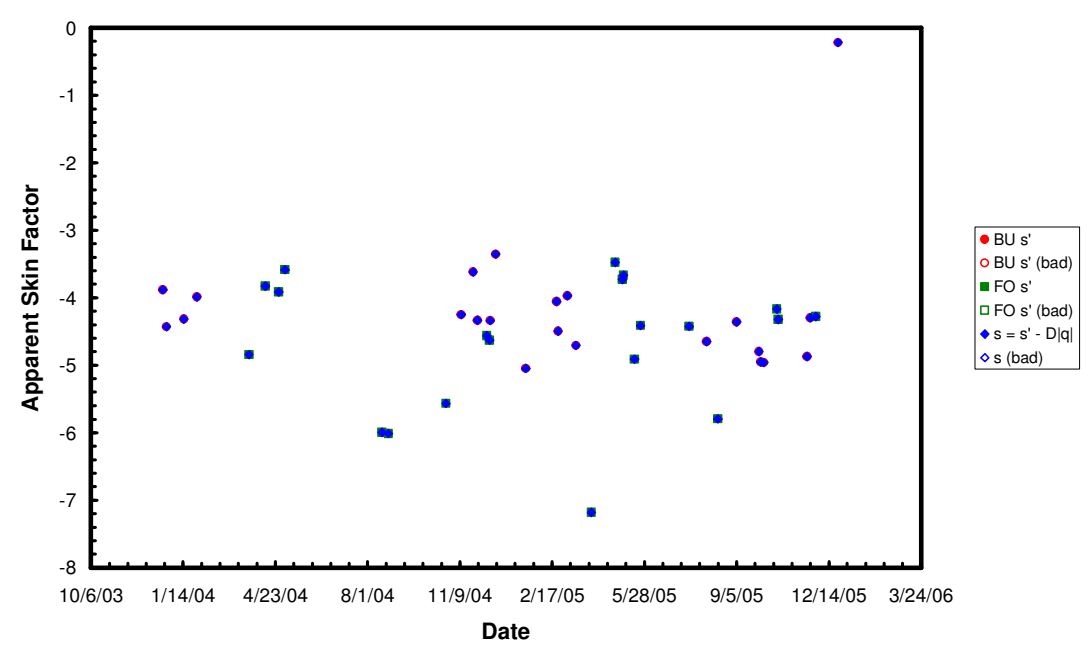




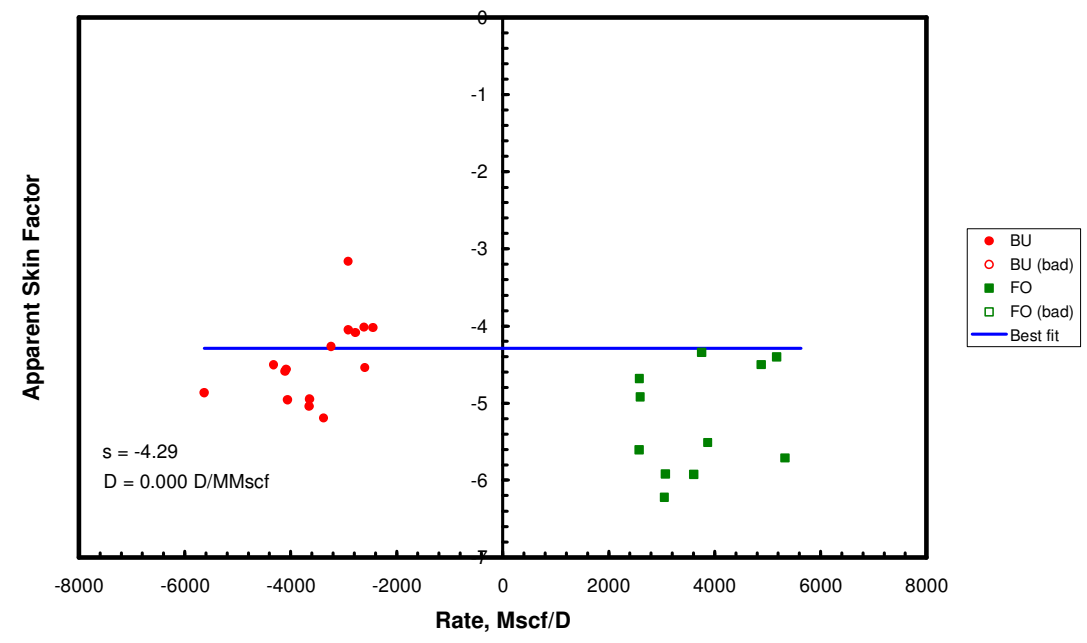

Well 12358

Apparent Skin Factor vs. Rate

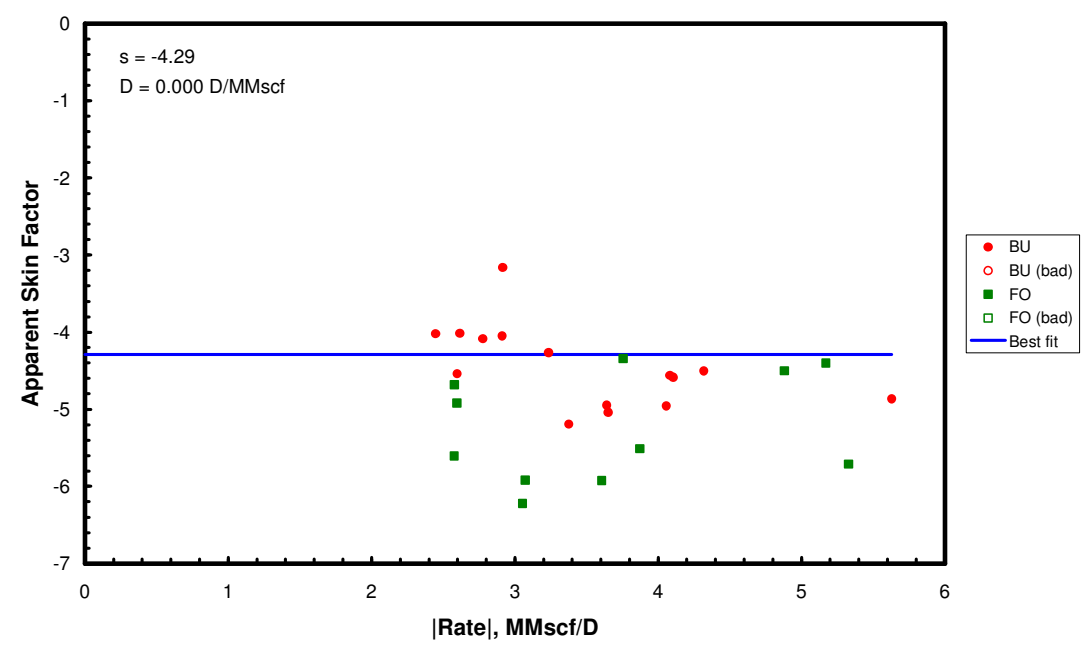

Well 12358

Apparent Skin Factor vs. Date

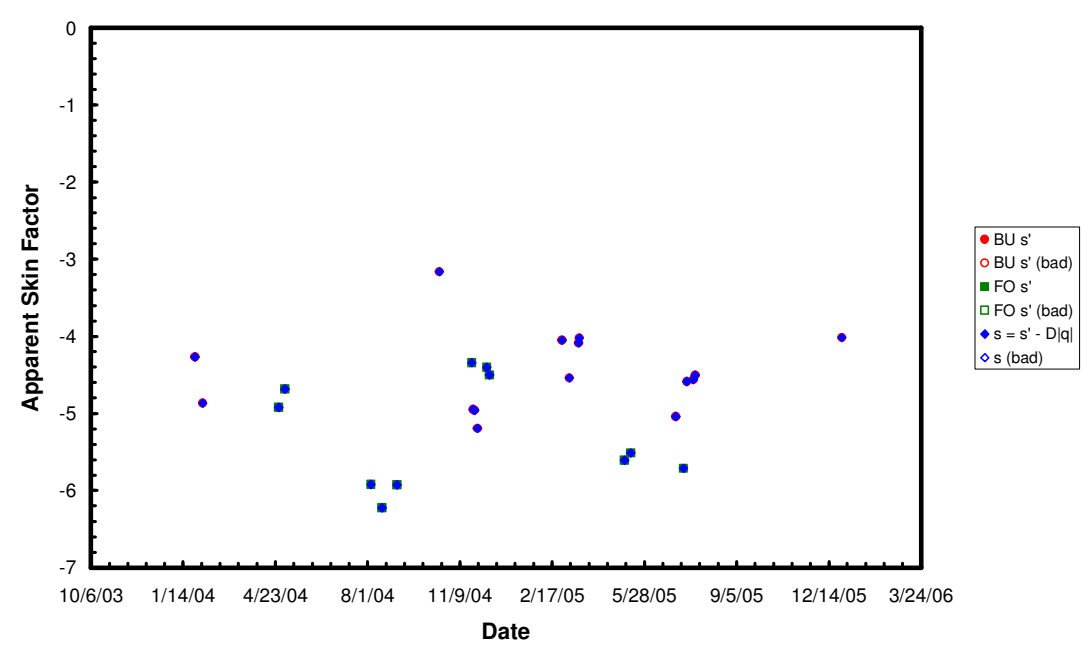




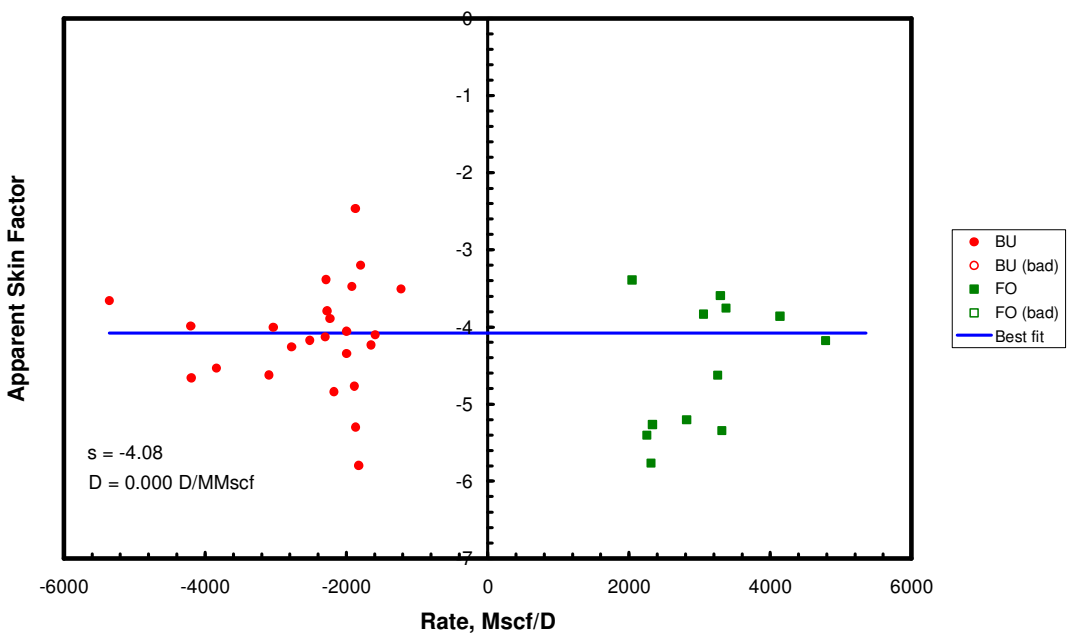

Well 12341

Apparent Skin Factor vs. Rate

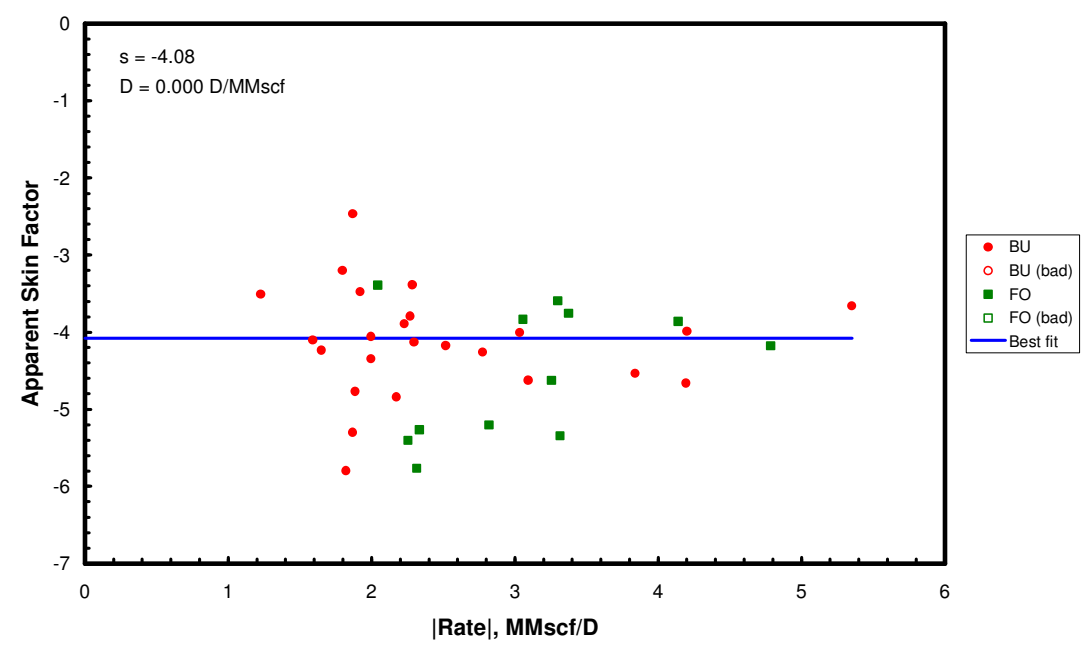

Well 12341

Apparent Skin Factor vs. Date

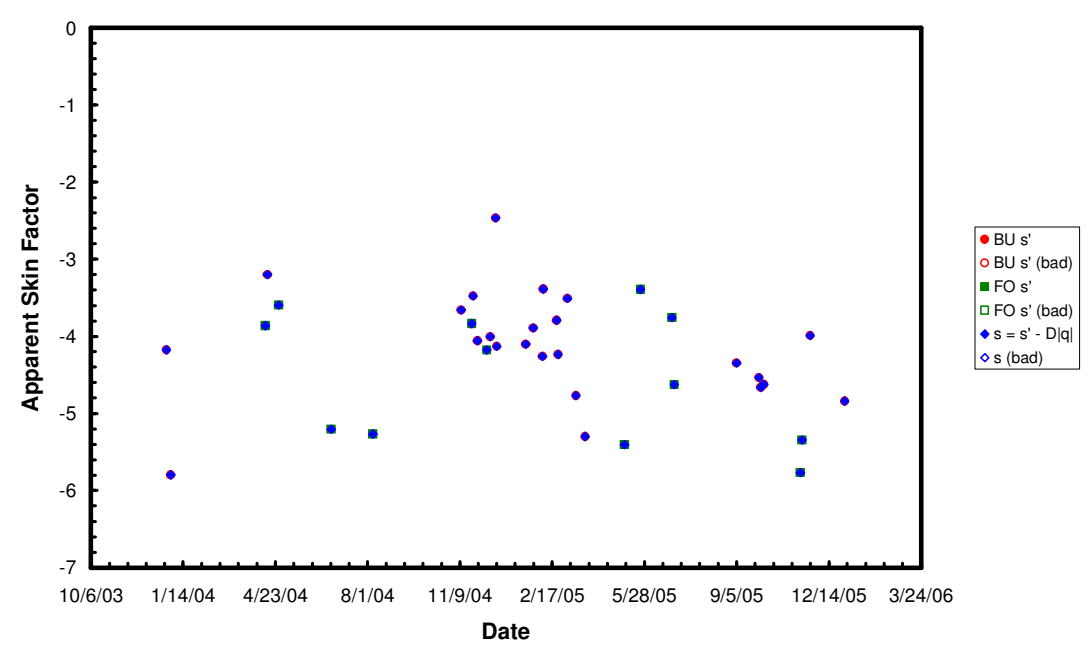




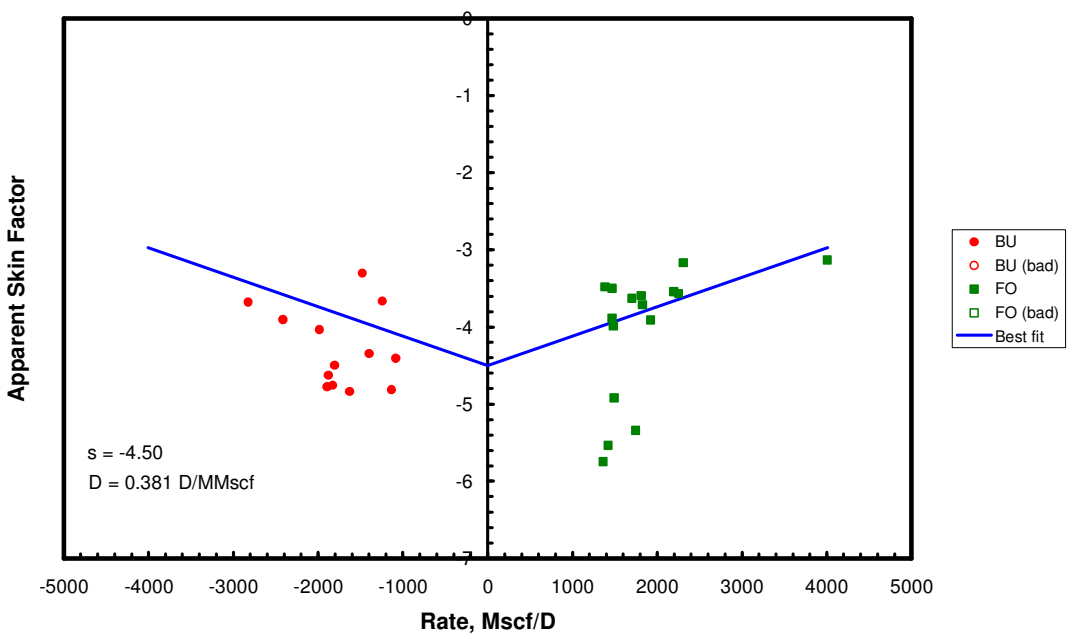

Well 12338

Apparent Skin Factor vs. Rate

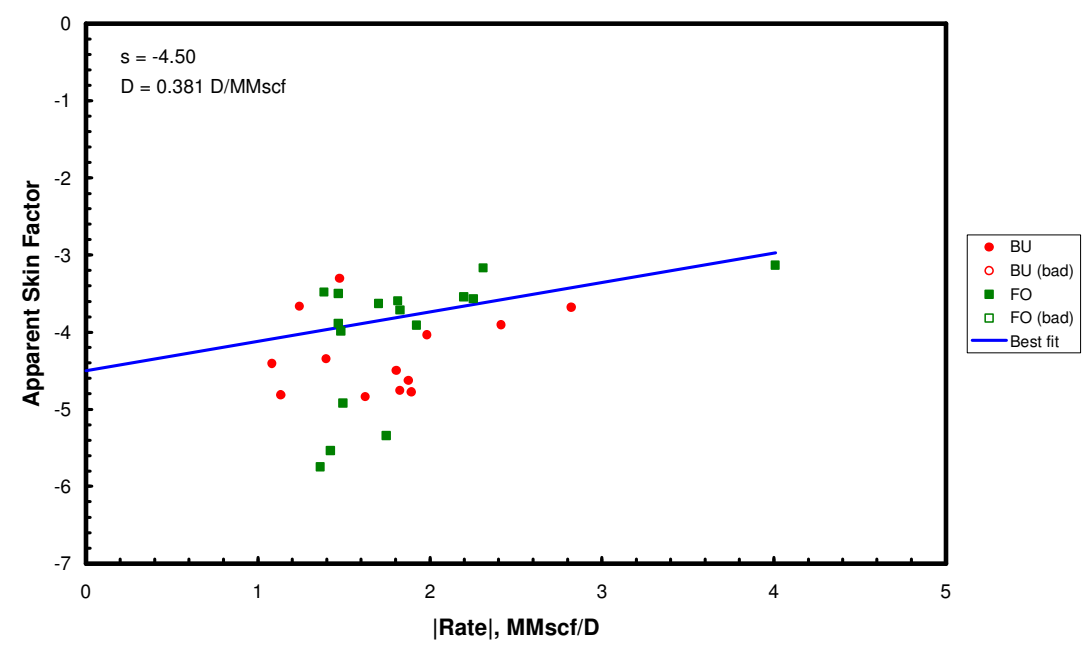

Well 12338

Apparent Skin Factor vs. Date

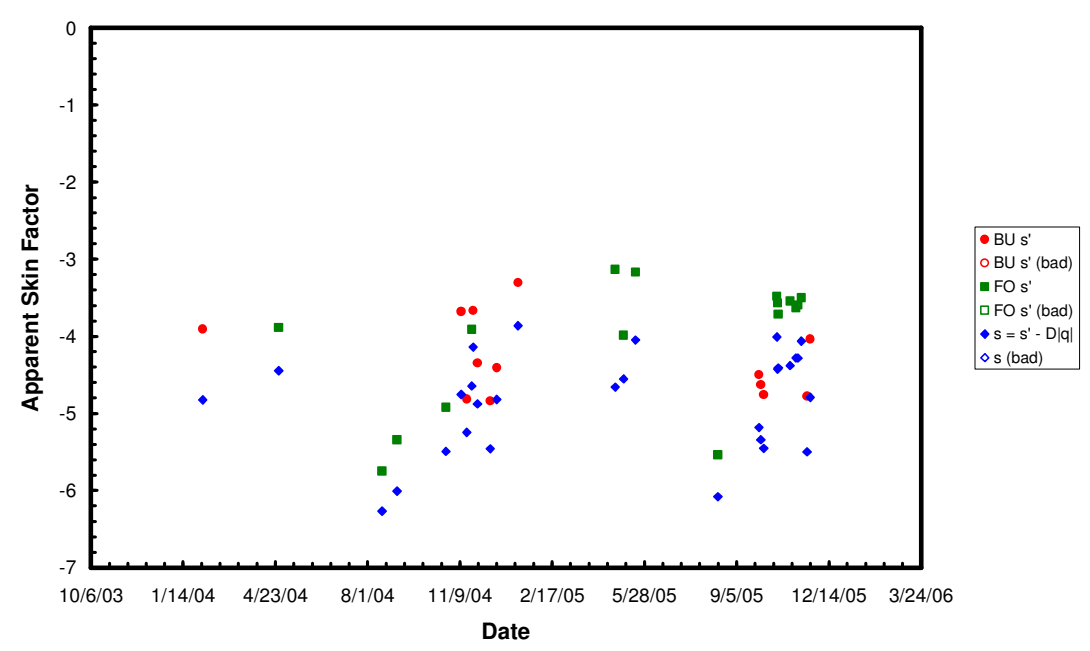




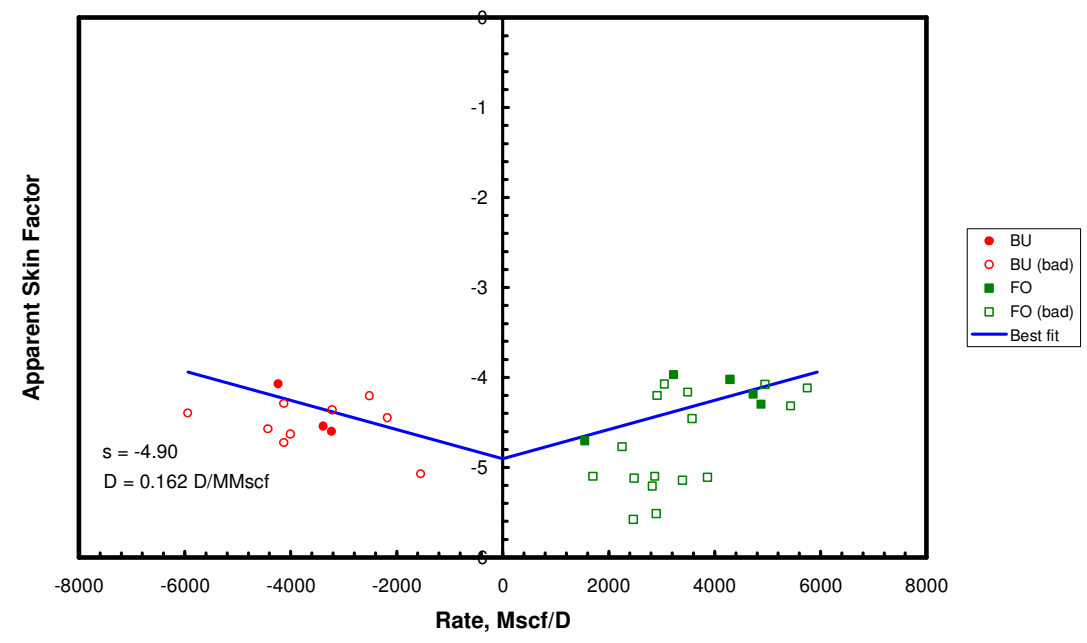

Well 12336

Apparent Skin Factor vs. Rate

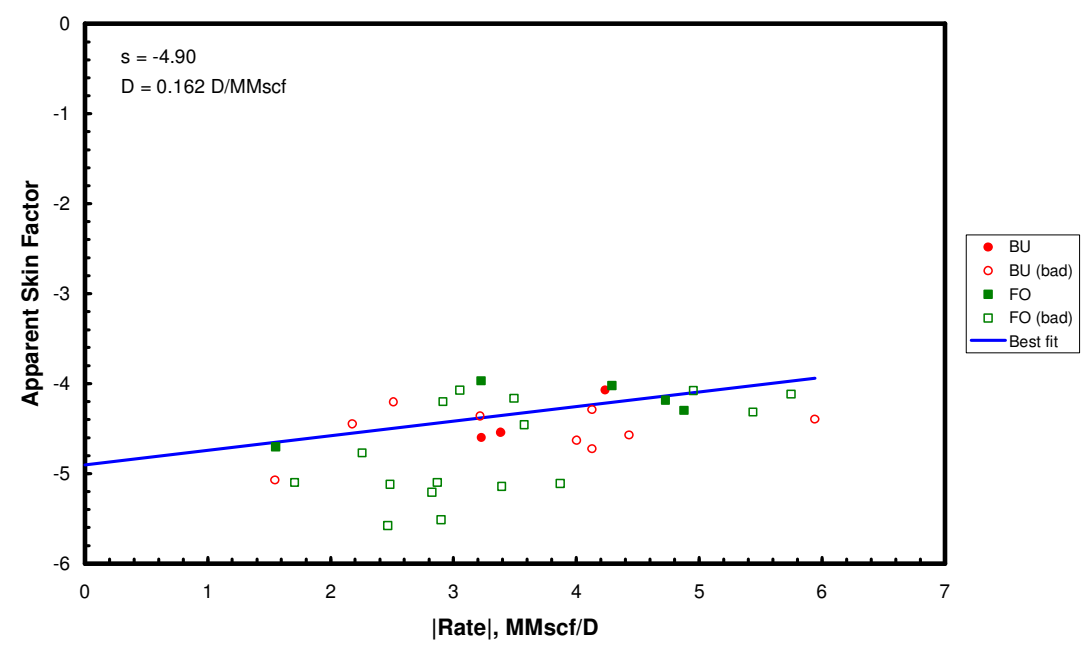

Well 12336

Apparent Skin Factor vs. Date

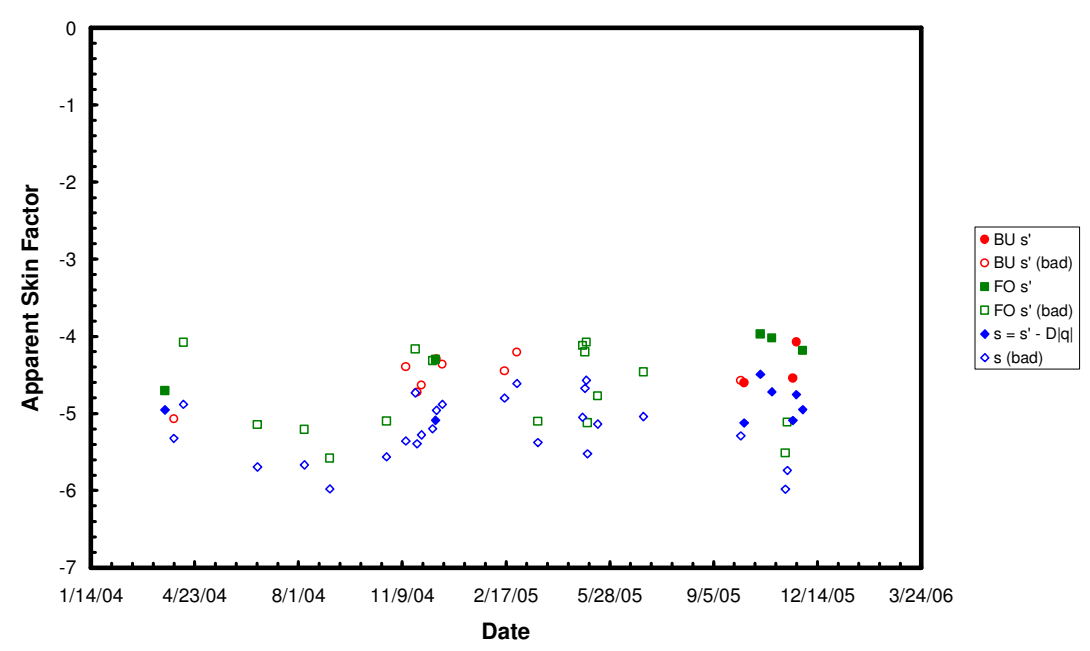




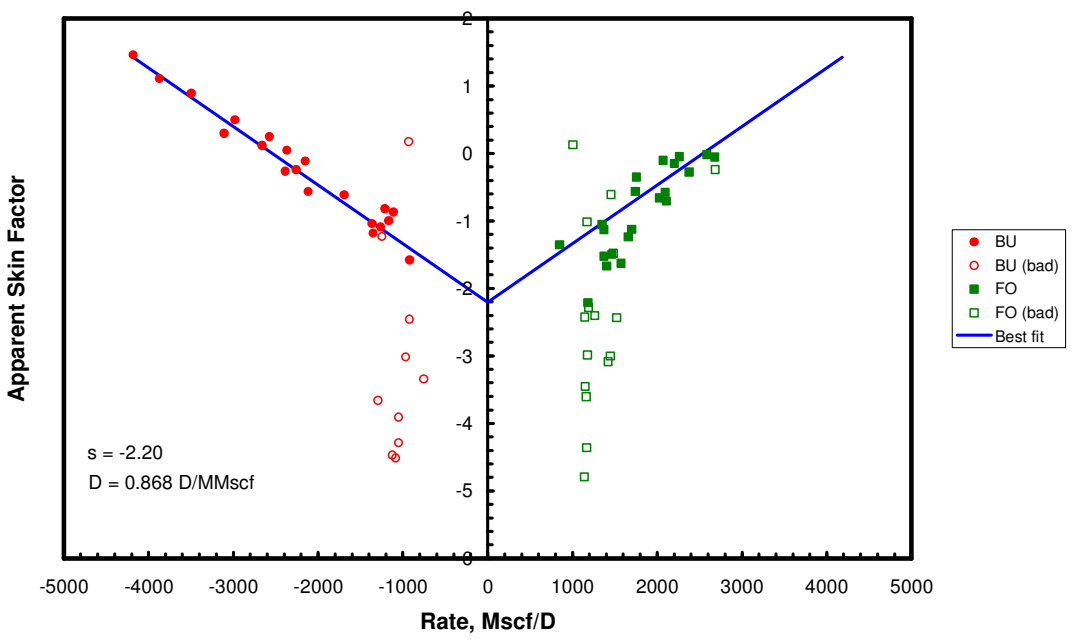

Well 12106

Apparent Skin Factor vs. Rate

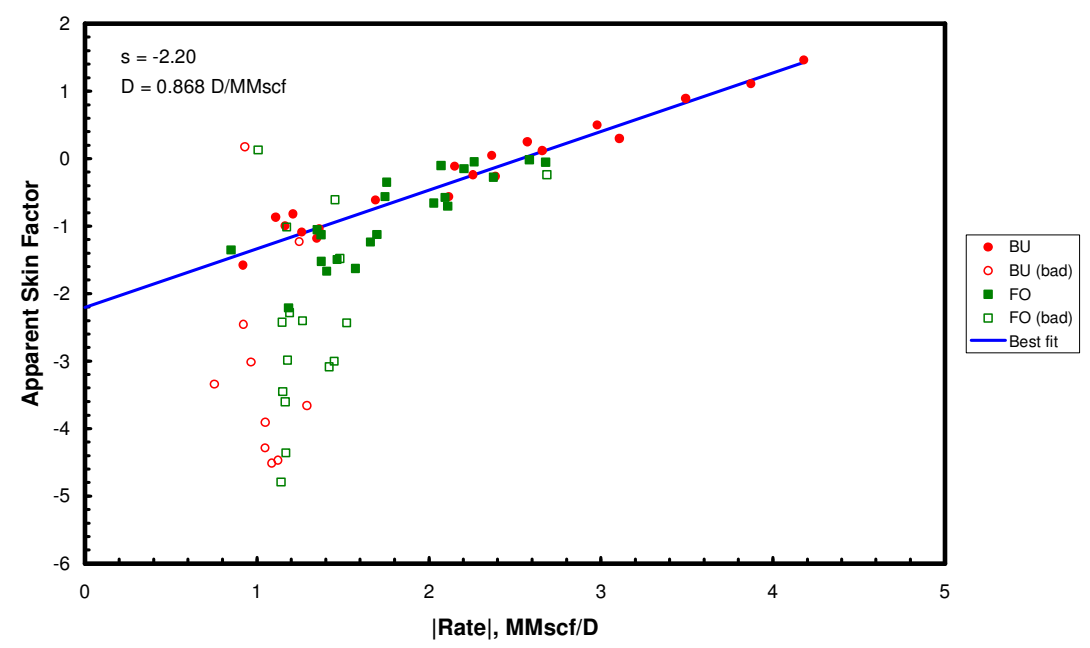

Well 12106

Apparent Skin Factor vs. Date

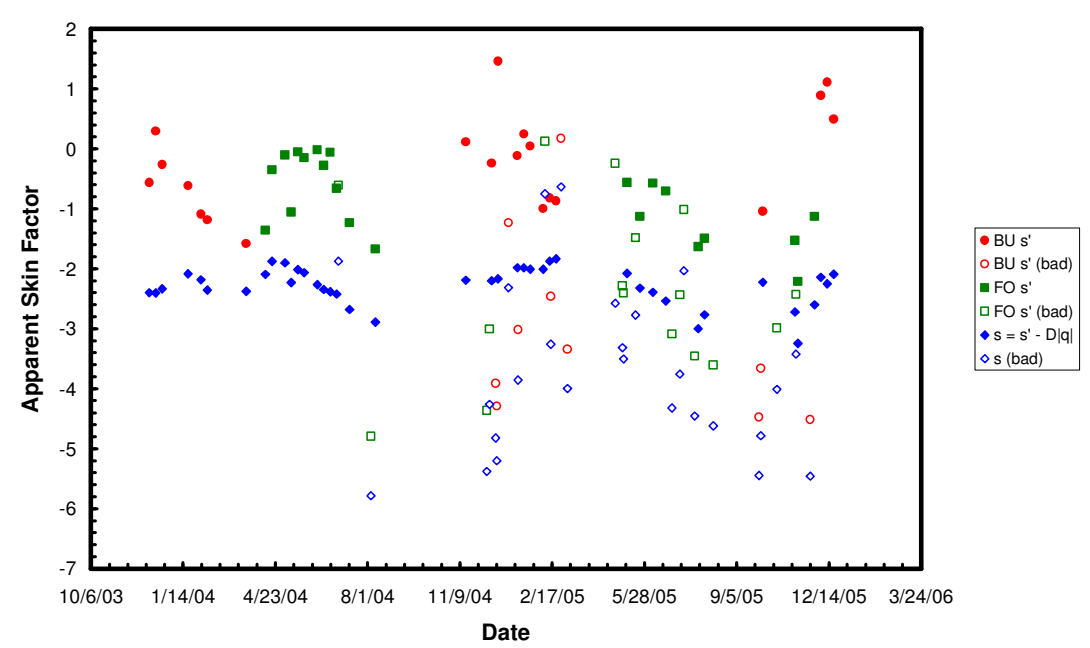




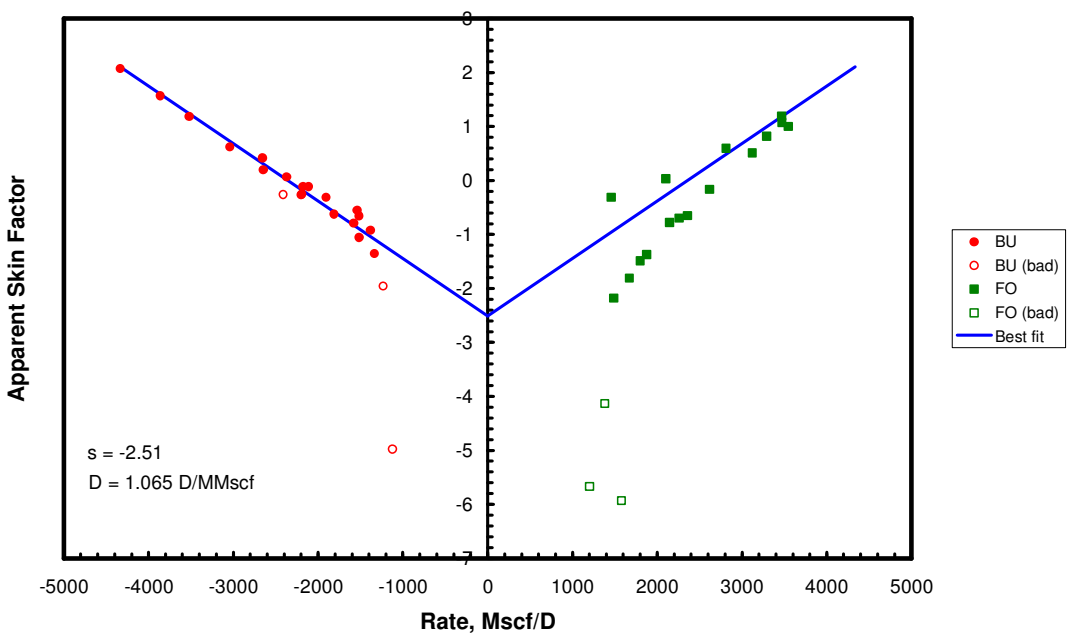

Well 12091

Apparent Skin Factor vs. Rate

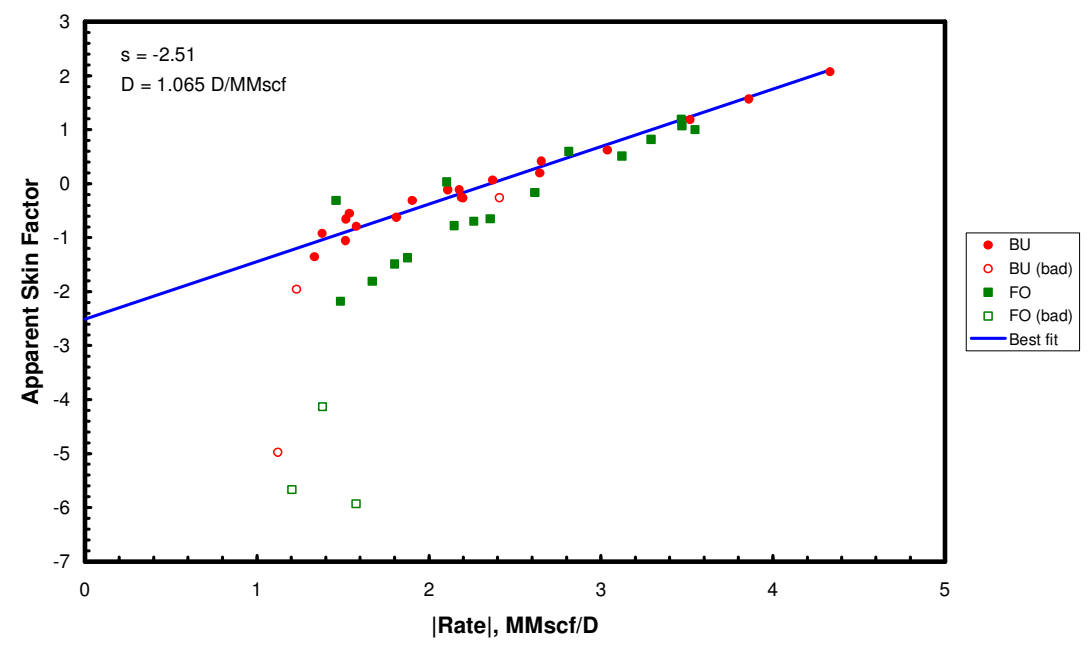

Well 12091

Apparent Skin Factor vs. Date

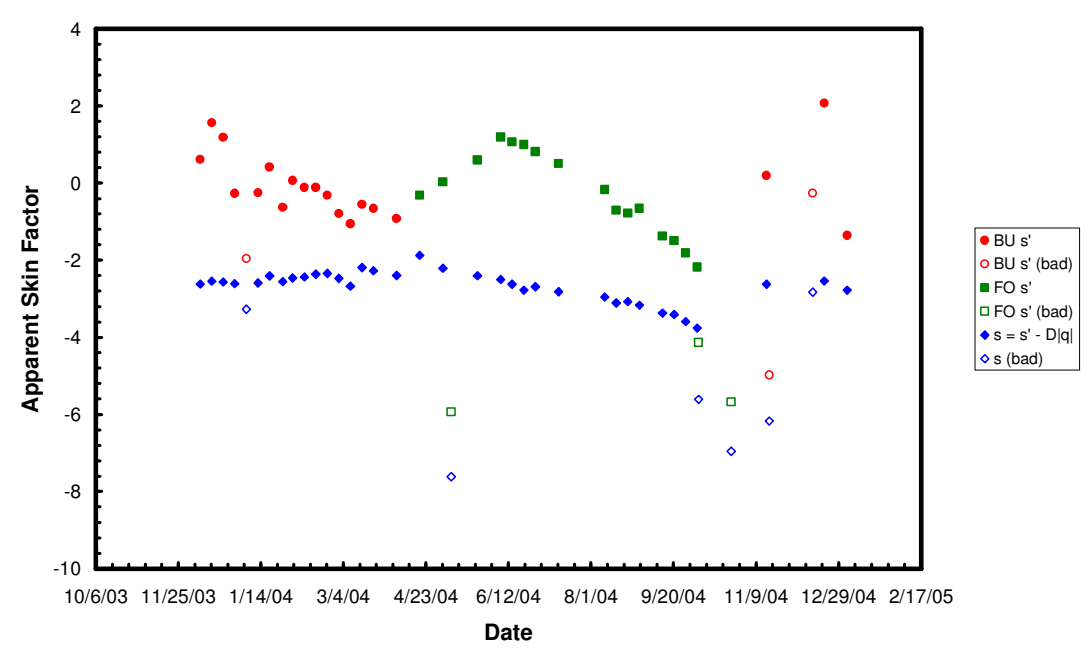




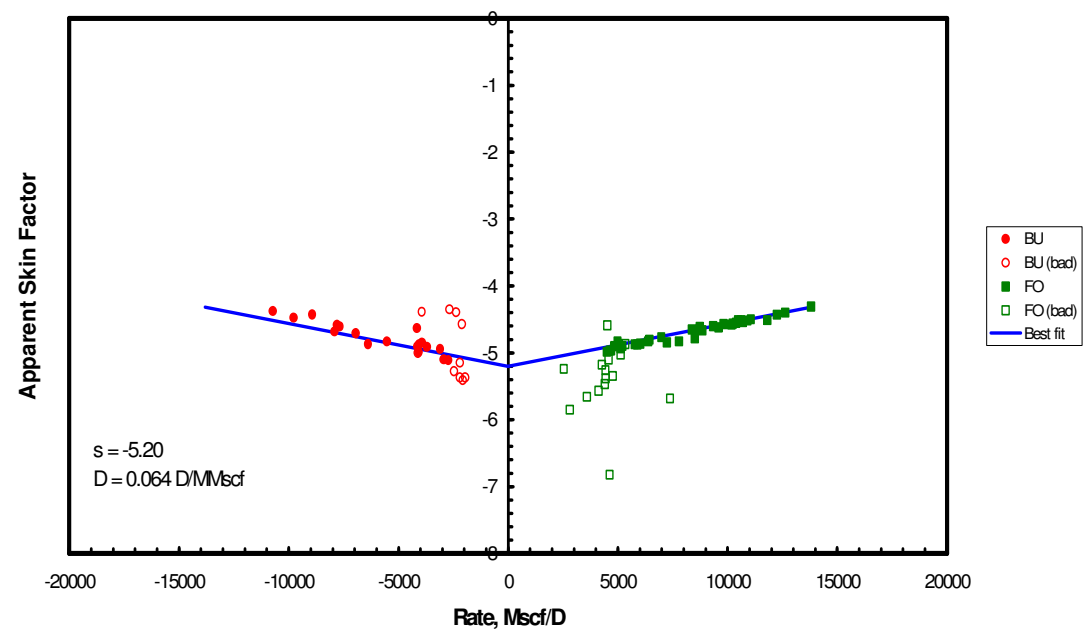

Well 12026

Apparent Skin Factor vs. Rate

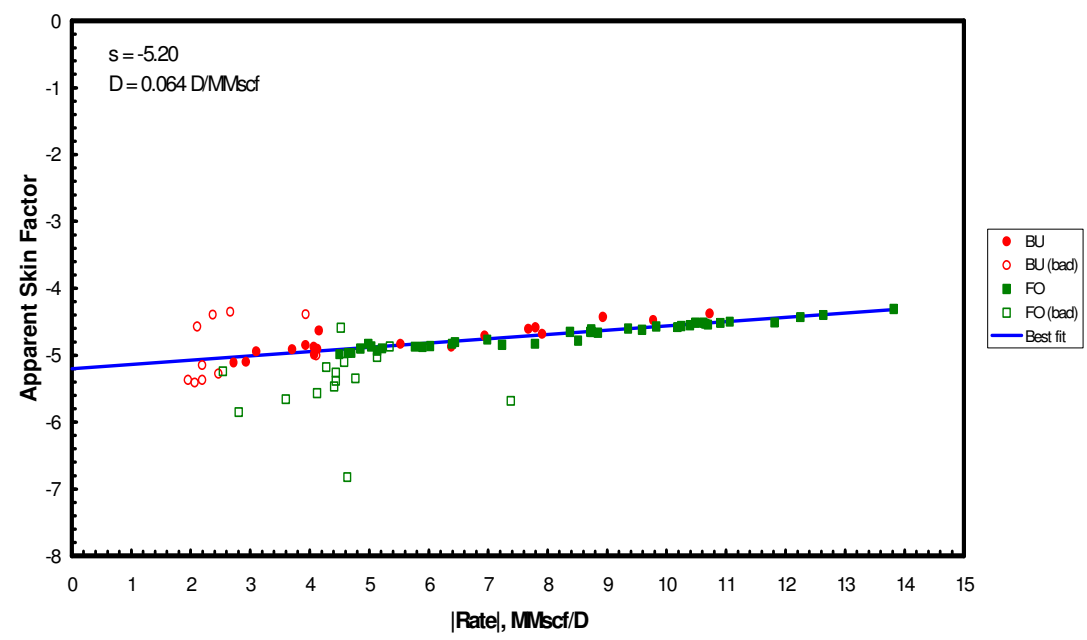

Well 12026

Apparent Skin Factor vs. Date

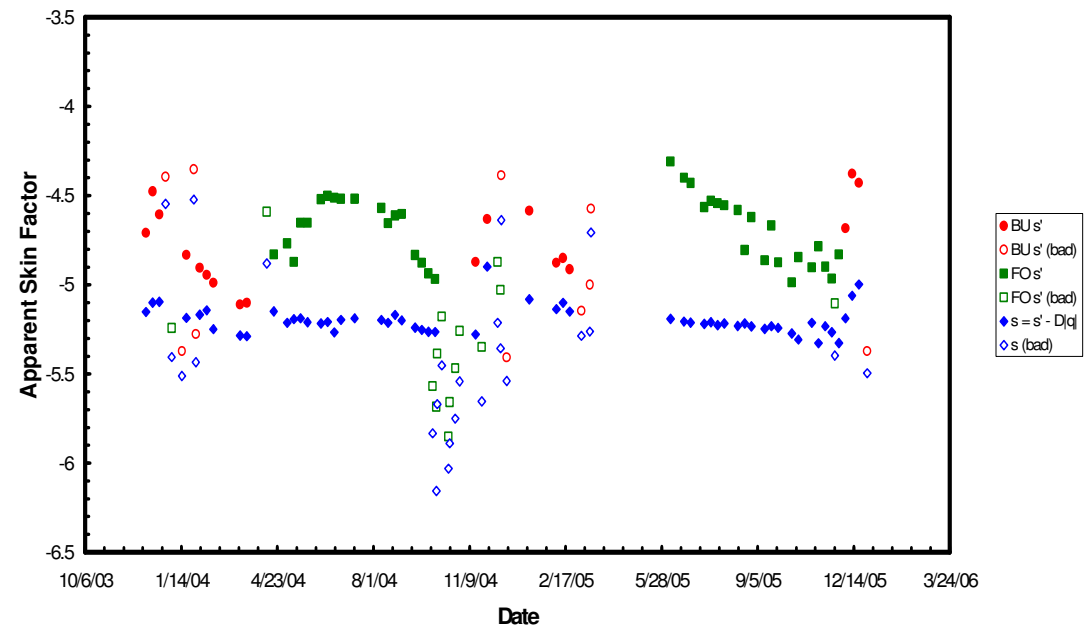


As evident from the well history plots below, no shut-in periods occurred during normal operations in two wells (Well 12387 and Well 12408), and erratic data trends were present in the raw data from two wells (Well 12127 and Well 12400), making meaningful analysis impossible.
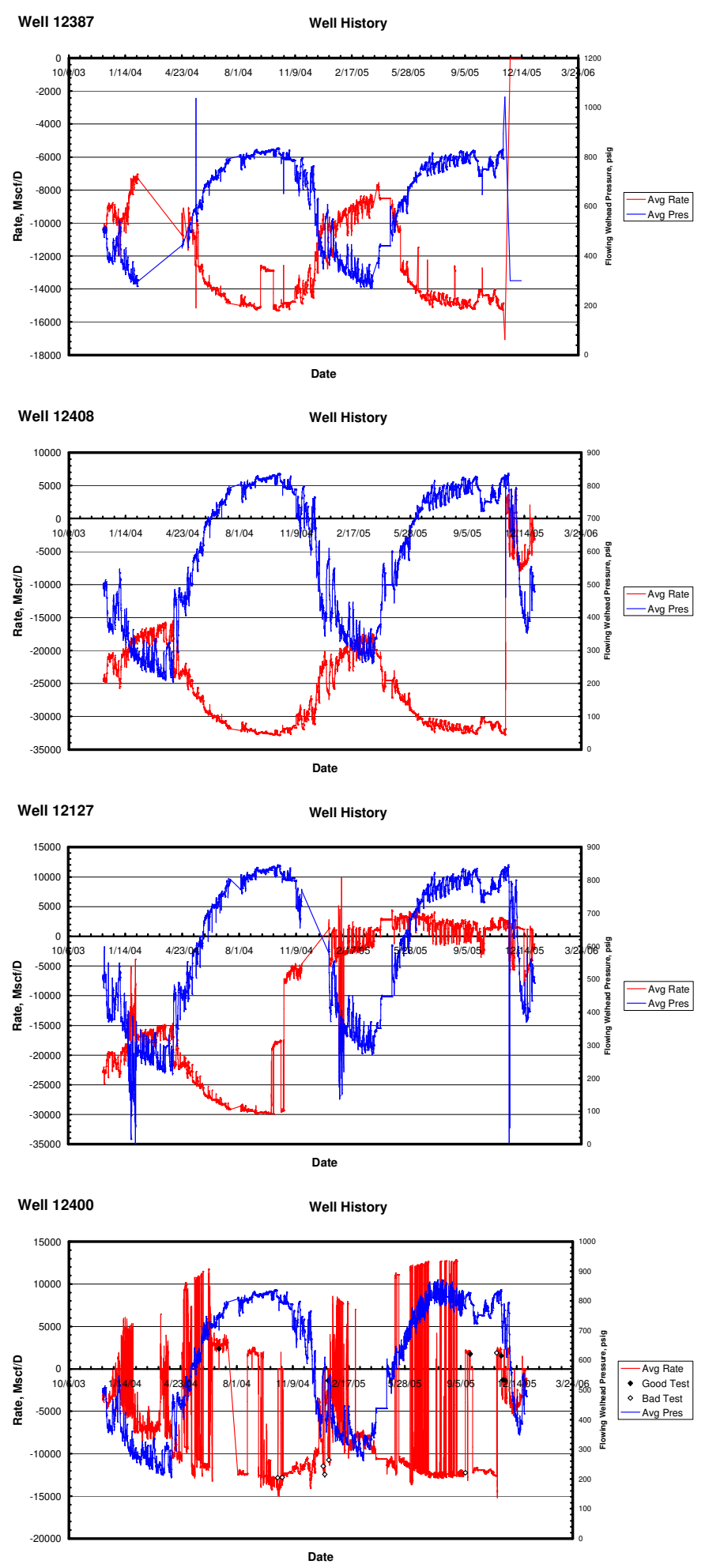
